Projeto de um sistema para monitoramento de hardware/software on-chip baseado em computação reconfigurável

Guilherme Stella Ravagnani 



\title{
Projeto de um sistema para monitoramento de hardware/software on-chip baseado em computação reconfigurável
}

\author{
Guilherme Stella Ravagnani
}

Prof. Dr. Eduardo Marques

(Orientador)

Dissertação apresentada ao Instituto de Ciências Matemáticas e de Computação, como parte dos requisitos para a obtenção do título de Mestre em Ciências de Computação e Matemática Computacional.

USP - São Carlos

Fevereiro de 2007 


Dedico este trabalho aos meus pais José Carlos e Rosemary, e a minha namorada Natália. 



\section{Agradecimentos}

Agradeço primeiramente a Deus, por ter me dado a graça de viver e por me dar a capacidade necessária para realização desse trabalho.

Aos meus pais José Carlos e Rosemary e principalmente a Nátalia, pela sua compreensão e paciência que teve durante o desenvolvimento deste trabalho.

Ao meu orientador Prof. Dr. Eduardo Marques, pela orientação desse trabalho e pelos conhecimentos transmitidos durante o mestrado.

A todos os colegas do ICMC-USP, em especial ao Maikon, por compartilharem comigo momentos de dedicação e descontração.

Ao $C N P q$ pelo apoio financeiro. 

"O mais importante da vida não é a situação em que estamos, mas a direção para a qual nos movemos."

(Oliver W. Holmes) 



\section{Resumo}

A tendência de integração de diversos componentes em um único chip tem proporcionado um aumento da complexidade dos sistemas computacionais. Tanto as indústrias quanto o meio acadêmico estão em busca de técnicas que possibilitem diminuir o tempo e o esforço gastos com a verificação no processo de desenvolvimento de hardware, a fim de garantir qualidade, robustez e confiabilidade a esses dispositivos. De forma a contribuir para várias aplicações envolvendo a verificação de sistemas, tais como busca por erros de projeto, avaliação de desempenho, otimização de algoritmos e extração de dados do sistema, o presente trabalho propõe um sistema de monitoramento baseado em computação reconfigurável, capaz de observar de forma não intrusiva o comportamento de um SoC (System-on-Chip) em tempo de execução. Tal sistema é composto por um módulo de monitoramento responsável por captar informações de execução de software em um processador embarcado e uma ferramenta de análise, chamada ACAD, que interpreta esses dados. Por meio da realização de experimentos, verificou-se que o sistema desenvolvido foi capaz de fornecer dados fiéis sobre a quantidade de acessos a memória e a outros periféricos, tempos de execução de porções (ou da totalidade) do código e número de vezes que cada instrução foi executada. Esses resultados permitem traçar, de maneira precisa, o comportamento de um software executado no processador softcore Nios II, contribuindo assim para facilitar o processo de verificação em sistemas baseados em computação reconfigurável. 


\section{Abstract}

The integration of several components on a single chip has motivated an increase in the complexity of computing systems. Both industry and academy are in search of new techniques to reduce time and effort spent with verification on hardware development process, guaranteeing quality, robustness, reliability to these devices. In order to contribute to applications in the system verification area, such as search for design errors, performance evaluation, algorithm optimization and data extraction from the system, this work proposes a monitoring system based on reconfigurable computing. This system must be able to have a run-time non-intrusive probe of a System-on-Chip behaviour. It is formed by a monitoring core responsible for capturing software execution information of a embedded processor and an analysis tool, called ACAD, that decodes the data. Empirically, the implemented system was able to provide precise data about the amount of memory and other peripherals accesses, time measurement for sections (or the entire) of the source code, and number of times each instruction was executed. These results allow to draw, in a accurate way, the behaviour of a software executed on the softcore Nios II processor, collaborating to make the verification process of systems based on reconfigurable computing easier. 


\section{Sumário}

Resumo $\quad x$

Abstract $\quad$ xi

Lista de Figuras $\quad$ xiii

Lista de Tabelas $\quad$ xiv

Lista de Abreviaturas $\quad$ xvi

$\mathbf{1}$ Introdução 1

1.1 Contextualização . . . . . . . . . . . . . . . . . . 1

1.2 Motivação e Objetivos . . . . . . . . . . . . . . . . . . . . 3

1.3 Organização do Trabalho . . . . . . . . . . . . . . . . . . . . 4

2 Teste, Debug e Análise de Desempenho 6

2.1 Considerações Iniciais . . . . . . . . . . . . . . . . . . 6

2.2 Teste . . . . . . . . . . . . . . . . . . . . . . . 6

$2.2 .1 \quad$ Planejamento do teste . . . . . . . . . . . . . . . 8

2.2 .2 Construir eventos de testes para revelar os defeitos . . . . . . 8

$2.2 .3 \quad$ Aplicar os eventos durante a execução do sistema . . . . . . . . . 8

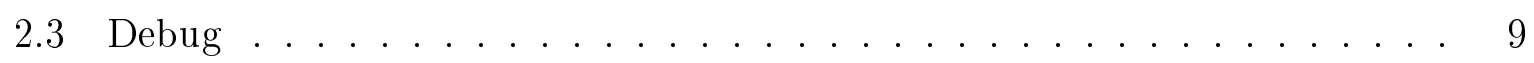

$2.4 \quad$ Análise de Desempenho . . . . . . . . . . . . . . . . . . . . . . . . . 9

2.5 Considerações Finais $\ldots \ldots \ldots$. . . . . . . . . . . . . . 10

$\begin{array}{lll}3 & \text { Monitoramento } & 11\end{array}$

3.1 Considerações Iniciais . . . . . . . . . . . . . . . . . . . . . . . 11

3.2 Probe Effect . . . . . . . . . . . . . . . . . . . . . . . . . . . 12

3.3 Monitoramento Síncrono e Assíncrono ～. . . . . . . . . . . . . . 13

3.4 Níveis de Abstração do Monitoramento . . . . . . . . . . . . . . . . . . 13 
$3.4 .1 \quad$ Nível de Sistema . . . . . . . . . . . . . . . . . . . . . . . 14

3.4 .2 Nível de Processo . . . . . . . . . . . . . . . . . . . . . . 14

3.4 .3 Nível de Função . . . . . . . . . . . . . . . . . . . . . . 15

3.4 .4 Nível de Instrução $\ldots \ldots \ldots \ldots$

3.5 Tipos de Sistemas de Monitoramento $\ldots \ldots \ldots \ldots \ldots$

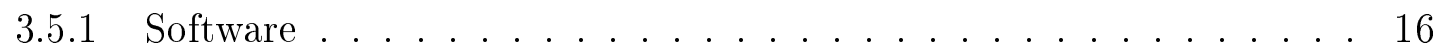

3.5 .2 Hardware . . . . . . . . . . . . . . . . . 17

3.5 .3 Híbrido . . . . . . . . . . . . . . . . . . . . . 19

3.6 Orientação do Monitoramento . . . . . . . . . . . . . . . . 20

$3.6 .1 \quad$ Monitoramento Orientado pelo Relógio $\ldots \ldots \ldots \ldots$

3.6 .2 Monitoramento Orientado pelo Evento . . . . . . . . . . . 21

3.6.2.1 Estrutura do Monitoramento de Eventos . . . . . . . . . 22

3.6.2.2 Gerenciamento do Monitoramento de Eventos . . . . . . . 23

3.6.2.3 Recursos Necessários para o Monitoramento de Eventos . 24

3.7 Problemas no Monitoramento de Tecnologias de Sistemas Embarcados. . . 25

3.8 Trabalhos relacionados . . . . . . . . . . . . . . . . . 26

$3.8 .1 \quad$ SignalTap II Embedded Logic Analyzer (ELA) . . . . . . . . . . 26

3.8 .2 Performance Counter Core . . . . . . . . . . . . . . . 27

3.8.3 ARM Embedded Trace Macrocell (ETM) e Embedded Trace Buffer

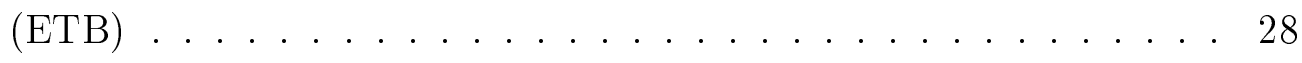

$3.8 .4 \quad$ ChipScope Pro $\ldots \ldots \ldots \ldots \ldots$

3.8 .5 MAMon . . . . . . . . . . . . . . . . . . . . . . . 29

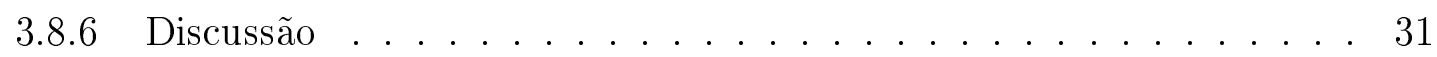

3.9 Considerações Finais $\ldots \ldots \ldots \ldots \ldots \ldots \ldots \ldots$

4 Computação Reconfigurável 32

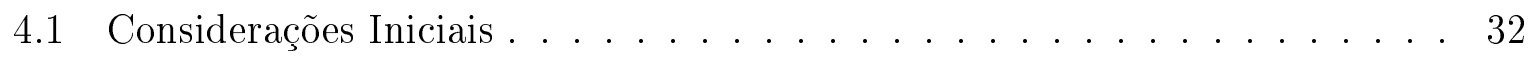

4.2 Tecnologia $\ldots \ldots \ldots \ldots \ldots \ldots$

$4.3 \quad$ FPGA (Field-Programmable Gate Arrays) $\ldots \ldots \ldots \ldots \ldots$

$4.3 .1 \quad$ Família Stratix II . . . . . . . . . . . . . . . . . . 37

4.4 Linguagem de Descrição de Hardware . . . . . . . . . . . . . . . . . . 39

4.5 Módulo de Hardware (Core) $\ldots \ldots \ldots \ldots \ldots$. . . . . . . . . 41

4.6 Considerações Finais $\ldots \ldots \ldots \ldots \ldots$. . . . . . . . . . . . . . . . 42

5 Plataforma de Desenvolvimento 43

5.1 Consideraçỗes Iniciais $\ldots \ldots \ldots \ldots \ldots$. . . . . . . . . . . . 43

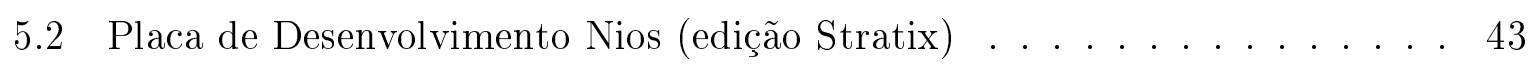

5.3 Processador Nios II $\ldots \ldots \ldots \ldots \ldots \ldots \ldots \ldots \ldots$

5.4 Barramento Avalon . . . . . . . . . . . . . . . . . . 48

5.5 Ferramenta SOPC Builder . . . . . . . . . . . . . . . 50 
$5.5 .1 \quad$ Arquitetura do Sistema SOPC Builder . . . . . . . . . . . . 51

5.5 .2 Componentes do SOPC Builder . . . . . . . . . . . . 52

$5.5 .3 \quad$ Fluxo de Desenvolvimento de Componentes . . . . . . . . . . 53

5.5.3.1 $\quad$ Projeto de Hardware do Componente . . . . . . . . . . 53

5.5.3.2 Projeto de Software do Componente . . . . . . . . . . 55

5.5.3.3 Editor de Componentes . . . . . . . . . . . 56

5.6 Considerações Finais . . . . . . . . . . . . . . . . . 58

6 Implementação e Resultados $\quad 59$

6.1 Considerações Iniciais $\ldots \ldots \ldots$. . . . . . . . . . . . . . . . . 59

6.2 Fluxo de um Projeto Hardware/Software em Ambiente Altera . . . . . . . 60

6.2 .1 Desenvolvimento do Hardware . . . . . . . . . . . . . . . 60

6.2 .2 Desenvolvimento do Software . . . . . . . . . . . . . . 62

6.3 Sistema de Monitoramento Hardware/Software On-Chip . . . . . . . . . 65

6.3.1 Modulo de Monitoramento Hardware/Software On-Chip . . . . . . 66

6.3 .1 .1 Módulo de Aquisição de Sinais . . . . . . . . . . . 66

$6.3 .1 .2 \quad$ Módulo de Monitoramento (Core) . . . . . . . . . . 69

6.3.1.3 Características do Módulo de Monitoramento . . . . . . . 73

6.3.2 Ferramenta ACAD (Aquisição, Configuração e Análise dos Dados) . 75

6.3.2.1 Aquisição dos dados . . . . . . . . . . . . 76

6.3.2.2 Configuração do Monitoramento . . . . . . . . . . 77

6.3.2.3 Análise dos dados . . . . . . . . . . . . . . . 79

$6.3 .3 \quad$ Estrutura de Arquivos do Módulo de Monitoramento . . . . . . . . 81

6.3 .4 Utilizando o Sistema de Monitoramento . . . . . . . . . . . . . . . 82

6.4 Validação e Resultados . . . . . . . . . . . . . . . . . . 85

6.4 .1 Processo de Validação . . . . . . . . . . . . . . . . . . . . . . . . . . . . . . . . . . . . . .

6.4 .2 Realização dos Experimentos . . . . . . . . . . . . 86

6.4 .3 Análise dos Resultados . . . . . . . . . . . . . . . 88

6.5 Considerações Finais . . . . . . . . . . . . . . . . . . . . 91

$\begin{array}{lll}7 & \text { Conclusões } & 92\end{array}$

7.1 Trabalhos Futuros . . . . . . . . . . . . . . . . . . 93

\begin{tabular}{lr}
\hline Referências Bibliográficas & 98
\end{tabular}

\begin{tabular}{ll}
\hline Apêndice A & 100
\end{tabular}

\begin{tabular}{|ll}
\hline Apêndice B & 104
\end{tabular} 


\section{Lista de Figuras}

1.1 Custo de teste versus custo fabricação, baseado em $[36] \ldots \ldots \ldots \ldots$

3.1 Relação entre nível de abstração do monitoramento e geração de eventos . 14

3.2 Técnica de monitoramento: Kernel . . . . . . . . . . . . . . . 17

3.3 Técnica de monitoramento: InLine . . . . . . . . . . . . . . . 17

3.4 Passos do monitoramento por hardware . . . . . . . . . . . . . . 19

3.5 Orientação do monitoramento . . . . . . . . . . . . . . . 20

3.6 Composição do monitoramento de eventos . . . . . . . . . . . . . . 23

3.7 Atual tecnologia utilizada na implementação de sistemas embarcados . . . 26

3.8 Diagrama de blocos do SignalTap II [6] . . . . . . . . . . . . . . . 27

3.9 Diagrama de blocos de um projeto SoC utilizando ETM e ETB $\ldots . . . .29$

3.10 MAMon (Visão superficial) . . . . . . . . . . . . . . . 30

4.1 Tecnologias para projetos de sistemas digitais $\ldots \ldots$. . . . . . . . . 33

4.2 Arquitetura interna de um FPGA . . . . . . . . . . . . . . . 36

4.3 Nova arquitetura $A L M$ da Altera $[32] \ldots \ldots \ldots \ldots \ldots$

4.4 Testes da Altera (ALM x. LUTs de 4 entradas) [32] . . . . . . . . . . . . . 39

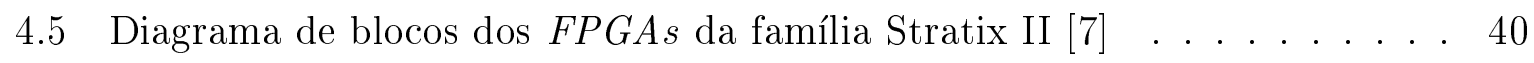

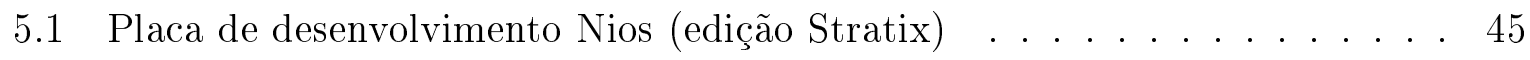

5.2 Diagrama de blocos do processador Nios II . . . . . . . . . . . . . 46

5.3 Interface da ferramenta SOPC builder . . . . . . . . . . . . . . . 50

5.4 Exemplo de um sistema gerado pelo SOPC Builder . . . . . . . . . . . . 51

5.5 Diagrama de blocos de um típico componente com uma interface escrava . 54

5.6 Uma parte do mapa de registradores do componente UART . . . . . . . 55

5.7 Aba de configuração de sinais do editor de componentes. . . . . . . . . . 57

6.1 Fluxo de Projeto HW/SW com ferramentas Altera, figura baseada em [33] 60

6.2 Camadas de um sistema baseado na biblioteca $H A L$, baseado em [3] $\ldots$. . . 64 
6.3 Estrutura de uma aplicação criada na ferramenta Nios II IDE, baseado em

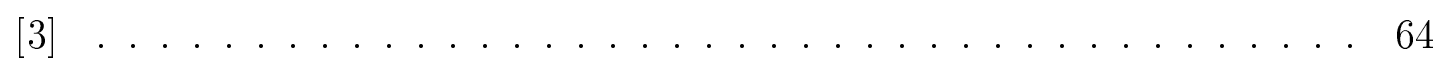

6.4 Visão Superficial do Sistema de Monitoramento Hardware/Software On-Chip 65

6.5 Diagrama de Blocos do Módulo de Monitoramento . . . . . . . . . . . . 66

6.6 Formato da mensagem originada pelo software . . . . . . . . . . . . 70

6.7 Formato da mensagem originada pelo hardware . . . . . . . . . . . 70

6.8 Módulo de Monitoramento portado para o SOPC Builder . . . . . . . . . . 75

6.9 Estrutura de funcionalidades da aplicação $\ldots \ldots \ldots$. . . . . . 76

6.10 Configuração da interface UART . . . . . . . . . . . . . . 78

6.11 Configuração do Módulo de Monitoramento através da ferramenta ACAD $\quad 79$

6.12 Parte de um histograma gerado pela ferramenta ACAD . . . . . . . . . . 80

6.13 Exemplo de relatório sobre o monitoramento do software (ferramenta ACAD) 80

6.14 Exemplo de relatório sobre o monitoramento do hardware (ferramenta

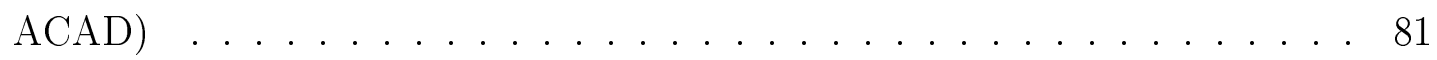

6.15 Estrutura de arquivos do Módulo de Monitoramento . . . . . . . . . . . . 82

6.16 Exemplo de um Software com Macros de Monitoramento . . . . . . . . . . 84

6.17 Parte do histograma sobre o comportamento do software (sem instrução customizada) ........................... 87

6.18 Parte do histograma sobre o comportamento do software (com instrução

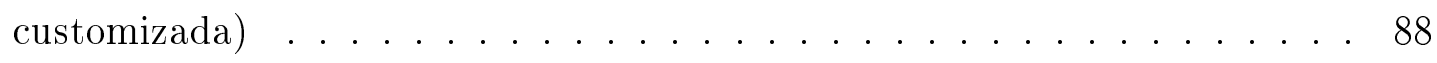

6.19 Diferença entre o hadware composto pelo MM e o composto pelo PC . . 89 


\section{Lista de Tabelas}

3.1 Características dos tipos de monitoramento . . . . . . . . . . . . 16

5.1 Níveis do Módulo de Depuração JTAG . . . . . . . . . . . . . . . . 47

6.1 Estrutura de Arquivos do Módulo de Monitoramento . . . . . . . . . . . . 83

6.2 Macros de acesso contitas no drive do Módulo de Monitoramento . . . . . 83

6.3 Dados comparativos entre o MM e o PC (sem instrução customizada) . . . 87

6.4 Dados do comportamento do hardware (sem instrução customizada) . . . . 87

6.5 Dados comparativos entre o MM e o PC (com instrução customizada) . . . 88

6.6 Dados do comportamento do hardware (com instrução customizada) . . . . 88

8.1 Macro que Ativa o Módulo de Monitoramento. . . . . . . . . . . . . . . . 99

$8.2 \quad$ Macro que Desativa o Módulo de Monitoramento. . . . . . . . . . . . . . 99

8.3 Macro que Inicia o Monitoramento de uma Seção. . . . . . . . . . . . . . . 99

8.4 Macro que Finaliza o Monitoramento de uma Seção. . . . . . . . . . . . . 100

8.5 Macro que Finaliza o Monitoramento. . . . . . . . . . . . . . . 100 


\section{Lista de Abreviaturas}

AES

ALM

ALU

ASIC

CAD

CES

CI

CLB

CPLD

$\mathrm{CPU}$

DDR

DDR2

DSP

EPLD

$\mathrm{E} / \mathrm{S}$

FPGA

HAL

HDL

HW

$\mathrm{IOB}$

IOE

IP

JTAG

$\mathrm{LAB}$

LCR

LE

LUTs

MPGA
Advanced Encryption Standard

Adaptive Logic Module

Aritmetic Logic Unit

Application Specific Integrated Circuit

Computer-Aided Design

C for Embedded System

Circuito Integrado

Configurable Logic Block

Complex Programmable Logic Device

Central Processing Unit

Double Data Rate

Double Data Rate 2

Digital Signal Processing

Erasable Programmable Logic Devices

Entrada e Saída

Field Programmable Gate Array

Hardware Abstraction Layer

Hardware Description Language

Hardware

Input Output Block

Input Output Element

Intellectual Property

Joint Test Action Group

Logic Array Block

Laboratório de Computação Reconfigurável

Logic Element

Look-up Tables

Mask-Programmable Gate Arrays 
PAL Programmable Array Logic

QDRII RAM Quad Data Rate 2 RAM

RAM

Random Access Memory

RLDRAM Reduced Latency DRAM

RTL

Register Transfer Level

SDRAM

Synchronous Dynamic Random Access Memory

SIA

Semiconductor Industry Association

SoC

System-on-Chip

SoPC

System-on-a-Programmable-Chip

SRAM

Static RAM

SW

Software

UART

Universal Asynchronous Receiver/Transmitter

ULA

Unidade Lógica Aritmética

VHDL

Very High Speed Integrated Circuit Hardware Description Language 


\section{Capítulo 1 \\ Introdução}

\subsection{Contextualização}

A busca do mercado por novos produtos e a enorme concorrência dos dias atuais forçou uma redução drástica no ciclo de vida dos produtos, fazendo com que o tempo para lançamento de um produto (em inglês, time-to-market) seja um dos parâmetros mais importantes com relação ao custo do produto final. Desta forma, existe uma grande pressão para reduzir o tempo de criação e lançamento de um produto no mercado antes que o mesmo já esteja ultrapassado tecnologicamente.

Porém, o constante avanço tecnológico dos semicondutores tem impulsionado o desenvolvimento de sistemas computacionais em um único circuito integrado (CI) aumentando de forma significativa a densidade e a heterogeneidade dos sistemas, sendo necessário um maior esforço de desenvolvimento no que diz respeito as etapas de concepção e validação do projeto.

Esta nova tecnologia de vários componentes integrados em um único chip é conhecida como SoC (System-on-Chip), que são sistemas compostos de milhões de transistores que englobam hardware digital e analógico em um único produto. Como exemplos de módulos que compõem um SoC podem-se citar processadores, controladores, módulos customizados de propriedade intelectual (IP cores), blocos de hardware reconfiguravel,etc. 
Uma previsão feita pela Semiconductor Industry Association (SIA) em [36] diz que próximo ao ano 2012 o custo de fabricação estará próximo do custo de teste de um sistema (Figura 1.1). Dentre os motivos que dificultam a queda no custo de teste, podemos citar o aumento do número de transistores por pino, o que dificulta o acesso e o controle dos nós internos do CI por um equipamento de verificação.

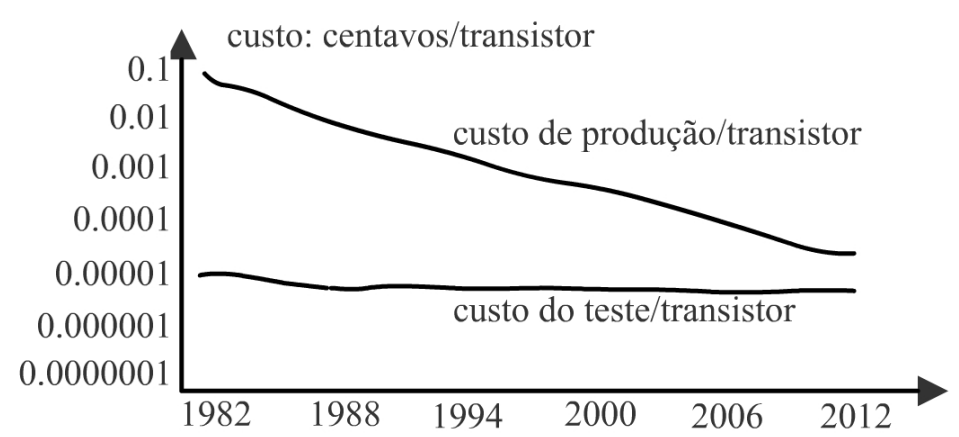

Figura 1.1: Custo de teste versus custo fabricação, baseado em [36]

A verificação de um $S o C$ é o mais sério gargalo no ciclo de desenvolvimento do projeto. De fato, a definição de uma linguagem e uma metodologia nos projetos de $S o C s$ é uma questão de tempo, no entanto, a verificação de um sistema é uma questão aberta e ambígua. A verificação funcional (conjunto de testes funcionais e de desempenho, tanto com o objetivo de verificar o adequado funcionamento do sistema e o de coletar os dados de funcionamento, como para verificar a perfeita compatibilidade entre os módulos) consome um tempo exagerado no ciclo de desenvolvimento do projeto. Existem várias estimativas, mas a maioria dos analistas e engenheiros concordam que até $70 \%$ do ciclo de desenvolvimento do projeto é consumido pela verificação do sistema [20].

A observação dentro dos projetos de $S o C s$ é hoje em dia suportada pela verificação no nível de transferência dos registradores $(R T L)$. Como os projetos de $S o C s$ tendem a aumentar de tamanho e complexidade, o processo de verificação necessita também ocorrer em nível de sistema. O suporte para verificação em nível de sistema já existe para a parte de software do $S o C$, na qual se utiliza a técnica de monitoramento baseado em software. Este tipo de monitoramento provê informações em nível de processo, como por exemplo, evento de sincronização das tarefas (iniciar, parar, bloquear, troca de execução, etc.), comunicação entre os processos (envio e recebimento de mensagens), utilização de recursos $(C P U$, memória, $I / O)$, interrupções externas, etc. Para extrair essas informações, 
normalmente, é necessário a instrumentação do software com instruções especiais de monitoramento que podem ser removidas depois da fase de validação [35]. A desvantagem deste tipo de instrumentação é que utiliza recursos do sistema observado, tais como, espaço de memória, tempo de execução (ciclos de $c l o c k$ ) da $C P U$, etc. Quando a instrumentação é removida o sistema pode mudar de comportamento ocasionando diferenças de tempo.

Como mencionado anteriormente, o hardware produzido ultimamente possui um alto nível integração, encapsulando sistemas completos em um único chip $(S o C)$, fazendo com que os tradicionais monitores de hardware encontrem inúmeras dificuldades. Processadores, componentes de $I / O$, memórias, módulos de hardware customizados, todos integrados no mesmo chip, sendo impossível para um monitor de hardware observar os sinais internos, estando acoplado externamente ao sistema. Para este tipo de sistema necessita-se a presença de um monitor residente dentro do chip (em inglês, on-chip) para coletar todas as informações indispensáveis para a análise do sistema, assim como evitar a interferência no comportamento do sistema observado [35].

\subsection{Motivação e Objetivos}

Com o aumento da complexidade dos sistemas computacionais através da integração de diversos componentes, as industrias e o meio acadêmico vêm procurando técnicas melhores para diminuir o tempo e o esforço gasto com a verificação no processo de desenvolvimento do projeto para garantir a qualidade, robustez, confiabilidade e disponibilidade dos dispositivos desenvolvidos.

A observação de sistemas computacionais em tempo de execução é indispensável durante os testes, debugging, otimização de algoritmos e na validação do projeto através da compreensão feita sobre o comportamento do sistema e de seu ambiente. Uma outra importante habilidade do monitoramento é a capacidade de observar o comportamento do sistema em vários níveis de abstração. Com isso, a informação de interesse é detalhada em diferentes níveis. Informações de alto nível referem-se a eventos como a comunicação entre processos e sincronismo, já as informações de baixo nível referem-se aos eventos ocorridos no processador ou no hardware dedicado durante a execução do sistema. A definição 
clássica para a observação de sistemas em tempo de execução é aplicada ao monitoramento, isto é, o processo de detectar, coletar e interpretar as informações através da observação do comportamento do sistema em execução.

Com um sistema de monitoramento adequado o projetista pode avaliar seu sistema por completo e com isso identificar os pontos que necessitem de alguma melhoria, seja na área de silício ou memória utilizada, otimização de algumas funções, gasto de energia, etc.

Este presente trabalho tem como objetivo descrever a implementação e utilização de um módulo (core) de monitoramento capaz de:

- Monitorar um sistema embarcado composto de hardware e software sem perturbar o seu comportamento durante a execução.

- Ser facilmente portável para qualquer SoPC (System-on-a-Programmable-Chip) que necessite de algum tipo de verificação.

- Coletar as informações geradas durante o monitoramento sem perda de dados e comprometimento do monitoramento.

- Apresentar as informações coletas de forma útil ao usuário, através de relatório e histogramas.

\subsection{Organização do Trabalho}

Este documento encontra-se organizado da seguinte forma:

- O capítulo 2 apresenta uma visão geral sobre teste, debug e análise de desempenho em sistemas computacionais, visando à obtenção de sistemas confiáveis, livres de erros e com possíveis melhorias de desempenho.

- No capítulo 3 é abordado o conceito de monitoramento de sistemas computacionais, citando as diferentes formas de monitoramento e os possíveis problemas e perturbações inseridas no comportamento do sistema observado. Os trabalhos relacionados a este projeto também são abordados neste capítulo. 
- O capítulo 4 apresenta alguns conceitos de computação reconfigurável e uma breve explicação sobre a tecnologia $F P G A$ e as linguagens de descrição de hardware através de sua importância atual para os projetos de CIs. O módulo de hardware (core) também é abordado neste capítulo.

- O capítulo 5 descreve os recursos de hardware e software que são utilizados para a implementação e validação do sistema.

- O capítulo 6 apresenta a implementaçãao do módulo de monitoramento desenvolvido neste trabalho.

- O capítulo 7 apresenta as conclusões obtidas e as sugestões para trabalhos futuros.

- Finalmente são apresentadas as Referências Bibliográficas. 


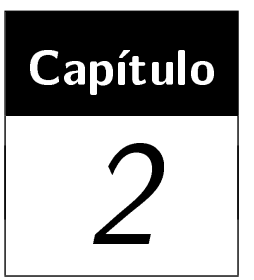

\section{Teste, Debug e Análise de Desempenho}

\subsection{Considerações Iniciais}

O requisito principal para obter um sistema confiável é determinar se um sistema eletrônico não possui erros. A confiabilidade em sistemas era principalmente desejável em aplicações militares e aeroespaciais. Porém, ultimamente, tem crescido o interesse em confiabilidade na maioria das áreas que envolvem computação.

Para atingir o grau de confiabilidade desejado podem-se realizar testes no circuito desenvolvido procurando defeitos de fabricação. Dependendo do tipo de testes, falhas induzidas por efeitos do ambiente e flutuação na tensão de alimentação também podem ser detectadas.

Além dos testes para a detecção de erros os projetistas utilizam ferramentas de análise de desempenho para encontrar os possíveis locais de gargalo do sistema, auxiliando no desenvolvimento de projetos otimizados e eficientes.

\section{$2.2 \quad$ Teste}

O projeto de SoCs pode empregar módulos de hardware complexos reutilizáveis, chamados de módulos de hardware. O principal objetivo do uso de módulos é a redução 
do tempo para o lançamento de um produto (em inglês, time-to-market), uma vez que estes módulos são pré-desenvolvidos e pré-verificados. O uso de módulos envolve dois grupos, os provedores e os usuários de módulos. No projeto baseado em múltiplos componentes em uma placa de circuito impresso, CIs já projetados, fabricados e testados são enviados para o usuário pelo provedor. O usuário precisa, neste caso, projetar, fabricar e testar a placa, utilizando os componentes como módulos livres de falhas. O teste, neste caso, se resume a teste de interconexão dos CIs. Em projeto de $S o C s$, os componentes são módulos que não estão testados, pois não estão fabricados. O teste e a fabricação de todo o sistema é responsabilidade do usuário, incluindo o teste dos próprios módulos.

O teste de sistemas baseados em módulos apresenta vários desafios adicionais em relação ao teste de sistemas em placa de circuito impresso, entre eles [30]:

- Teste interno de módulos: Com a redução do tamanho do transistor e o aumento da freqüência de operação, o desenvolvimento de teste de alta qualidade (porém, de baixo custo) está se tornando um desafio maior. Os modelos de falhas são inadequados, uma vez que defeitos de atraso induzidos pelo roteamento estão se tornando mais freqüentes.

- Transferência de conhecimento de teste do módulo: Uma vez que o teste envolve dois atores, o provedor e o usuário do módulo, há uma necessidade de padronização na transferência de informação a respeito de teste. Por exemplo, cobertura de falhas, padrões de teste, protocolos de teste, modos de teste, entre outros.

- Acesso de teste aos módulos embutidos: Módulos são componentes internos aos SoCs, podendo conter diversos níveis de hierarquia. Assim, é necessário definir um método para levar os padrões de teste às entradas e capturar as suas respostas.

- Integração e otimização do teste do sistema: SoCs são formados por módulos, lógica definida pelo usuário $(L D U)$ e lógica de interconexão. Desta forma, o integrador do sistema deve escolher um compromisso entre diversos parâmetros como tempo de teste, acréscimo de área de silício, degradação de desempenho, qualidade de teste, consumo de potência e custo total de teste. 
O propósito da realização de testes é revelar as falhas e assegurar que não ocorrerá defeito no sistema durante sua operação. O teste consiste nos seguintes passos: Planejamento do teste, construir eventos de testes para revelar os defeitos e aplicar os eventos durante a execução do sistema.

\subsubsection{Planejamento do teste}

O processo de teste inicia-se pela formulação de uma estratégia, definindo a cobertura do teste, critérios, modelagem do comportamento da execução, etc. O modelo pode servir como uma especificação do comportamento do sistema durante sua execução. Este comportamento pode, por exemplo, ser a ordem no qual os processos são invocados.

\subsubsection{Construir eventos de testes para revelar os defeitos}

Os eventos de teste podem ser gerados partindo da especificação ou da implementação do sistema. O evento de teste baseado na especificação do sistema pode ser utilizado durante o desenvolvimento e até antes da implementação estar completa. Já o evento baseado na implementação requer conhecimento dos detalhes de implementação e deve ser realizado após o desenvolvimento do sistema

\subsubsection{Aplicar os eventos durante a execução do sistema}

O comportamento do sistema pode ser examinado de acordo com o que for observado durante a execução de teste. Portanto, é essencial analisar as saídas produzidas, para através da verificação dos resultados poder avaliar o sistema.

Observar o comportamento do sistema em tempo de execução pode ser feito utilizando monitores baseados em software, hardware ou uma combinação entre hardware e software (monitores híbridos), detalhado na seção 3.5 . 


\subsection{Debug}

Teste e debug são atividades semelhantes se for levado em consideração o processo de encontrar erros. No entanto, teste é um processo mais automático de expor diferentes entradas no sistema, e avaliar seus resultados (saídas) [35]; enquanto que debug é o processo de encontrar, analisar e remover os erros do sistema [15].

A execução de uma parte de código implementada ou especificada de forma errada pode alterar o estado do sistema, como por exemplo, atribuindo valores errôneos em variáveis, violando endereços de memória, etc, e conseqüentemente alterando o resultado (valores de saída) fornecido pelo sistema. Para identificar um erro é indispensável à capacidade de reproduzir esta falha repetidamente, requerendo o conhecimento das condições iniciais (valores de entrada) e execuções deterministas.

Para sistemas seqüenciais sem características de tempo-real, é aceitável a utilização de um mesmo conjunto de valores iniciais e estados interno do sistema para poder reproduzir uma falha. Para sistemas distribuídos de tempo-real, a reprodução das falhas é mais complicada devido ao tempo e problemas na ordem de execução.

\subsection{Análise de Desempenho}

A análise de desempenho é utilizada para compreender melhor o sistema que já está concluído ou prototipado. Através desta análise é possível encontrar gargalos de desempenho e extrair diversos parâmetros do sistema, tais como, o tempo de execução e de resposta, atraso de comunicação de vários tipos, entre outros. Alguns recursos são importantes de serem analisados principalmente em projetos eficientes de sistemas embarcados. Dentre estes recursos pode-se citar o consumo de energia e de memória e utilização da área de silício. Com a aquisição destas informações sobre o sistema, os projetistas poderão avaliar dentre outros fatores, o escalonador de tarefas e estimar a alocação de recursos.

Existem alguns fatores desejáveis para as técnicas e ferramentas de análise de desempenho [25]: 
- Deve ser não-intrusivo: O processo de medida não deve alterar o sistema ou degradar o seu desempenho.

- Deve ser não oneroso: A ferramenta de coleta de dados não deve custar uma quantia significante de tempo ou dinheiro.

- Dever ser modificável ou estendível: Sistemas de computação e microprocessadores sofrem constantes alterações e devem ser fácil estender ou modificar a ferramenta para atuar no sistema atualizado.

- Deve medir todas as atividades incluindo atividades do kernel ou do usuário: Atualmente é fácil construir ferramentas que analisam somente as atividades dos usuários. No entanto, existem atividades do sistema operacional e de hardwares dedicados que são importantes para uma análise completa do sistema.

- Dever ser de fácil utilização: Ferramentas de difícil utilização, normalmente, são sub-utilizadas e propensas a uma taxa maior de erros do usuário.

\subsection{Considerações Finais}

Neste capitulo foram apresentados conceitos gerais sobre teste, debug e análise de desempenho em sistemas computacionais, visando à obtenção de sistemas confiáveis, livres de erros e com possíveis melhorias de desempenho. As técnicas para obter um sistema confiável e determinar se um sistema eletrônico não possui erro apresentado neste capítulo são utilizadas na indústria com sucesso há alguns anos. Porém, como já salientado anteriormente, o crescente grau de integração e o conseqüente aumento de desempenho dos SoCs têm inviabilizado o uso de algumas técnicas. Com isso, a criação de novos métodos para a análise deste tipo de sistema tem se tornado uma necessidade.

No próximo capítulo será abordado o conceito de monitoramento de sistemas computacionais, citando as diferentes formas de monitoramento e os possíveis problemas e perturbações inseridas no comportamento do sistema observado. No entanto, é dado um destaque ao monitoramento de eventos no qual este trabalho é baseado. 


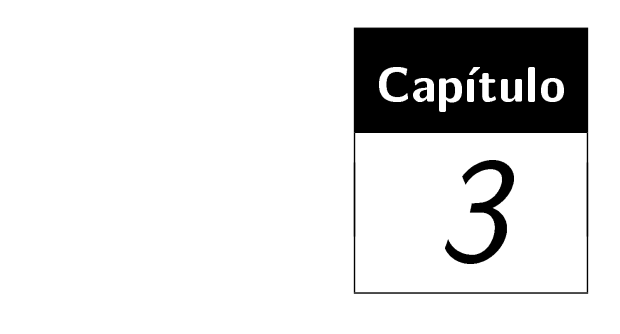

Monitoramento

\subsection{Considerações Iniciais}

Monitoramento é o processo de coletar informações em tempo de execução para teste, debugging, análise de desempenho [12], dimensionamento de recursos, otimização de algoritmos e análise do escalonador de tarefas [35]. Um monitor fornece ao usuário descrições dos eventos que serão monitorados, coleta e integra informações interessantes pertencentes aos eventos e apresenta ao usuário uma significante representação das atividades do sistema.

Um monitor pode ajudar projetistas de hardware e software não só a entender o comportamento de sua aplicação em tempo de execução, mas também a corrigir possíveis gargalos de desempenho.

Em geral, o monitoramento é dividido em dois níveis: o nível mais baixo refere-se ao processo de detectar o objeto de interesse. Isto é feito, normalmente, por um objeto que é inserido no sistema que, quando executado ou ativado, indica que um evento de interesse foi detectado. Este objeto pode ser uma instrução ou uma função que é inserida no software, como também pode ser um sensor físico conectado no hardware. Isso irá depender do nível de abstração importante ao usuário. O nível mais alto é definido pelo processo de coletar o evento detectado e salvá-lo em um buffer de memória ou enviá-lo a 
um sistema de computação externo para posterior análise.

O principal problema no processo de monitoramento é a interferência na execução que pode ser introduzida no sistema observado. Este tipo de perturbação pode acarretar mudanças no desempenho ou no comportamento, principalmente, em sistemas sensíveis ao tempo, como por exemplo, sistemas de tempo real. Este tipo de problema é conhecido com probe effect e será discutido a seguir.

\subsection{Probe Effect}

O probe effect, também conhecido com o nome de princípio da incerteza de Heisenberg (em inglês, Heisenberg's uncertainty principle) quando aplicado à engenharia de software [29], pode ser visível quando um código é adicionado ou removido do sistema, ou o sistema é modificado de uma outra forma que possa implicar no aumento do tempo de execução. Modificando o sistema de qualquer forma, pode-se alterar seu comportamento. Códigos extras podem requerer tempo computacional e outros recursos. A remoção de códigos liberará recursos que podem ser usados por tarefas que deveriam estar bloqueadas. Este tipo de problema também pode ser percebido se houver uma diferença no comportamento do sistema que está sendo testado e o mesmo sistema não sendo testado. Existem algumas maneiras de eliminar o probe effect.

- Deixando os códigos ou sensores no sistema final: Desta maneira, o método de monitoramento utilizado durante o desenvolvimento é deixado no produto final. Evitando com isso alterações no comportamento do sistema com a retirada do monitor. A desvantagem é que o produto final pode ter um desempenho inferior e um custo adicional[35].

- Utilizando hardware não-intrusivo: Monitores de barramento e analisadores lógicos são típicos exemplos de hardware passivo, os quais não interferem no sistema. Outras técnicas são o uso de memórias multi-portas, memórias refletivas e uso de hardware especial. Existem também sistemas de monitoramento híbrido no qual utilizam o suporte de hardware junto com a instrumentação feita em software. A desvantagem 
desta solução pode ser o alto custo do produto devido ao hardware extra.

\subsection{Monitoramento Síncrono e Assíncrono}

Chodrow et al. [17] distinguem entre monitoramento síncrono e assíncrono. A diferença chave é a localização do monitor no sistema a ser observado. No monitoramento síncrono, o monitor, assim como os sensores, estão localizados dentro do sistema a ser observado. Isto é, o sistema e o monitor competem pelos mesmos recursos. Ao contrario, no monitoramento assíncrono o monitor reside fora do sistema. O overhead causado pelo monitoramento síncrono pode agravar o probe effect. Em contraste, o monitoramento assíncrono tem a possibilidade de controlar este overhead, como por exemplo, carregando o monitor em um hardware adicional no sistema.

\subsection{Níveis de Abstração do Monitoramento}

Um sistema pode ser monitorado em diferentes níveis de abstração, como a informação de interesse é detalhada em diferentes níveis. Informações de alto nível referem-se a eventos como a comunicação entre processos e sincronismo. Por outro lado, informações de baixo nível referem-se a eventos parecidos com um registro passo-a-passo da execução de um processo [35].

O nível de sistema é o nível mais alto de abstração do monitoramento e representa uma visão lógica ou a visão que o usuário tem do sistema. O monitoramento no nível de processo inclui a comunicação, sincronismo e mudanças de estado dos processos. O monitoramento no nível de função refere-se ao comportamento interno do processo, observando os eventos produzidos pelas funções ou procedimentos. Por fim, o monitoramento em nível de instrução que se refere aos eventos ocorridos no processador ou no hardware dedicado durante a execução do sistema (por exemplo, acesso a cache ou outro tipo de memória, interrupções, chamadas de sistema, etc).

O nível de abstração do monitoramento está inversamente relacionado com o número de eventos gerados pelo sistema e também sobre possíveis overheads causados na coleta 
de dados. Isto ocorre pelo fato de um monitoramento com baixo nível de abstração gerar mais eventos freqüentes se comparado a um de alto nível, como pode-se ver na Figura 3.1 .

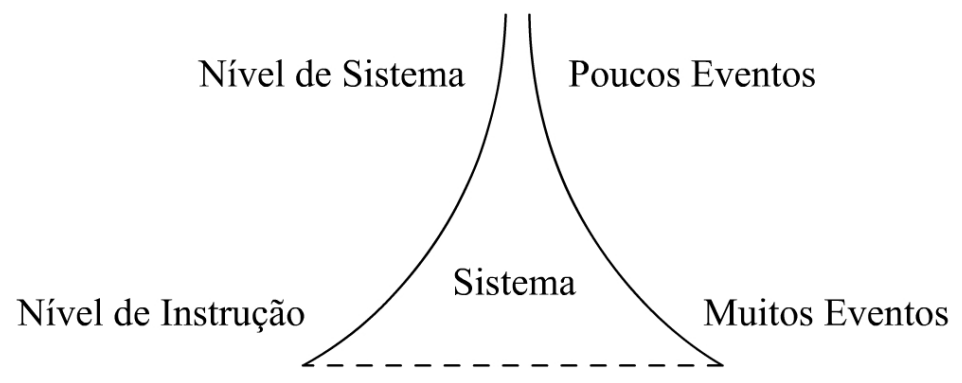

Figura 3.1: Relação entre nível de abstração do monitoramento e geração de eventos

\subsubsection{Nível de Sistema}

O nível de sistema é o nível mais alto de abstração do monitoramento representando uma visão lógica e superficial do sistema, observando somente o comportamento externo do sistema ou a interações entre sistemas diferentes. Este tipo de monitoramento não detecta violações de comportamento interno que não afetam o comportamento externo ou não detectam até a violação corromper eventualmente o comportamento externo. Mesmo quando um erro de comportamento externo é detectado, a fonte do erro dentro do sistema é difícil de ser encontrada. Esse nível de informação é normalmente utilizada para testar o sistema durante os estágios finais no processo de desenvolvimento[35].

\subsubsection{Nível de Processo}

No monitoramento em nível de processo é observado a comunicação entre o processo e o sistema, a interação entre os processos e os eventos relacionados com o controle do estado do processo, que podem estar em três estados diferentes:

- Execução: Indica que processo está de posse do processador;

- Pronto: Indica que o processo aguarda apenas por uma chance para ser processado;

- Espera: Indica que o processo aguarda por algum evento ou recurso do sistema para continuar sua execução. 
Neste nível de abstração são considerados os eventos que podem alterar o estado de um processo em execução, perturbando com isso o comportamento da execução.

Os seguintes eventos podem ser considerados como eventos em nível de processo: criação e finalização do processo, mudanças de estado, operações de $I / O$ e comunicação e sincronização entre os processos.

\subsubsection{Nível de Função}

O objetivo do monitoramento em nível de função é monitorar o comportamento interno do processo para determinar as funções ou procedimentos com algum problema. Através deste nível de abstração é possível verificar várias propriedades interessantes não se limitando a comportamentos externos. O ponto fraco deste nível de monitoramento é que a instrumentação no sistema alvo é muito complicada e requer um alto nível de conhecimento da estrutura do sistema. Além disso, a instrumentação pode alterar a semântica do sistema alvo se não for inserido de forma correta.

\subsubsection{Nível de Instrução}

O monitoramento em nível de instrução que se refere aos eventos ocorridos no processador ou no hardware dedicado durante a execução do sistema, tais como, acesso a cache ou outro tipo de memória, interrupções, chamadas de sistema, etc. Neste tipo de monitoramento é necessária a utilização de um hardware dedicado para esta tarefa, porque é muito difícil analisar todas as instruções executadas sem que haja uma perda de desempenho do sistema observado. Uma outra opção é analisar somente as instruções que afetam a execução do programa; como por exemplo, saltos condicionais, exceções, etc.

\subsection{Tipos de Sistemas de Monitoramento}

Soluções para coletar informações relevantes de sistemas de computação podem ser classificadas em três categorias: monitoramento por hardware, software ou híbrido. A Tabela 3.1 resume as características de cada tipo de monitoramento, na qual serão expli- 
cadas detalhadamente no decorrer desta seção.

\begin{tabular}{|c|c|c|c|c|}
\hline $\begin{array}{c}\text { Tipo de } \\
\text { Monitoramento }\end{array}$ & $\begin{array}{c}\text { Nível de } \\
\text { Abstração }\end{array}$ & $\begin{array}{c}\text { Tamanho do } \\
\text { Log de Eventos }\end{array}$ & $\begin{array}{c}\text { Overhead da } \\
\text { Instrumentação }\end{array}$ & Flexibilidade \\
\hline Hardware & Baixo & Grande & Baixo & Baixa \\
\hline Software & Alto & Pequeno & Alto & Alta \\
\hline Híbrido & Alto & Pequeno & Baixo & Alta \\
\hline
\end{tabular}

Tabela 3.1: Características dos tipos de monitoramento

\subsubsection{Software}

Monitoramento por software consiste de programas que detectam estados de um sistema. Estes monitores também englobam um conjunto de instruções que detectam eventos. Este tipo de monitoramento utiliza somente software para realizar suas tarefas. Códigos de instrumentação dedicados são inseridos no sistema alvo previamente às atividades de monitoramento.

O código de monitoramento pode ser inserido dentro da aplicação ou junto com o kernel do sistema. Em ambos os casos, eventos de interesse são gerados, detectados e processados (isto é, armazenados) pelo próprio sistema alvo, podendo com isso alterar o tempo de execução do sistema observado. No entanto, a vantagem óbvia do monitoramento por software é sua flexibilidade. Para se realizar teste e debug num sistema com níveis satisfatórios de segurança é preciso observar o sistema, e isto incluí a adição de códigos de instrumentação no software (aplicação e kernel). Com isso, é possível ter um monitoramento significantemente melhor se comparado a métodos baseados em monitoramento por hardware.

A principal desvantagem é que ele sempre gera algum tipo de efeito no sistema observado, porque esta instrumentação utiliza recursos do sistema alvo, tais como, espaço de memória e ciclos de clock do processador (tempo de execução).

No monitoramento por software é possível identificar diferentes tipos de técnicas, dependendo do lugar onde são implementadas. Algumas destas técnicas são apresentadas a seguir:

- Kernel: Este tipo de monitoramento observa o escalonador de tarefas, interrupções, 
ect. (Figura 3.2). Estes tipos de monitores tipicamente não são programáveis pelo projetista da aplicação, mas de preferência dão uma infra-estrutura para o kernel. Deste modo, para evitar o probe efect, estes tipos de monitores devem ser deixados permanentemente no kernel, contribuindo com overhead, mas diminuindo com as perturbações causadas com sua retirada.

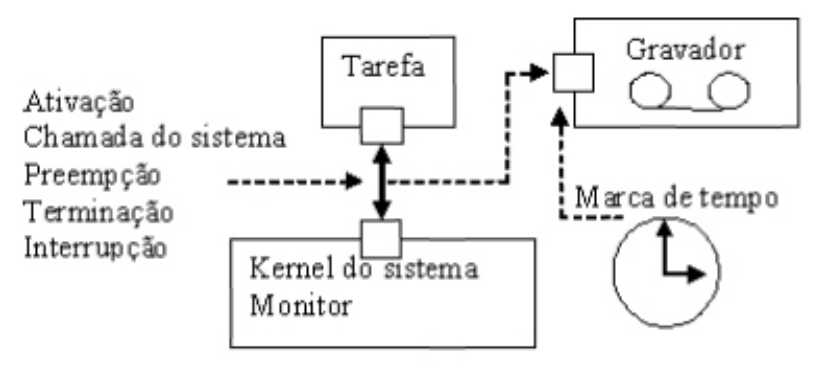

Figura 3.2: Técnica de monitoramento: Kernel

- InLine: São os monitoramentos em nível de função que adicionam saídas auxiliares para a tarefa instrumentada (Figura 3.3). Estes tipos de saídas são observadas partindo necessariamente de um perspectiva de monitoramento, teste ou debugging. Sendo elas parte do código da aplicação, elas estarão nas medidas e estimações do tempo de execução. Isto também significa que é necessário verificar o sistema alvo para tentar eliminar o probe effect.

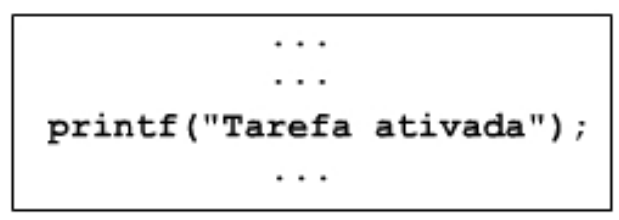

Figura 3.3: Técnica de monitoramento: InLine

\subsubsection{Hardware}

Um monitor baseado em hardware é um dispositivo que não faz parte do sistema a ser monitorado. Esses monitores detectam os estados de diferentes barramentos do hardware por onde passam os sinais do comportamento do software. O monitor detecta e armazena 
os eventos através de sensores, os quais são associados ao sistema. Estes sensores estão localizados na camada de hardware [17], e assim, não utilizam os recursos do sistema alvo.

Um dos objetivos do monitoramento por hardware é o de evitar, ou minimizar a interferência na execução do sistema (monitoramento não-intrusivo). O processo de monitoramento pode ser chamado de não-intrusivo, desde que a observação limite-se a somente ler as variáveis do sistema utilizando um hardware passivo conectado ao barramento ou aos sinais do sistema. Esta definição de monitoramento não-intrusivo significa que a aplicação não requer nenhum tipo de modificação para o seu funcionamento.

Este tipo de monitoramento trabalha diretamente na camada física. Então, a geração explicita de um evento não é necessária. Eles são dispositivos eletrônicos conectados a sistemas dedicados e detectam sinais que caracterizam o fenômeno a ser observado. A detecção e o processamento do evento é feito inteiramente pelo monitor e seu módulo de controle, não compartilhando com isso nem recurso computacional com o sistema alvo. No entanto, se o monitoramento por hardware não for reconfigurável, a introdução de custos e a perda de flexibilidade podem limitar o seu uso [26].

Do ponto de vista econômico, o custo do monitoramento por hardware terá impacto somente no desenvolvimento do produto, e não no custo de produção, desde de que o monitor possa ser removido integralmente do sistema alvo.

A não-portabilidade, a carência da possibilidade de reajustes e o baixo nível de detalhes das observações limitam severamente a viabilidade deste método de monitoramento. Entretanto, a tendência atual é o desenvolvimento de aplicações especificas de hardware utilizando FPGAs e VHDL [12], dando a oportunidade de integrar mecanismos de monitoramento não-intrusivos neste tipo de hardware, permitindo um ganho de flexibilidade e redução de custos.

Em geral, a atividade realizada por este tipo de monitor pode ser descrita através dos seguintes passos (Figura 3.4): detecção do evento, comparação do evento, coleta do evento. No primeiro passo, a detecção, o monitor escuta continuamente os sinais gerados pelo sistema. No segundo passo, os sinais detectados são comparados com um modelo pré-definido no qual define o que pode ser considerado como evento. Quando um sinal 
se encaixa com um modelo de evento, o processo então ativa o último passo, ou seja, a coleta é quando um dado do evento é coletado e armazenado [35]. O evento coletado pode ser armazenado localmente no monitor ou ser transferido para um computador com uma maior capacidade de armazenamento.

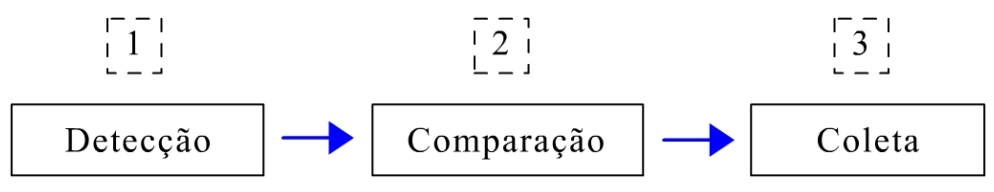

Figura 3.4: Passos do monitoramento por hardware

\subsubsection{Híbrido}

O método de monitoramento híbrido é utilizado para aumentar o nível de abstração e diminuir o conjunto de informações gravadas. Eles são implementados com a adição de alguns códigos de ativação no software, no qual utilizam um número mínimo de instruções auxiliadas por um hardware que armazena os eventos significativos.

Monitores híbridos possuem as vantagens de ambos os tipos de monitoramentos (HW/SW). Este tipo de monitoramento utiliza extensões de software para gerar sinais especiais que são observados por dispositivos de hardware externos conectados ao sistema através do barramento de dados/ endereço do processador ou através de um ponto de rede. Estes dispositivos reconhecem e armazenam os eventos detectados. Ambos métodos possuem prós e contras. Monitoramentos por software, por um lado são baratos e altamente flexíveis, mas eles perturbam o sistema monitorado. Monitoramentos por hardware não necessariamente interferem no sistema monitorado, mas estes sistemas são altamente dependentes do processador alvo e, deste modo, são caros e inflexíveis se comparado ao monitoramento por software.

Usando este método as limitações do monitoramento por hardware podem ser aliviadas, ainda que os problemas de custo e não-portabilidade podem permanecer. Com a adição de um hardware dedicado ao monitoramento, as instruções adicionadas ao sistema ou a aplicação devem possuir recursos suficientes para evitar o probe effect. 


\subsection{Orientação do Monitoramento}

O processo de coletar informações do sistema pela ferramenta de monitoramento pode ser pela orientação de eventos ou orientada pelo relógio [16]. O monitoramento orientado pelo relógio atua observando o estado de cada processo em intervalos de tempo constantes por um processo independente. No entanto, o monitoramento orientado a eventos observa o sistema alvo e é ativado quando ocorre um evento previamente definido. Este tipo de monitoramento pode ser divido ser classificado de três formas diferentes conforme mostra a Figura 3.5 e detalhado na seção 3.6 .2 .

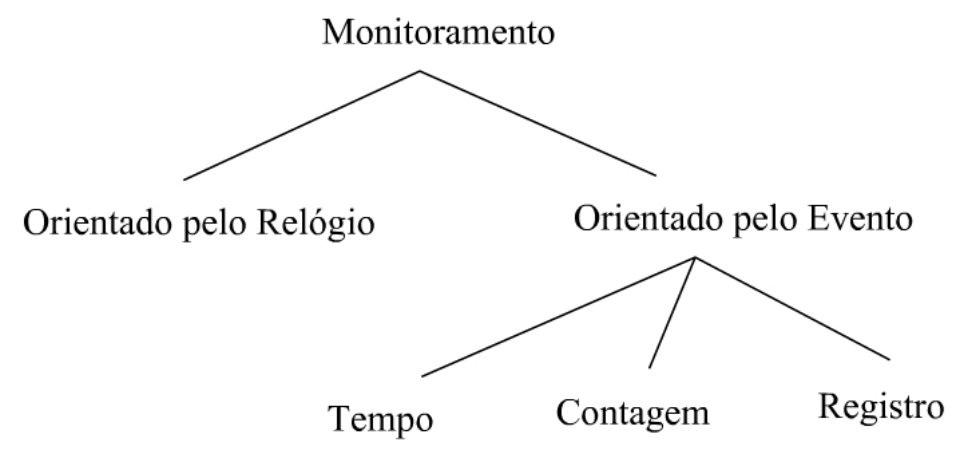

Figura 3.5: Orientação do monitoramento

\subsubsection{Monitoramento Orientado pelo Relógio}

Neste tipo de monitoramento um processo, independente do processo alvo, registra através de intervalos de tempo periódicos as informações referentes à execução do sistema. O período de atuação do monitoramento é normalmente definido pelo usuário ou a ferramenta monitora o sistema até o fim de sua execução. O intervalo de tempo para o registro das informações depende do sistema operacional e pode ser alterado em sistemas de código fonte aberto como o Linux.

As ferramentas prof e gprof são muito utilizadas pela comunidade acadêmica e são exemplos típicos desta categoria de monitoramento. Estas ferramentas produzem estatísticas sobre a execução de um programa, como por exemplo, quantas vezes cada função foi chamada, a quantidade de tempo que cada função consumiu, etc. Os dados são armazenados em arquivos de registro (em inglês, trace files) que são analisados após 
o monitoramento. Por exemplo, o tempo gasto em uma função ou procedimento de um programa sendo executado é supostamente proporcional ao número de vezes que a função ou o procedimento é registrado pelo monitor [16]. Ferramentas de medida de desempenho baseadas neste tipo de orientação são intensamente utilizadas na execução de debugguing em programas seqüenciais. É possível observar a execução de sistemas em nível de abstração alto sem perturbá-lo, mas nem sempre isso é possível, causando com isso algum tipo de overhead no sistema.

\subsubsection{Monitoramento Orientado pelo Evento}

O monitoramento orientado a eventos (ou monitoramento de eventos) é acionado pela ocorrência de eventos previamente determinados. Um evento pode ser definido como uma comunicação entre o sistema e o usuário, a mudança de estado de um processo, a chamada de uma função, interrupções, etc.

Neste tipo de monitoramento, normalmente, os dados são construídos e registrados através da adição de algumas características ao evento, tais como, o tempo exato em que o evento ocorreu, o tipo de evento, quem o gerou, etc. Existem diferentes tipos de eventos e diferentes formas de avaliá-los. A seguir, serão detalhadas as três formas de utilização destes eventos, conhecidos como monitoramento de eventos através da análise de tempo, contagem e registro:

- Tempo: Através do monitoramento do sistema é possível fazer várias medições de tempo, das mais diversas características. Por exemplo, é possível medir o tempo gasto por uma determinada função na realização da sua tarefa, o tempo de utilização do processador, o tempo gasto entre a troca de dados na memória (swapping), etc.

- Contagem: Neste tipo de monitoramento utiliza-se um contador para cada propriedade observada, o qual é incrementado de acordo com a ocorrência dos eventos. Através da contagem é possível obter informações estatísticas do sistema de forma simples e não intrusiva.

- Registro ou Tracing: O registro consiste na coleta de todas as ocorrências de um ou 
mais eventos em um certo intervalo de tempo. Isto é, este tipo de monitoramento é utilizado quando todas as ocorrências de eventos devem ser conhecidas. Ele representa o comportamento do sistema em execução por uma seqüência de eventos. Diferentemente dos monitoramentos através do tempo e da contagem, ele é utilizado para análises eficientes e completas do comportamento do sistema. Com isso, monitoramentos baseados em registros geram um volume muito grande de dados. A forma mais comum e direta para reduzir este volume de dados é coletando apenas os eventos de interesse e não todos os eventos que ocorrerem durante a execução do programa.

\subsubsection{Estrutura do Monitoramento de Eventos}

O monitoramento de eventos é visto como um conjunto de funções (sensor, coletor de dados, análise) durante sua execução. Um monitor de eventos é principalmente um coletor de eventos que recebe ou produz eventos (observações) aos sensores que armazenam essas observações em banco de dados chamado de log de eventos.

Um sensor é uma instrumentação do objeto monitorado. Por exemplo, a instrumentação pode ser feita com um hardware adicional que nos permite observar os sinais do barramento do processador ou a instrumentação pode ser feita com um código adicional, permitindo observar o que acontece no objeto monitorado. Isto é, o sensor registra algum evento de interesse. O sensor pode captar esses eventos diretamente ou indiretamente. Por exemplo, para monitorar o estado de um processador diretamente é utilizado uma interface de teste padrão (como a interface JTAG) ou um circuito interno (hardware), emulando o processador, o qual concede a habilidade de captar os eventos, desde que seja possível observar os eventos internos do processador diretamente. Ao contrário, o monitoramento de eventos do estado de um processador via seu barramento é feito indiretamente, porque estes monitores observam o estado do processador através do fluxo de sinais em seu barramento [31].

Uma visão do monitoramento de eventos é ilustrada na Figura 3.6. A composição do evento é o processo de coletar o dado da fonte (objeto monitorado), sinalizar a base de 
dados (armazena a ocorrência de eventos) e analisá-lo on-line ou off-line dependendo da complexidade dos eventos.

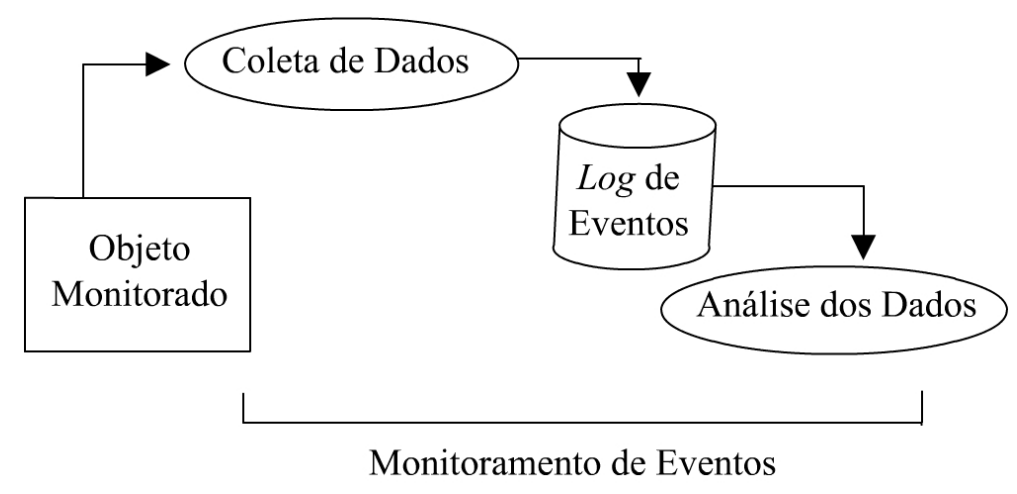

Figura 3.6: Composição do monitoramento de eventos

\subsubsection{Gerenciamento do Monitoramento de Eventos}

O monitoramento de eventos segue parte das diretrizes do tradicional gerenciamento de monitoramento. Os tradicionais passos resumidos por Snodgrass [37] nos sistemas computacionais de monitoramento ocorrem através das 4 etapas seguintes definidas em [31]:

1. Projeto e Implementação do Sistema: (a) Configuração do Sensor: Este passo envolve a decisão de qual informação cada sensor registrará (possivelmente informará) e onde cada sensor estará localizado, se necessário; (b) Instalação do Sensor: Os sensores são codificados (ou construídos em hardware) e inseridos numa localização correta no sistema monitorado. Os dados da coleta podem ser armazenados externamente ou no próprio sensor.

2. Configuração do Sistema: (a) Habilitando os Sensores: Alguns sensores ficam permanentemente habilitados, registrando o monitoramento dos dados durante todo o tempo de execução (caso do monitoramento de eventos) ou armazenando (e possivelmente relatando) esses dados, enquanto outros podem estar individualmente ou coletivamente habilitados, indiretamente ou diretamente por estímulos do usuário.

3. Execução do Sistema: (a) Geração de Dados: O objeto monitorado é executado, e os dados coletados são analisados imediatamente ou armazenados em uma memória 
principal ou secundária para posterior análise. A reconfiguração dinâmica geralmente não é possível nesta etapa, pois não é possível mudar o que os sensores deveriam gravar em tempo de execução (a menos que os sensores sejam projetados a se adaptarem a este tipo de mudança).

4. Análise dos Dados Gerados: (a) Especificação da Análise: Na maioria dos sistemas, é fornecida ao usuário uma lista de análises suportadas; algumas vezes uma simples linguagem de comando está disponível. (b) Exibir Especificações: É fornecido ao usuário um conjunto de formatos (também especificado através de um menu ou uma linguagem de comando), dispondo de uma lista de pacotes de dados para compor relatórios ou simples gráficos. (c) Análise dos Dados: Normalmente, a análise dos dados ocorre em conjunto, depois dos dados terem sido coletados, devido ao alto custo computacional deste tipo de análise. (d) Exibir Geração: Geralmente, este passo ocorre imediatamente depois da análise dos dados, ainda que poucos pacotes de monitoramento permitam que uma análise dos dados seja exibida posteriormente.

\subsubsection{Recursos Necessários para o Monitoramento de Eventos}

Os recursos necessários para o monitoramento são divididos em duas partes. Em primeiro lugar, o tamanho do log de eventos é importante desde que a memória, disco, etc. são requeridos para seu armazenamento. Em segundo lugar, o custo do overhead em termos de processador pode ser significante [31].

Os eventos ocorridos devem ser armazenados, no mínimo, até eles serem analisados. O armazenamento pode ser feito pelo $\log$ de todos os eventos (isto é, sem filtragem) ou são otimizados, pela compressão dos dados ou utilizando contadores para observar quantas vezes uma tarefa particular é executada; de preferência anotando cada ocorrência [31]. Mesmo com estes processos de otimização, é importante reduzir o máximo possível o tamanho do $\log$ de eventos, porque com isso se reduzirá a necessidade de alguns recursos, tais como a quantidade de memória e também diminuirá o tempo de análise dos resultados, o qual é dependente do tamanho do log de eventos. Se o nível de abstração é menor, mais eventos devem ser registrados para extrair as informações necessárias do sistema 
se comparados a um alto nível de abstração. Por exemplo, assumindo que deseja-se monitorar a execução de um código, uma possibilidade é através do registro de todos os sinais do barramento do hardware (eventos do barramento). Por outro lado, se uma linguagem de alto nível é monitorada por um monitor baseado em software, poucos eventos serão registrados. Visto que as funções ou procedimentos são transformados em várias instruções de máquina, o número de observações necessárias para reconstruir o que está sendo executado é maior para o monitor baseado em hardware se comparado ao monitor baseado em software. As diferenças entre os tipos de monitoramento estão detalhadas na seção 3.5 .

\subsection{Problemas no Monitoramento de Tecnologias de Sistemas Embarcados}

Uma grande extensão de componentes são utilizados para implementar sistemas embarcados [39]: microprocessadores, microcontroladores, processador de sinal digital $(D S P)$, uma grande variedade de dispositivos (ASICs, EPLD, CPLD, FPGA, etc.), componentes específicos para comunicação, monitor gráfico, $I / O$, computação paralela de alto desempenho, etc. A maioria destes componentes são programáveis; isto significa que o software define todas as funcionalidades do sistema.

Mais e mais, o sistema embarcado é implementado como um sistema distribuído baseados em processadores heterogêneos por várias razões: o custo pode ser menor se comparado ao uso de um único e poderoso processador, o número de dispositivos (modularidade) pode ser importante e esses dispositivos geralmente requerem uma distancia física no silício. A Figura 3.7 ilustra a atual tecnologia utilizada em sistemas embarcados.

Com o aumento da integração do chip, já é possível encontrar todas as partes (convencional microprocessador, DSP, interfaces de I/O, uma FPGA para adicionar funções customizadas) de um sistema em um único componente $S o C$.

É possível imaginar as dificuldades de soluções para teste e debug. Algumas funções são implementadas em software e outras em hardware. Eles têm que se comunicarem, para 


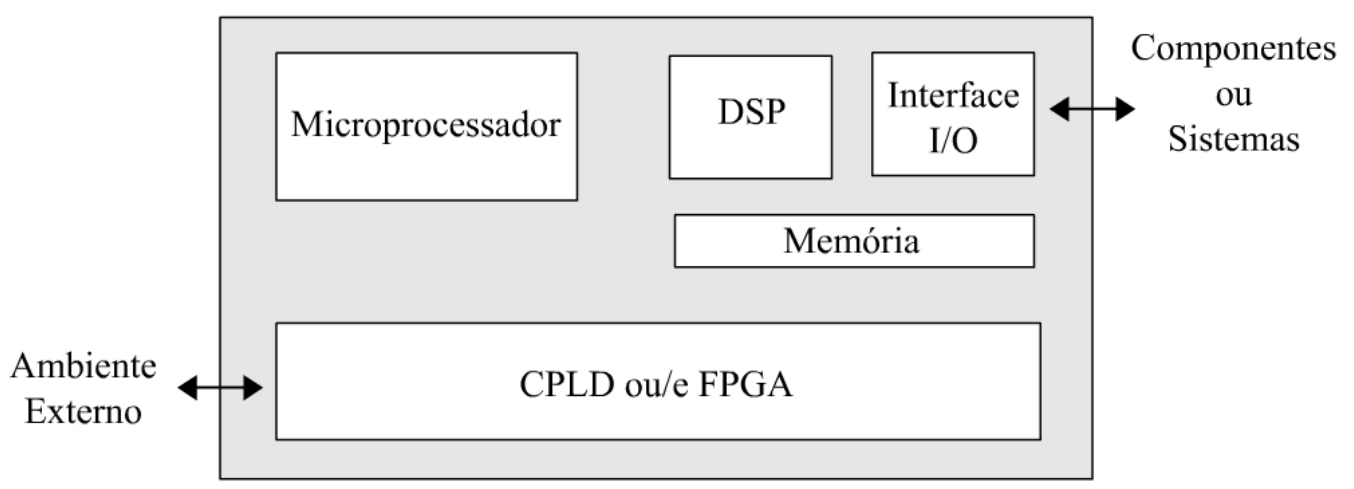

Figura 3.7: Atual tecnologia utilizada na implementação de sistemas embarcados

satisfazer restrições de tempo e desempenho. Uma técnica de monitoramento apropriada para todo a aplicação é a principal solução para coletar informações necessárias para o entendimento do comportamento global do sistema. Mas, coletar de forma apropriada informações relevantes aos projetistas não é uma tarefa fácil porque não se tem uma visibilidade de toda solução analisando externamente o chip. Na realidade, o número de $I / O s$ é bem menor se comparado aos estados internos do sistema. A capacidade de observação e controle de cada chip é muito baixa. Então, a situação encontra-se no mesmo patamar de muitos anos atrás quando o conceito de projetos para testabilidade de circuitos integrados era emergente. Mas, aqui o objetivo é diferente, pois é necessário analisar o sistema não depois da fabricação, mas nos níveis funcional e de sistema durante o desenvolvimento da arquitetura e implementação do projeto. Um dos objetivos desta pesquisa é propor uma técnica eficiente para resolver estes problemas.

\subsection{Trabalhos relacionados}

\subsubsection{SignalTap II Embedded Logic Analyzer (ELA)}

O analisador lógico SignalTap II [6] é uma solução de depuração desenvolvida pela Altera que permite ao projetista examinar o comportamento dos sinais internos do hardware, sem a necessidade de adição de pinos extras de E/S no projeto de dispositivos programáveis.

Esta funcionalidade vem junto com o software Quartus II e não requer alteração nos 
arquivos do projeto para ser adicionado ao sistema. A ferramenta de depuração captura o comportamento dos sinais em tempo real e armazena os dados coletados nos blocos de memória internos do dispositivo, estes dados são transferidos e disponibilizados na forma de onda para o software Quartus II através do cabo de comunicação JTAG como o USB-Blaster.

O SignalTap II permite ao projetista amostrar até 1.024 sinais diferentes de cada dispositivo, podendo armazenar no máximo $128 \mathrm{~KB}$ de dados de cada sinal amostrado. Alem disso, é possível utilizar até 10 gatilhos (em inglês, triggers) que são configurados para definir o momento em que o analisador lógico iniciará a coleta de dados do sinal. A Figura 3.8 mostra o diagrama de blocos do SignalTap II de um projeto FPGA.

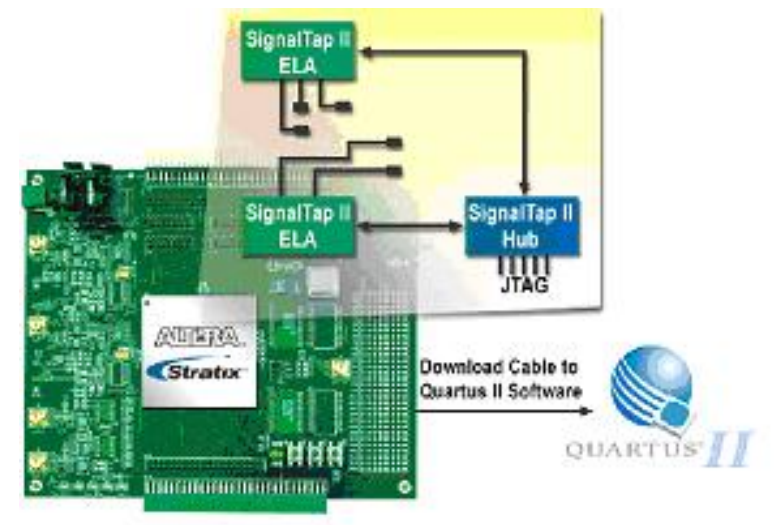

Figura 3.8: Diagrama de blocos do SignalTap II [6]

\subsubsection{Performance Counter Core}

O Performance Counter (PC) [4] como o SignalTap II [6] também é desenvolvido pela Altera e permite ao projetista analisar os programas de software de forma relativamente não intrusiva em tempo real, por meio da geração de um arquivo traçador de perfil (em inglês, profilers) . Com o PC é possível medir o tempo de execução de até 7 (sete) seções, para cada módulo (em inglês, core) do PC inserido no projeto. A configuração é feita pelo projetista através da inserção de instruções de inicio e fim para cada seção no código do programa.

Este módulo é disponibilizado pelo software SOPC Builder que faz parte do kit de desenvolvimento Nios da Altera, e é facilmente integrado a qualquer sistema gerado pelo 
SOPC Builder. Ele é projetado para ser utilizado em sistemas baseados no barramento Avalon, como o processador softcore Nios II.

O Performance Counter Core é composto por um conjunto de contadores definidos em duas categorias. Os contadores de tempo (64 bits) que registram o número de ciclos de clock gasto por cada seção demarcadas no código e os contadores de eventos (32 bits) que registram o número de vezes que a seção é executada.

\subsubsection{ARM Embedded Trace Macrocell (ETM) e Embedded Trace Buffer (ETB)}

O Embedded Trace Macrocell [10] prove a capacidade de depuração e trace para a série ARM de módulos de processadores. A macro célula pode ser configurada em software para capturar somente um conjunto de informação que são disponibilizadas através de uma porta de trace dedicada e uma memória temporária FIFO, permitindo que os dados coletados sejam lidos do chip para uma porta externa de análise sem afetar o desempenho do processador. Se os dados coletados exceder a capacidade de transmissão da porta de trace e da memória temporária, poderá ocorrer perda de dados.

O ETM possui várias funcionalidades como, comparadores de dados/endereços, comparadores de identificadores de contexto, contadores (16 bits), gatilhos e filtros configuráveis etc. Podendo, com isso, coletar o número de instruções executadas, o número de instruções de transferência da memória/registradores e o total de leitura/escrita a memória.

A funcionalidade do ETM pode ser aperfeiçoada com a adição de um Embedded Trace Buffer (ETB), que é uma área de memória onde as informações de trace são armazenadas ao invés de ser exportada imediatamente através da porta de trace do dispositivo [9], como mostra a figura 3.9. As informações armazenadas no ETB podem ser lidas uma vez que coleta tenha sido terminada. Isso pode ser feito através da porta JTAG do dispositivo. 


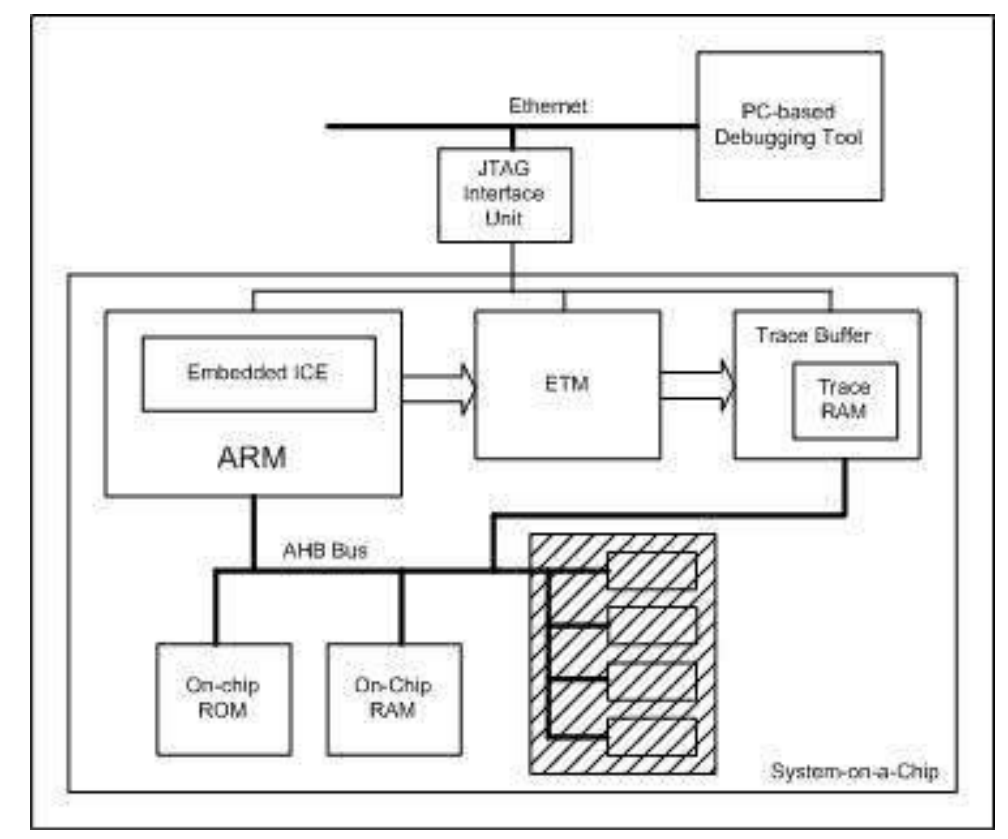

Figura 3.9: Diagrama de blocos de um projeto SoC utilizando ETM e ETB

\subsubsection{ChipScope Pro}

O ChipScope Pro [40] é uma ferramenta de verificação e depuração em tempo real para FPGAs desenvolvida pela Xilinx. Ela é composta por softcores (ILA, IBA, ATC2 and VIO) que são inseridos no nível de projeto (em inglês, design) ou no nível de descrição das interconexões entre os componentes do circuito (em inglês, netlist). O ChipScope Pro captura os dados dos sinais dentro do chip e os envia para uma ferramenta externa de análise através de cabos de comunicação como,o Platform USB Programming.

Esta ferramenta prove acesso a estrutura do barramento IBM CoreConnect que é utilizado pelos processadores IBM Powerpc 405 core e o Xilinx MicroBlaze softcore, este acesso é provido pelo módulo IBA que permite ao projetista visualizar as transações que ocorrem entre o processador e os periféricos. Podendo, com isso, analisar sinais do barramento, transações, detectar violações de protocolos e realizar a depuração de hardware e software.

\subsubsection{MAMon}

O projeto MAMon apresentado em [35] por Shobaki é uma tentativa de prover a implementação on-chip de um monitor de hardware baseado em eventos e uma ferramenta 
de depuração de softwares em SoCs com um ou mais processadores. O MAMon é composto por três partes(Figura 3.10): (i) A Unidade de Verificação (em inglês, Probe Unit) na qual se conecta a lógica interna do $S o C$, (ii) a Ferramenta de ambiente localizada num sistema computacional externo e (iii) o link de comunicação entre a Unidade de Verificação e a feramenta de ambiente, chamada de Host Interface.

Através da Unida de Verificação o MAMon tem acesso aos sinais do componente $S o C$ como, sinais do barramento (dados, controles, endereço), indicação de interrupção, dados de comunicação etc. Então, estes sinais são detectados, registrados (tempo de ocorrência) e armazenados nos pacotes de eventos que serão enviados a ferramenta de ambiente, para serem processados e analisados.

O MAMon é todo projetado em $V H D L$ e pode ser instanciado e conectado no nível de descrição do sistema ou no nível de transferência dos registradores (RTL). Ele utilizou a Arquitetura SARA (Scalable Architecture for Real-Time Applications) [27] como plataforma alvo para o desenvolvimento do sistema. Esta arquitetura prove uma estrutura para aplicações em tempo real e também uma arquitetura flexível que simplifica a escalabilidade de processadores.

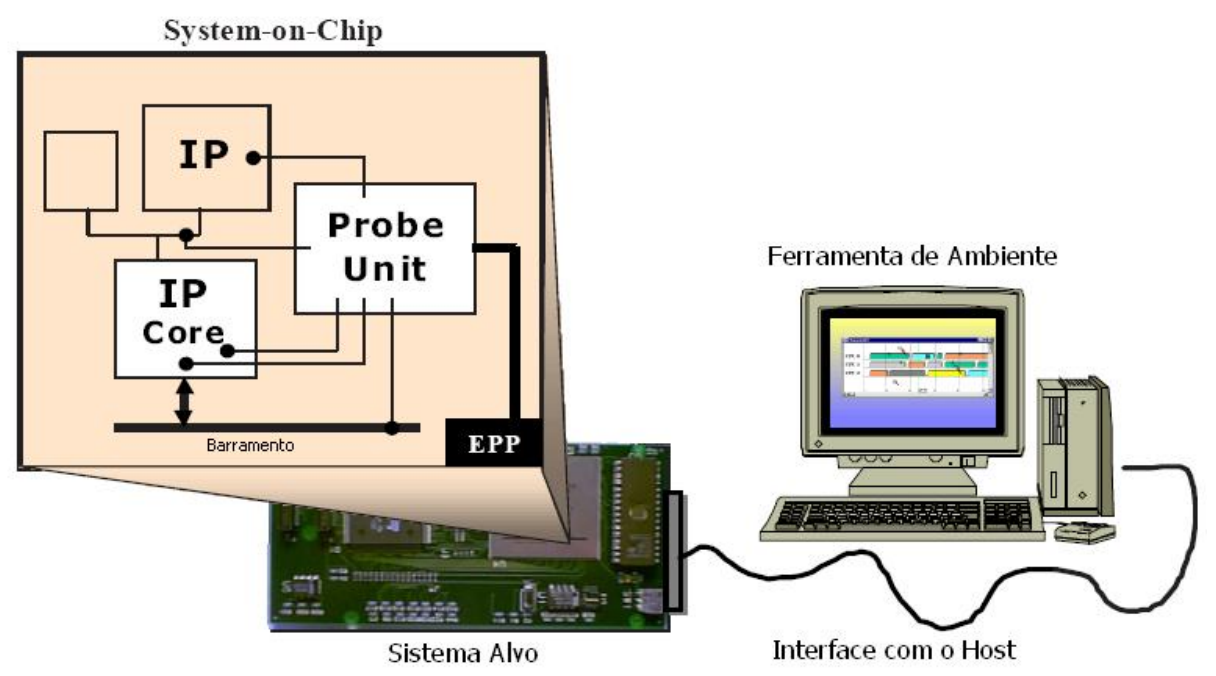

Figura 3.10: MAMon (Visão superficial) 


\subsubsection{Discussão}

O módulo de monitoramento proposto neste trabalho proporciona um monitoramento híbrido do mesmo estilo dos monitores avaliados acima, com algumas funcionalidades a mais se comparado ao Performance Counter e outras funcionalidades focadas em diferentes análises e resultados se comparado ao SignalTap. As outras ferramentas citadas são projetadas para um determinado tipo de tecnologia que não atendem as necessidades deste trabalho como, ChipScope Pro, ETM e o MAMon. Contudo, a ferramenta que mais se aproxima a este trabalho é o MAMon proposto por Mohammed El Shobaki, que implementa um sofisticado monitor on-chip para ser utilizado em projetos de SoCs e ASICs.

\subsection{Considerações Finais}

De importância relevante para a proposta deste trabalho, este capítulo abordou os principais assuntos relacionados ao monitoramento de sistemas computacionais. Primeiramente, introduzindo os problemas causados por alguns tipos de monitoramento (probe effect). Logo após foi mencionado a classificação do monitoramento entre síncrono e assíncrono por Chodrow et al. [17] e os níveis de abstração do monitoramento, como também as três formas que um monitor pode ser constituído: software, hardware ou híbrido, que são definições importantes para o entendimento entre os tipos de monitoramento. Por fim, foi mostrado algumas características do monitoramento orientado a eventos e alguns trabalhos relacionados a este projeto.

O capítulo a seguir apresenta alguns conceitos de computação reconfigurável e uma breve explicação sobre a tecnologia FPGA, as linguagens de descrição de hardware e os módulos de hardware (core). 


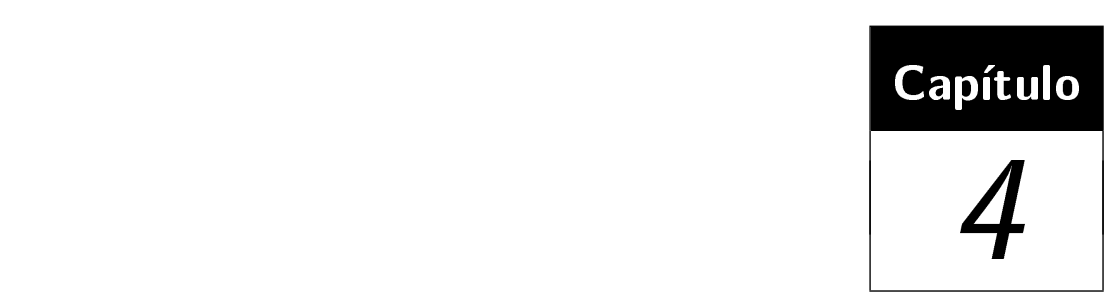

\section{Computação Reconfigurável}

\subsection{Considerações Iniciais}

"Computação reconfigurável representa uma nova idéia em filosofia de computação, na qual algum agente de hardware de propósito geral é configurado para realizar uma tarefa específica, mas pode ser reconfigurado sob demanda para realizar outras tarefas específicas" [1].

Muitas aplicações emergentes em telecomunicações, multimídia e sistemas embarcados necessitam que suas funcionalidades permaneçam flexíveis, mesmo depois de o sistema ter sido manufaturado [21]. Tal flexibilidade é fundamental, uma vez que requisitos dos usuários, características dos sistemas, padrões e protocolos podem mudar durante a vida do produto. Essa flexibilidade também pode prover novas abordagens de implementação voltadas para ganhos de desempenho, redução dos custos do sistema ou redução do consumo geral de energia.

A implementação de sistemas que demandam flexibilidade, alto desempenho, alta taxa de transferência de dados e eficiência no consumo de energia são possibilitadas por essas tecnologias. Isto inclui aplicações de televisão digital, comunicações sem fio reconfiguráveis, sistemas de computação de alto desempenho, processamento de imagens em tempo real e produtos para consumo atualizáveis remotamente, entre outros. 
Esta flexibilidade pode ser conseguida através de atualizações de software, mas desta forma a mudança é limitada somente à parte programável dos sistemas. Desenvolvimentos recentes na tecnologia de FPGAs têm introduzido suporte para modificações rápidas do hardware do sistema. Essas modificações referem-se a mudanças na configuração dos circuitos digitais.

\subsection{Tecnologia}

Os sistemas computacionais podem ser construídos utilizando-se de diferentes tecnologias (Figura 4.1), a escolha da tecnologia adequada deve ser realizada com base no tipo de projeto que se pretende executar.

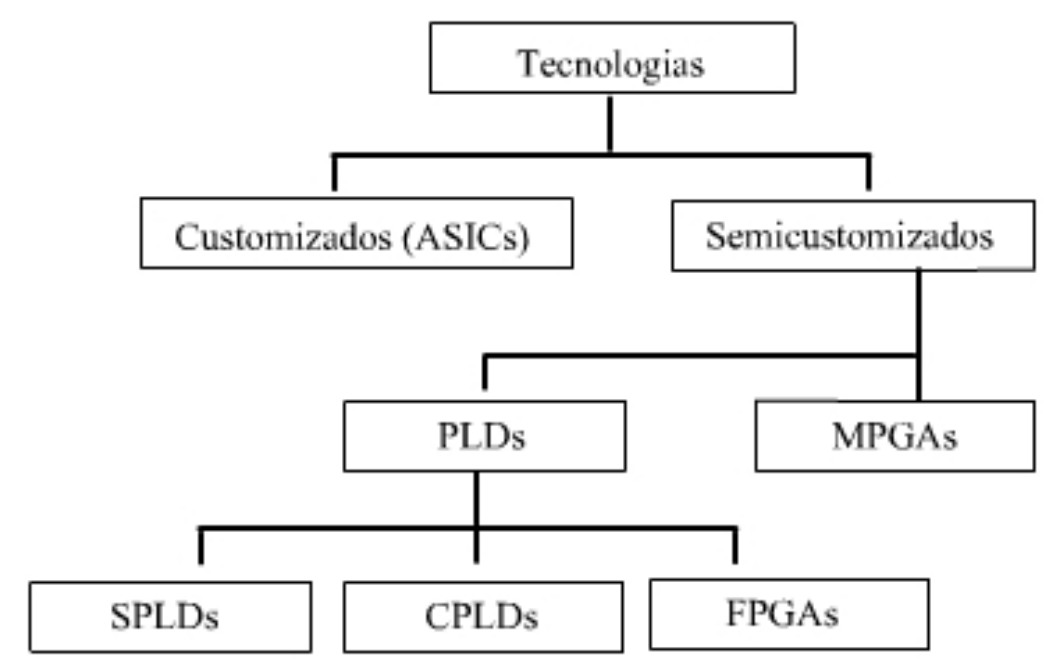

Figura 4.1: Tecnologias para projetos de sistemas digitais

Customizados (ASICs): São aqueles que necessitam de um processo de fabricação especial, que requer máscaras específicas para cada projeto. Em aplicações que requerem um grande volume de produção, os altos custos do projeto e dos testes são amortizados. O ASIC é projetado para executar operações com alto grau de especificidade. Portanto, são extremamente rápidos e eficientes para a operação para a qual foram implementados. No entanto, uma vez terminado o $A S I C$ não pode ser modificado.

Semicustomizados: Os projetos semicustomizados utilizam uma mistura entre a criação de projetos e a utilização de componentes pré-projetados. Com isso, ele provê uma forma mais rápida e barata de se projetar e produzir um sistema computacional digital. 
- MPGA (Mask-Programmable Gate Arrays): A MPGA consiste de um array de elementos que podem ser interconectados de acordo com as especificações do usuário. Nesse tipo de implementação, o processo de fabricação é agilizado pelo uso de máscaras genéricas de módulos pré-projetados, mas ainda necessita de máscaras específicas para a interconexão dos módulos. O projeto é normalmente facilitado por uma biblioteca de células, proporcionando um tempo de desenvolvimento mais curto e custos mais baixos em relação aos CIs customizados;

- PLD(Programmable Logic Device): Essa tecnologia possui como principal característica a capacidade de programação (configuração) pelo usuário, eliminando o processo de fabricação e facilitando assim as mudanças de projetos. Em comparação com outras tecnologias, os PLDs apresentam um ciclo de projeto muito curto e custos muito baixos, podendo ser mapeado instantaneamente através de ferramentas $C A D$, que também facilita as alterações no projeto.

O conceito de computação reconfigurável já existe há algum tempo. Até processadores de propósitos gerais utilizam alguns destes conceitos básicos, por exemplo, reutilizando componentes computacionais para computações independentes e utilizando multiplexadores para controlar o roteamento entre estes componentes. Entretanto, o termo computação reconfigurável, como ele é utilizado nas atuais pesquisas, refere-se aos sistemas que incorporam algum tipo de hardware programável, adaptando o seu uso através de inúmeros pontos físicos de controle. Estes pontos de controle podem ser alterados periodicamente para executar diferentes aplicações utilizando o mesmo hardware.

De forma simplificada, pode-se definir a computação reconfigurável como sendo a capacidade que um hardware possui de ser programado e reprogramado após sua fabricação. Cabe ressaltar que essa programação ou reprogramação pode ser feita de maneira dinâmica (em tempo de execução) ou de maneira estática (com o sistema desligado).

A computação reconfigurável introduz um conceito de hardware virtual que antes não existia. Neste conceito só é necessário estar ativo no sistema o hardware dedicado necessário para executar as tarefas naquele instante. Desta forma, sempre que uma parte do hardware virtual não é mais necessária ela é retirada do projeto e sempre que uma nova 
funcionalidade é requerida ela é adicionada ao projeto e o chip é reconfigurado (análogo ao conceito de memória virtual). Essa característica de possuir hardware virtual faz com que a computação reconfigurável se adapte as reais necessidades da aplicação (software). Com isso, obtém-se a flexibilidade do software com o desempenho do hardware. Além disso, preenche-se a lacuna que existia anteriormente entre o software (flexível e lento) e o hardware (inflexível e rápido) [18].

Os recentes avanços em computação reconfigurável são em sua maioria derivados de tecnologias desenvolvidas para FPGAs durante a década de 80. As FPGAs foram originalmente criadas para servir como um dispositivo híbrido entre PALs (pequenos PLDs) e $M P G A s$. A FPGA é em sua totalidade programável eletricamente, significando que o custo do projeto físico é amortizado sobre as várias aplicações implementadas no circuito e o hardware pode ser adequado (reconfigurado) a aplicação rapidamente.

\subsection{FPGA (Field-Programmable Gate Arrays)}

A tecnologia FPGA tem evoluído em direção aos mais altos índices de desempenho, elevados níveis de densidade e menores custos de fabricação. Esse fato tende a se acentuar nos próximos anos, tornando cada vez menor a distância entre as FPGAs e os chips diretamente implementados no silício $(A S I C s)$. Isto tem possibilitado o emprego desta tecnologia na implementação de arquiteturas cada vez mais complexas. Além desses avanços, os fabricantes de FPGA têm introduzido, no decorrer dos anos, cada vez mais recursos de reconfigurabilidade em tais dispositivos.

Um dispositivo FPGA típico possui uma arquitetura interna (Figura 4.2) composta de uma matriz de blocos lógicos configuráveis (CLB - Configurable Logic Block) cercados por uma rede de interconexão programável, formada de blocos de interconexão. Circundando todo o circuito, existem os blocos de entrada e saída (IOB - Input Output Block), que também são programáveis, e que servem como interface entre o mundo exterior e a lógica interna do dispositivo. A arquitetura de um $C L B$ varia de família para família e de fabricante para fabricante, mas basicamente são compostos de pontos de entrada, que se conectam a blocos que implementam funções puramente combinacionais ( LUT - Look- 
up Table), multiplexadores que direcionam o fluxo dos sinais internamente ao CLB; e de registradores (tipicamente flip-flops) que estão ligados às saídas e também podem realimentar as entradas dos geradores de funções combinacionais. Todos os elementos são configuráveis e propiciam uma grande flexibilidade para implementação de funções. A rede de interconexão programável é composta por diferentes tipos de segmentos de conexão, capazes de interligar a maioria das entradas e saídas dos CLBs entre si e aos $I O B s$. Isso tudo permite que circuitos complexos, máquinas de estado, e algoritmos sejam implementados em FPGAs. Como podemos observar existem recursos disponíveis para a implementação de paralelismo na arquitetura interna dos dispositivos reconfiguráveis.

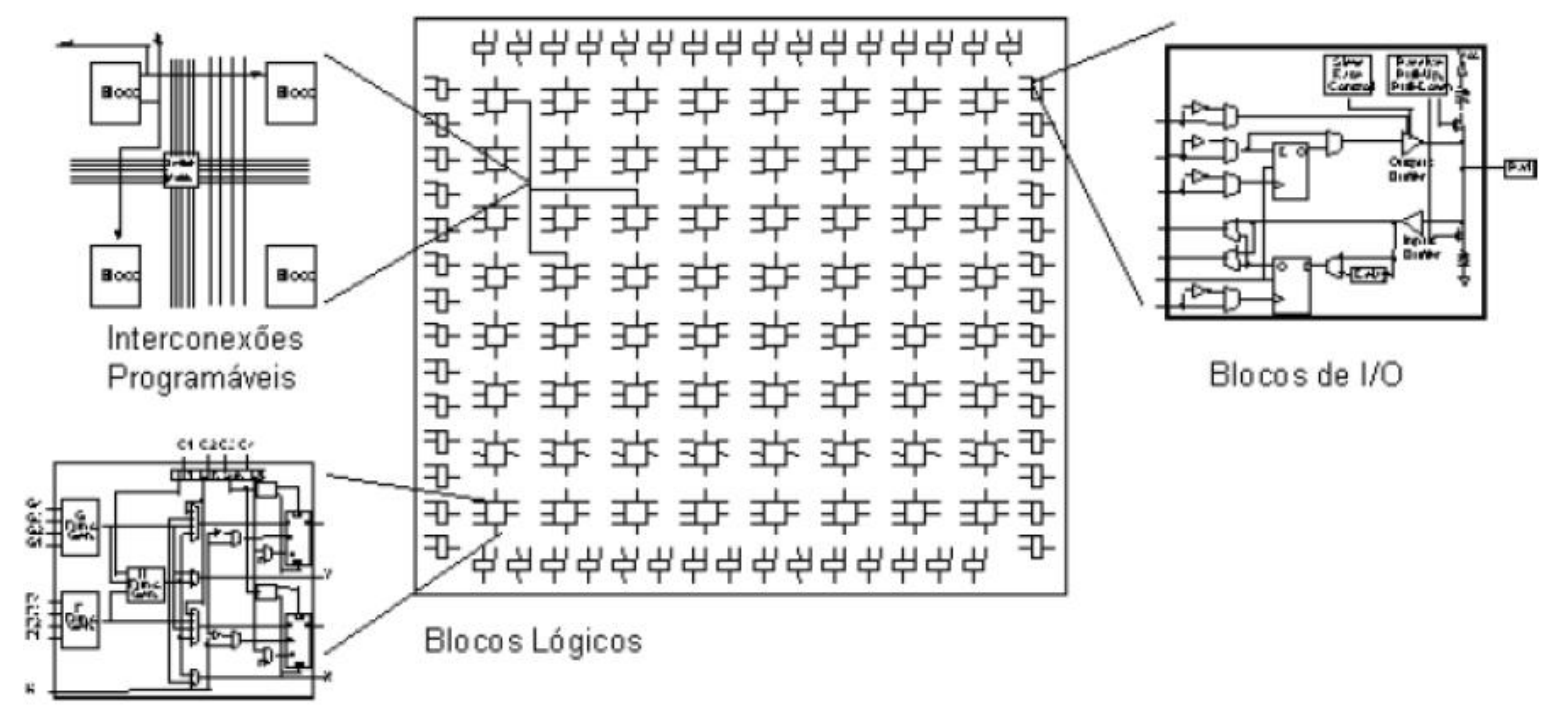

Figura 4.2: Arquitetura interna de um FPGA

Cada elemento reconfigurável pode variar de uma simples $L U T$ de 3 bits até uma complexa unidade lógica aritmética (ALU - Aritmetic Logic Unit) de 4 bits ou mais. Esta diferença em termos (nível) de simplicidade/complexidade é chamada granularidade do dispositivo reconfigurável. Dispositivos mais simples (de grão fino) são indicados para aplicações de manipulação no nível dos bits, enquanto os mais complexos (dispositivos de grão grosso) são indicados para aplicações que envolvem computações mais complexas como manipulações de imagens e outras típicas aplicações de caminho de dados, com manipulação de dados com largura (codificação) de vários bits.

Os FPGAs foram introduzidos pela empresa Xilinx Inc. no ano de 1985 [14] através 
da família XC2000 com no máximo $1.8 \mathrm{~K}$ LEs. Com o avanço tecnológico na produção de dispositivos programáveis foi possível aumentar a densidade destes dispositivos de forma espantosa em poucos anos, podendo citar a família Stratix II [7], o último lançamento da Altera, com até 180K LEs, permitindo a construção de sistemas extremamente complexos em um único chip, os chamados System-on-a-Programmable-Chip (SoPC).

\subsubsection{Família Stratix II}

A família Stratix II [7] é baseada em uma arquitetura de 90-nm, 1.2-V, tecnologia de programação $S R A M$ e novas estruturas lógicas que maximizam seu desempenho e possibilita aproximar-se de 180.000 LEs de densidade.

A Stratix II oferece até 9Mbits de memória on-chip (tecnologia TriMatrix da Altera) e tem até $96 D S P$ blocos com algumas configurações de multiplicadores (9-bit x 9-bit, 18-bit x 18-bit e 36-bit x 36-bit) para eficientes implementações de filtros de alto desempenho e outras funções $D S P$. Várias interfaces de alta-velocidade de memórias externas são suportadas, incluindo DDR, SDRAM, DDR2, RLDRAM II, QDRII SRAM e SDR SDRAM [7].

As Memórias TriMatrix fornecem três diferentes tamanhos. O software Quartus II automaticamente particiona a memória definida pelo usuário nos blocos de memória embutidos usando as mais eficientes combinações. O projetista pode também determinar manualmente a memória para um bloco de tamanho específico ou misturar o tamanho dos blocos.

A Stratix II é primeira a codificar um arquivo de bitstream usando o algoritmo AES para proteger o projeto. Esta característica de segurança introduzida pela Altera pode reduzir de forma significante a ameaça de engenharia reversa e deixar esta família mais atraente a grupo de desenvolvimento que necessitam de segurança em seus projetos [7].

Uma das principais mudanças encontrada na Stratix II é a troca da tradicional célula lógicaLUT de 4 entradas. A $L U T$ de 4 entradas foi a estrutura básica de um FPGA durante anos. Várias análises, experimentos e artigos acadêmicos têm mostrado que, em média, uma estrutura de 4 entradas é o tamanho de uma célula básica mais eficiente para 
implementações genéricas dos mais variados tipos de projetos lógicos.

A Altera resolveu quebrar com esta tradição; eles desenvolveram uma nova célula de largura variável chamada de ALM (Adaptive Logic Module). Um ALM parece como uma LUT de 7 entradas (ou 8 dependendo de como é contado) que pode ser flexível alterando o número de configurações (Figura 4.3) como por exemplo 5 entradas +3 entradas ou 4 entradas +4 entradas. Com a divisão das entradas, muitas configurações podem ser criadas. Esta arquitetura permite o melhor dos dois mundos: a eficiência de um elemento lógico compacato com o desempenho de um amplo. Com uma LUT de 4 entradas, por exemplo, uma função de 5 entradas pode requerer 2 níveis de lógica e até 3 LUTs para implementar. Com o $A L M$, uma função de 5 entradas pode ser implementada em um único $A L M$ com um nível de lógica e ainda deixar 3 entradas para uma função opcional. Isso significa que poucas portas são necessárias para implementar a mesma lógica e muitas vezes com menos níveis de lógica entre os registradores. O efeito disto pode ser menos área ocupada no silício, alto desempenho e poucos recursos de roteamento consumidos.

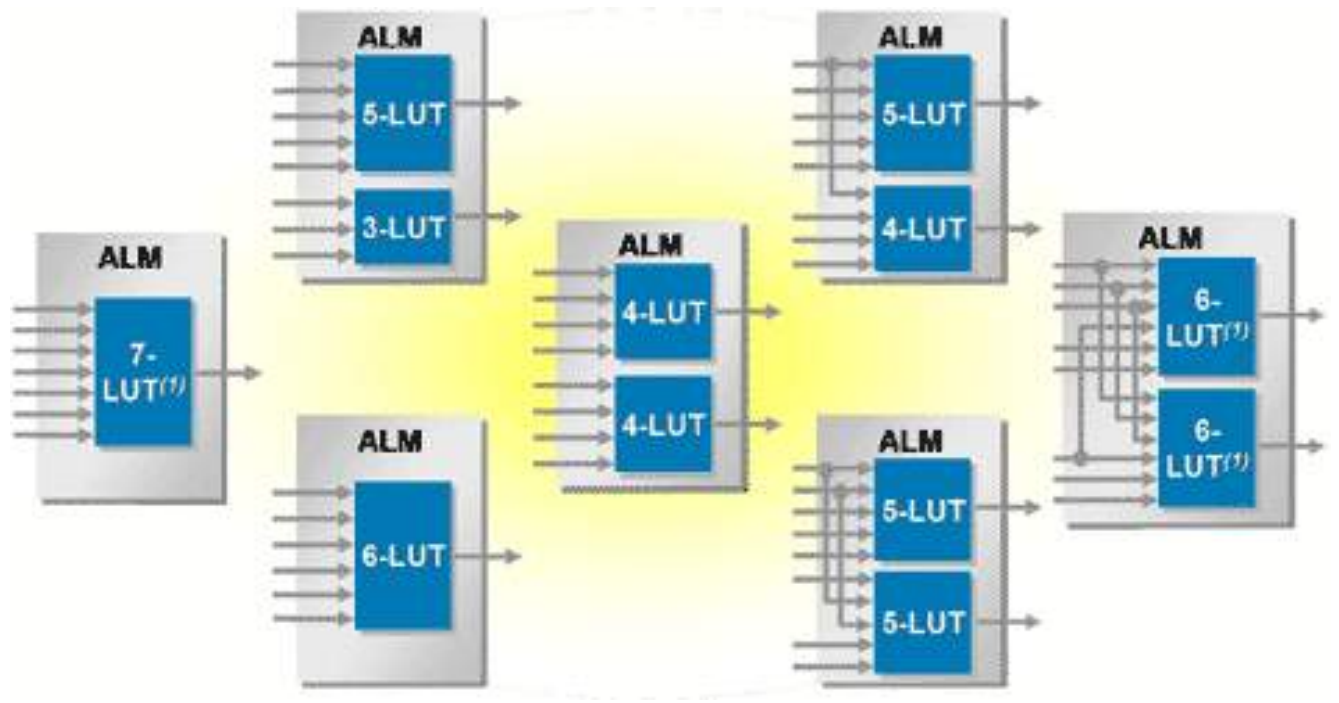

Figura 4.3: Nova arquitetura $A L M$ da Altera [32]

A Altera analisou cerca de 100 projetos e isso traduziu em uma melhora arquitetural de 1.25X na utilização lógica se comparada com a arquitetura anterior Stratix. Muitas vezes um aprimoramento na arquitetura pode significar uma melhora de $80 \%$ dos projetos, nenhum efeito em $10 \%$ e sérias degradações em outros 10\%. No caso da Stratix II ALM, as mudanças pareceram ser bem mais positivas. Mais de $95 \%$ dos testes realizados pela 
Altera mostrou que houve uma eficiente melhora com esta nova arquitetura, algumas com mais de $200 \%$ de melhora e nenhuma com significante degradação [32]. Na Figura 4.4 demonstra a relativa eficiência da arquitetura $A L M$ (StratixII) versus a $L U T$ de 4 entradas (Stratix).

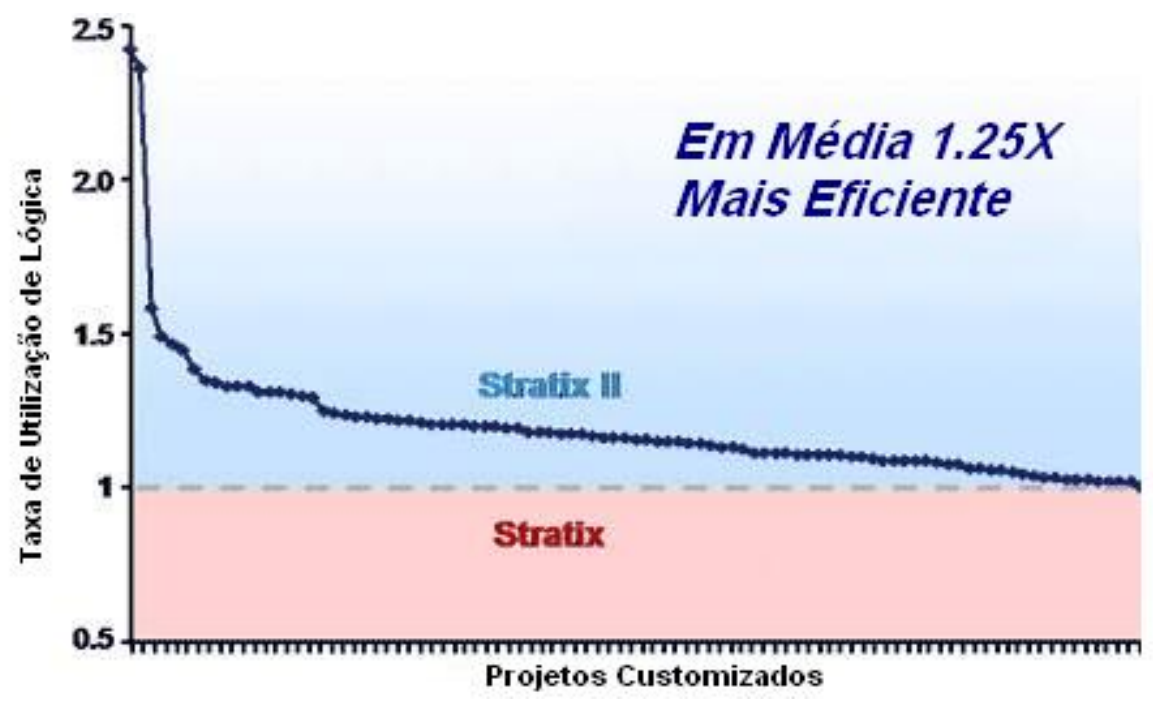

Figura 4.4: Testes da Altera (ALM x. LUTs de 4 entradas) [32]

Esta família contém uma arquitetura baseada em linhas e colunas de interconexão de comprimento e velocidade variada para prover a ligação dos sinais entre os $L A B s$ (logic array blocks), cada $L A B$ consiste de oito $A L M s$ que foram projetados para prover eficientes implementações de funções lógicas.

A Figura 4.5 mostra o diagrama de blocos dos dispositivos da família Stratix II. Elementos de entrada e saída (IOEs), localizados nas extremidades das linhas e colunas de $L A B s$, alimentam cada pino de E/S do dispositivo. Cada elemento possui um buffer bidirecional de E/S e seis registradores para registrar sinais de entrada, saída e saídahabilitada. Os pinos do FPGA suportam diversos padrões de E/S e quando utilizados com clock dedicado podem operar com as memórias externas.

\subsection{Linguagem de Descrição de Hardware}

As linguagens de descrição de hardware (em inglês, HDLs - Hardware Description Languages) são atualmente os métodos mais comuns para projetos utilizando FPGAs. 


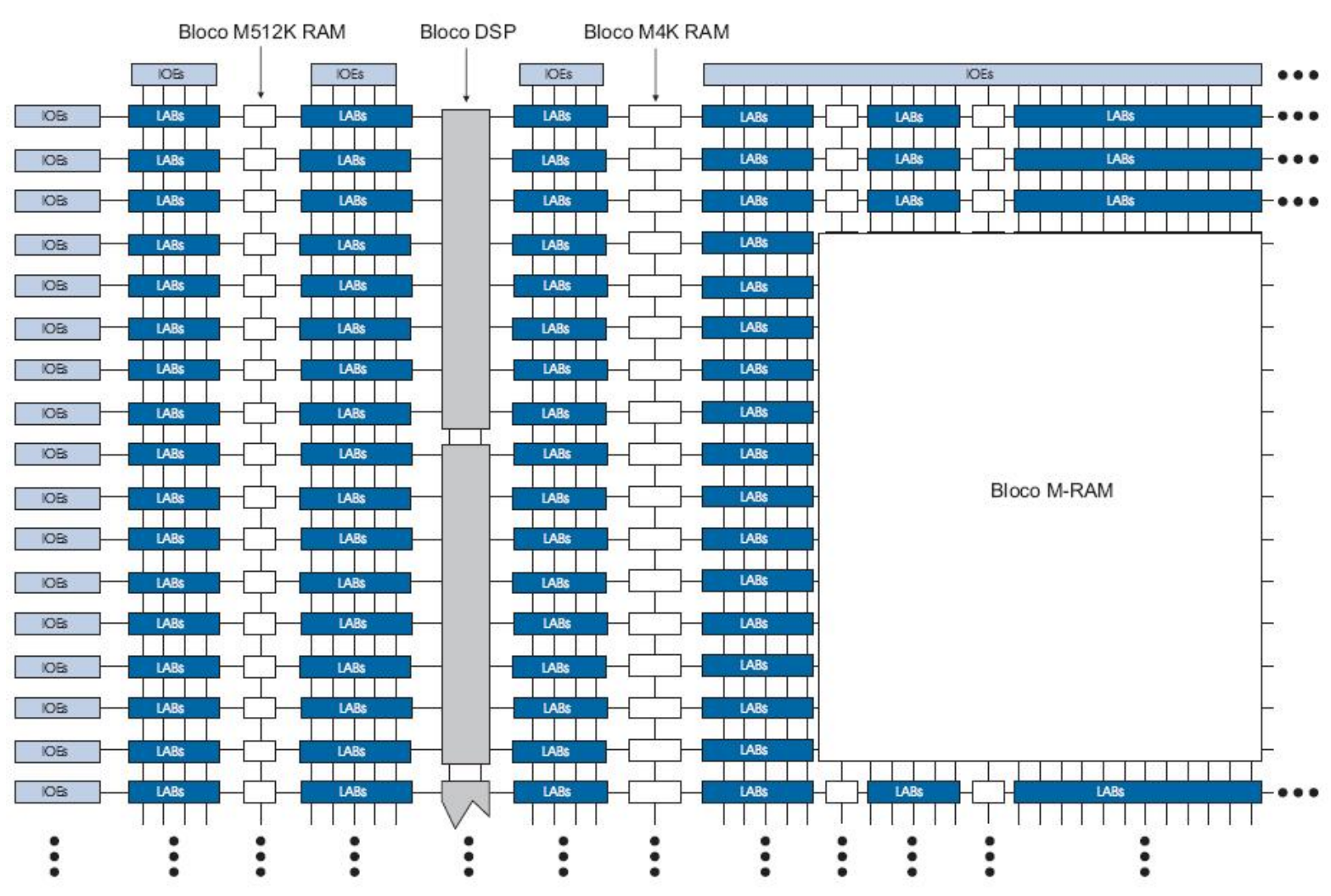

Figura 4.5: Diagrama de blocos dos FPGAs da família Stratix II [7]

Linguagens como VHDL [24] e Verilog [23] são comumente utilizadas na construção de projetos de hardware. Linguagens de alto nível como C são inerentemente seqüenciais. Elas definem o comportamento da aplicação como uma serie de instruções. Hardware, por outro lado, é inerentemente paralelo e é definido normalmente em termos de portas lógicas conectadas entre si através de um meio físico. Este tipo de característica é encontrada nas $H D L s$, em outras palavras sinais e módulos. Sinais são os equivalentes das variáveis nas linguagens de alto nível. Ao invés de representar uma posição na memória, como as linguagens de alto nível, nas HDLs elas representam conexões.

Módulos são blocos lógicos com uma determinada interface. A interface representa o caminho para os sinais de entrada e saída dos blocos lógicos. Um tipo especial de sinal é o clock. Clock é o elemento central nos projetos de sistemas de hardware. Por exemplo, HDLs incluem características capazes de expressar funcionalmente um clock sincronizado. Uma característica adicional as HDLs é a capacidade de incluir informações sobre tempo nos projetos permitindo uma maior precisão na simulação. Por exemplo, adicionando valores reais para os possíveis atrasos nos sinais provendo um comportamento 
mais próximo da realidade para o hardware simulado. Enquanto que as HDLs eram inicialmente utilizadas nos projetos como linguagem de simulação, nos dias de hoje elas vêem melhorando a capacidade de síntese lógica e sendo utilizadas com sucesso como uma linguagem de projeto.

\subsection{Módulo de Hardware (Core)}

A complexidade atual dos circuitos digitais induz os projetistas de hardware a utilizarem módulos pré-projetados, denominados cores [13]. Um core é um módulo de hardware complexo, digital ou analógico, podendo ser descrito em diferentes níveis de abstração e podem ser utilizados na concepção de sistemas maiores e mais complexos conhecidos como $S o C$ [1]. Como exemplos de cores pode-se citar: processadores, memórias, controladores, barramentos, etc.

Quanto à sua disponibilização, pode-se classificar um projeto de core como sendo licenciável ou proprietário. Um core licenciável é aquele em que o proprietário licencia um projeto e um conjunto de ferramentas conferindo a tarefa de projeto do sistema e sua fabricação ao usuário. Um core proprietário é aquele em que a preocupação principal do proprietário é proteger suas propriedades intelectuais, resultando em baixo risco de propriedade intelectual $(I P)$, já que estes disponibilizam apenas a interface externa ao usuário.

Segundo Zorian e Gupta em [41] os cores podem ser classificados de três formas:

- Hard cores: são otimizados para uma tecnologia específica e não podem ser modificados pelo projetista. Estes cores possuem um layout e planta baixa (em inglês, floorplanning) prédefinidos. Possuem como maior vantagem a garantia dos tempos de propagação do circuito (timing). Sua desvantagem é a de não permitir qualquer tipo de modificação ou personalização.

- Firm cores: netlist (lista de conexões) gerado para a tecnologia empregada, que muda de fabricante para fabricante. Este tipo de core pode ser parcialmente parametrizado pelo projetista, permitindo que sua arquitetura seja adaptada à necessi- 
dade do projeto. Entretanto, como o netlist é específico para uma dada tecnologia, existe a dificuldade do uso de componentes fornecidos por fabricantes diferentes.

- Soft cores: descritos em linguagens de descrição de hardware (como VHDL [24] ou Verilog [23]), oferecendo flexibilidade e independência de tecnologia. O core pode ser modificado e empregado com tecnologias de diferentes fabricantes. Contudo, os soft cores apresentam como desvantagens: (i) a não garantia de se atingir os critérios temporais do circuito, uma vez que este ainda não foi sintetizado [34]; (ii) a baixa proteção à propriedade intelectual, uma vez que o core é código aberto.

\subsection{Considerações Finais}

Neste capítulo foram apresentados alguns conceitos de computação reconfigurável e uma breve explicação sobre a tecnologia $F P G A$, que será a arquitetura utilizada para a implementação do projeto. Este capítulo também abordou as linguagens de descrição de hardware e sua importância atual para os projetos de hardware e os módulos de hardware (core), que estão sendo muito utilizados pelos projetistas para reduzir o tempo de desenvolvimento dos projetos.

No próximo capítulo serão apresentados os recursos de hardware e software, destacando algumas ferramentas EDA, essenciais para o desenvolvimento deste trabalho. 


\section{Capítulo \\ 5 \\ Plataforma de Desenvolvimento}

\subsection{Considerações Iniciais}

Este capítulo descreve os recursos de hardware e software que são utilizados no desenvolvimento deste trabalho e a maneira como estes recursos são utilizados. O hardware apresentado é composto pelo Kit de desenvolvimento Nios (edição Stratix); o software apresentado é composto por um conjunto de ferramentas de desenvolvimento de sistemas em plataformas programáveis, que são integradas pela ferramenta EDA (Electronic Design Automation) Quartus II. Este capítulo aborda também as estruturas do processador softcore Nios II e do barramento Avalon.

\subsection{Placa de Desenvolvimento Nios (edição Stratix)}

A implementação e validação do sistema proposto em FPGA (Field Programmable Gate Array), é realizada utilizando-se o a placa de desenvolvimento do kit Nios (edição Stratix), que oferece uma plataforma de desenvolvimento para SoC (Systems-on-Chip) baseado em dispositivos da Altera. A placa possui um FPGA EP1S10F780C6ES, da Altera, que contém 10.570 elementos lógicos, além de 920Kbits de memória on-chip. Esta placa de desenvolvimento possui as seguintes características (Figura 5.1): 
- 8 Mbytes de memória flash;

- 16 Mbytes de memória SDRAM (RAM Dinâmica Síncrona);

- 1 Mbyte de memória SRAM (RAM Estática Assíncrona);

- Lógica para configuração da Stratix a partir da memória Flash;

- Conector para cartão de memória FlashTM;

- Conector Mictor para executar debug de hardware and software;

- Duas portas DB9 de comunicação RS-232;

- Dispositivo ethernet MAC/PHY;

- 4 botões do tipo push-button, 8 LEDs e dois display de 7-segmentos para uso geral;

- Conector e cabo JTAG para download de datastream (dados de configuração do FPGA);

- Circuito de Power-on reset (circuito que é acionado toda vez que o sistema for energizado);

\subsection{Processador Nios II}

O Nios II [28] é um processador softcore configurável e de propósito geral desenvolvido pela Altera. Se opondo aos microcontroladores disponíveis atualmente no mercado, que são normalmente hardcore. Este contexto "configurável"significa que o processador possui características que podem ser adicionadas ou removidas, se adequando aos objetivos de desempenho ou de custo.

O processador Nios II possui três configurações básicas: (i) configuração econômica, que utiliza entre 600-700 ELs (elementos lógicos), (ii) configuração padrão, que utiliza entre 1200-1400 ELs e permite a uso de cache de instrução, predição de brachs e operações aritméticas em hardware, (iii) configuração completa, que utiliza entre 1400-1800 ELs e 


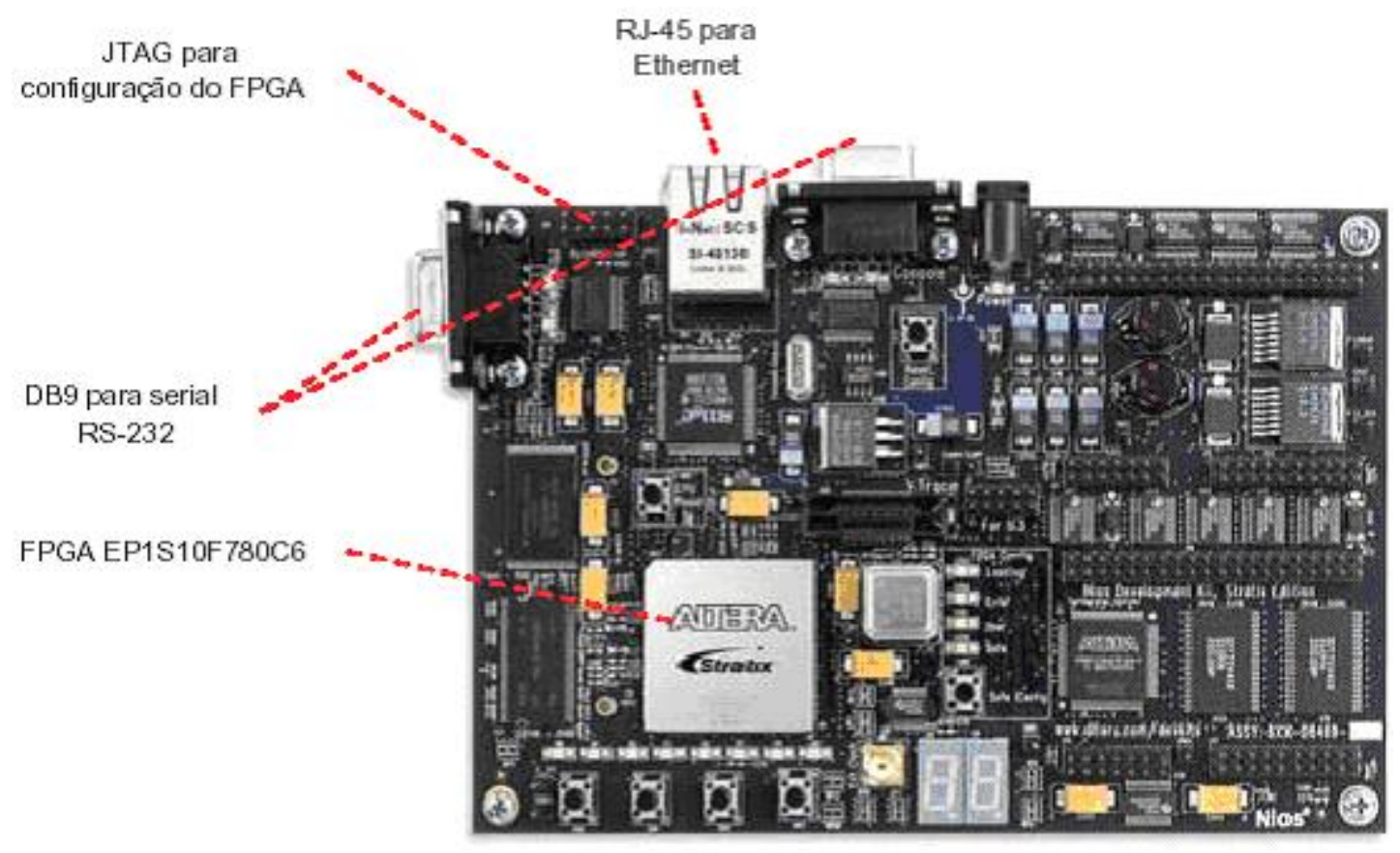

Figura 5.1: Placa de desenvolvimento Nios (edição Stratix)

também permite o uso de cache de dados e predição dinâmica de brachs. As principais características da arquitetura do Nios II estão ilustradas na Figura 5.2.

- Controle de interrupção: O processador possui 32 níveis de solicitação de interrupção, provendo uma única entrada para cada fonte de interrupção. A prioridade da IRQ é determinada pelo software, no qual também é possível habilitar e desabilitar qualquer fonte de interrupção individualmente.

- Controle de exceção: Todas as exceções, incluindo interrupções de hardware, induzem o processador a transferir a exceção para um único endereço (endereço de exceção). Este endereço é especificado em tempo de projeto.

- Unidade lógica aritmética: A ULA suporta adição, subtração, multiplicação e divisão de operandos com ou sem sinal.

- Interface para instruções customizadas: A ULA se conecta diretamente a lógica da instrução customizada, permitindo o desenvolvimento de instruções em hardware que são acessadas e utilizadas como instruções nativas.

- Cache de Dados: A cache de dados pode variar de 512 a 64kbytes ou desabilitá-la. 
- Cache de Instrução: A cache de instrução pode variar de 512 a 64 kbytes ou desabilitála.

- Completo conjunto de instruções de 32-bit;

- 32 registradores de propósitos gerais;

- Suporte para memória on-chip e off-chip;

- Freqüência máxima de operação $250 \mathrm{MHz}$.

- Barramento de dados e instrução de 32-bit;

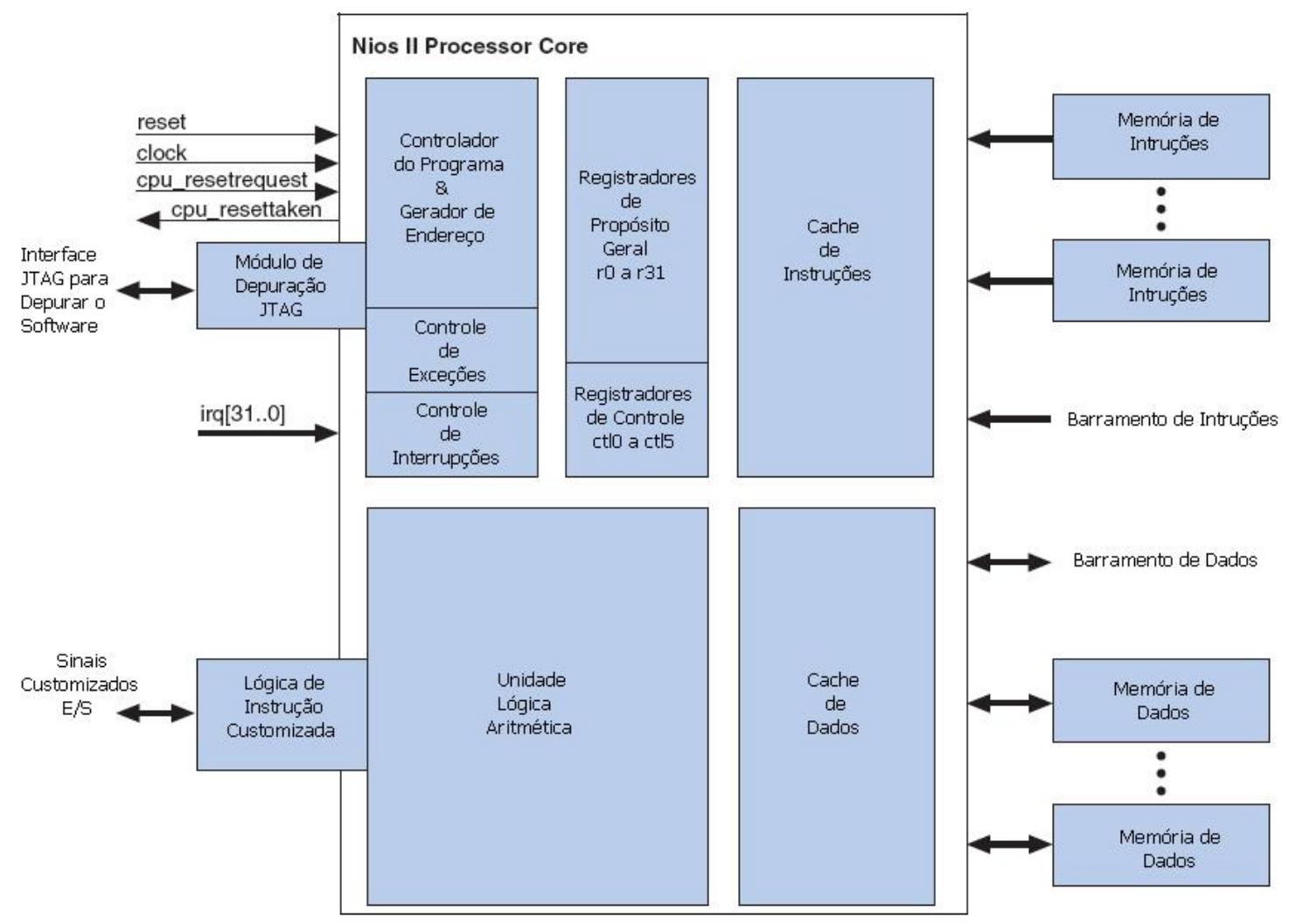

Figura 5.2: Diagrama de blocos do processador Nios II

A arquitetura do Nios II possui um módulo de depuração que se conecta ao circuito elétrico da interface de teste JTAG da FPGA Altera. Possibilitando com isso, que ferramentas de depuração externas tenham acesso ao processador via interface padrão JTAG. No lado do processador, o módulo de depuração se conecta a sinais internos do Nios II, 
permitindo o controle sobre o processador sem a necessidade de interferência em software para isso.

O módulo de depuração JTAG consegue o controle do processador através da introdução de um sinal de interrupção em hardware (hardware breakpoint), ou escrevendo uma instrução de interrupção dentro da memória do programa que será executado (software breakpoint).

Este módulo de depuração possui 4 níveis de configuração que consomem diferentes quantidades de recursos on-chip. Na Tabela 5.1 é possível verificar uma lista detalhada das características de cada um desses níveis.

Tabela 5.1: Níveis do Módulo de Depuração JTAG

\begin{tabular}{|l|c|c|c|c|}
\hline Função & Nível 1 & Nível 2 & Nível 3 & Nível 4 (1) \\
\hline \hline Lógica Utilizada & $300-400$ LEs & $800-900$ LEs & $2.400-2.700$ LEs & $3.100-3.700$ LEs \\
\hline $\begin{array}{l}\text { Memória On-Chip } \\
\text { Utilizada }\end{array}$ & 2 M4Ks & 4 M4Ks & 2 M4Ks & 4 M4Ks \\
\hline $\begin{array}{l}\text { Pinos de E/S Externos } \\
\text { (2) }\end{array}$ & 0 & 0 & 0 & 0 \\
\hline Conexão JTAG & Sim & Sim & Sim & Sim \\
\hline Donwload de Software & Sim & Sim & Sim & Sim \\
\hline Software Breakpoints & Indefinido & Indefinido & Indefinido & Indefinido \\
\hline Hardware Breakpoints & Nenhum & 2 & 2 & 4 \\
\hline Triggers de Dados & Nenhum & 2 & 2 & 4 \\
\hline Trace On-Chip & Nenhum & Nenhum & $\begin{array}{c}\text { Acima de } 64 \mathrm{~K} \\
\text { frames }\end{array}$ & $\begin{array}{c}\text { Acima de 64K } \\
\text { frames }\end{array}$ \\
\hline Trace Off-Chip (4) & Nenhum & Nenhum & Nenhum & $\begin{array}{c}\text { Acima de 128K } \\
\text { frames }\end{array}$ \\
\hline
\end{tabular}

Notas da Tabela 5.1:

(1) Nível 4 requer a aquisição de uma atualização no software da empresa FS2 (First Silicon Solutions).

(2) Não inclui os pinos dedicados a interface JTAG.

(3) Requer uma licença adicional da empresa FS2 para utilizar mais de 16 quadros (em inglês, frames).

(4) Trace off-chip requer a aquisição de um hardware adicional da empresa FS2. 


\subsection{Barramento Avalon}

O barramento Avalon é um barramento com arquitetura simples projetado para conectar processadores e periféricos em sistema desenvolvido com lógica programável. Este barramento possui uma interface que especifica a conexão entre as portas mestre e escravo dos componentes, como também especifica o tempo necessário para a comunicação com estes componentes.

Este barramento é a estrutura central (em inglês, backbone) dos sistemas construídos no SOPC Builder, sendo o principal meio de comunicação entre os componentes periféricos do projeto. O barramento Avalon é um conjunto de sinais de controle, dados, endereçamento e lógica de arbitragem que interligam os componentes para formar o sistema.

O barramento Avalon prove vários serviços aos periféricos conectados ao barramento.

- Multiplexação de endereço: O barramento possui multiplexadores que transferem os dados que partem de um periférico escravo até o periférico mestre de destino.

- Decodificação de endereço: A lógica de decodificação de endereços produz um sinal de chip-select para cada periférico. Isto simplifica o projeto do periférico, porque não é necessário que ele realize nenhum tipo de decodificação na linha de endereço.

- Geração de estado de espera (em inglês, Wait-State): A geração deste tipo de sinal faz com que a transferência entre componentes do sistema se estenda por um ou mais ciclos do barramento. Estados de espera podem ser gerados para atrasar um periférico mestre em casos que o periférico escravo não possa responder em tempo hábil.

- Redimensionamento dinâmico do barramento: O redimensionamento dinâmico do barramento esconde detalhes da interface de periféricos com comprimento de sinais diferentes entre si. Por exemplo, em caso de um periférico mestre 32-bit realizar uma transferência de leitura partindo de uma memória de 16-bit, o redimensionamento dinâmico executa automaticamente duas leituras na memória e entrega 32 bits de dados ao periférico mestre. Desta forma, se reduz à quantidade de lógica e/ou 
complexidade do software no periférico mestre, porque ele não precisa se preocupar com as características de cada periférico escravo.

- Interrupção Prioritária: Quando um ou mais periféricos escravos geram interrupções. Neste caso, o barramento Avalon passa as interrupções de forma organizada em uma lista de prioridades para os devidos periféricos mestres.

- Transferência com latência: O barramento Avalon possui uma lógica interna que permite a transferência com latência entre interfaces mestre-escravo.

- Transferência (leitura e escrita) em fluxo: O barramento Avalon possui uma lógica interna que permite a transferência em fluxo (em inglês, streaming) entre interfaces mestres-escravos.

Os periféricos construídos para o barramento Avalon são classificados como mestre ou escravo. Um periférico mestre é um periférico que pode iniciar uma comunicação através do barramento. Este tipo de periférico tem no mínimo uma interface mestre, no qual se conecta ao módulo do barramento Avalon. Este periférico pode possuir interfaces escravas, que permitem receber solicitações, através do barramento, iniciadas por outros periféricos mestres. Desta forma, um periférico escravo pode somente aceitar uma comunicação e nunca iniciar algum tipo de transferência através do barramento.

Estes periféricos podem ser memórias e processadores, como também os tradicionais componentes periféricos, por exemplo, UART, PIO (Parallel I/O), entre outros. Qualquer lógica que possua interface com sinais de controle, dados e endereço pode se tornar um periférico Avalon.

O barramento Avalon é gerado automaticamente pelo SOPC Builder, tornando automático este processo de integração entre o processador e os outros periféricos do sistema. Com isso, o projetista é poupado da tarefa de conectar os componentes do sistema no módulo do barramento, se limitando a especificar através de uma interface gráfica somente as ligações entre as interfaces e o barramento. 


\subsection{Ferramenta SOPC Builder}

O SOPC (System-on-a-programable-chip) Builder, integrado ao Quartus II, é uma ferramenta de desenvolvimento de sistemas que simplifica a tarefa de criação de projetos SOPC baseados em processadores, periféricos e memórias. O SOPC Builder possibilita ao projetista definir e gerar um completo sistema em lógica programável em muito menos tempo do que utilizando o tradicional método manual de integração.

Usando o tradicional método de projetos SOC (system-on-chip), o projetista é obrigado a unir manualmente os pedaços de arquivos HDLs principais (top-level) do sistema, tornando esta tarefa difícil e propensa a erros. Já utilizando o SOPC Builder, o projetista pode especificar os componentes através de uma interface gráfica (GUI) e as interconexões lógicas são geradas automaticamente (Figura 5.3 ).

Lista de Componentes Disponiveis

Tabela de Componentes Ativos

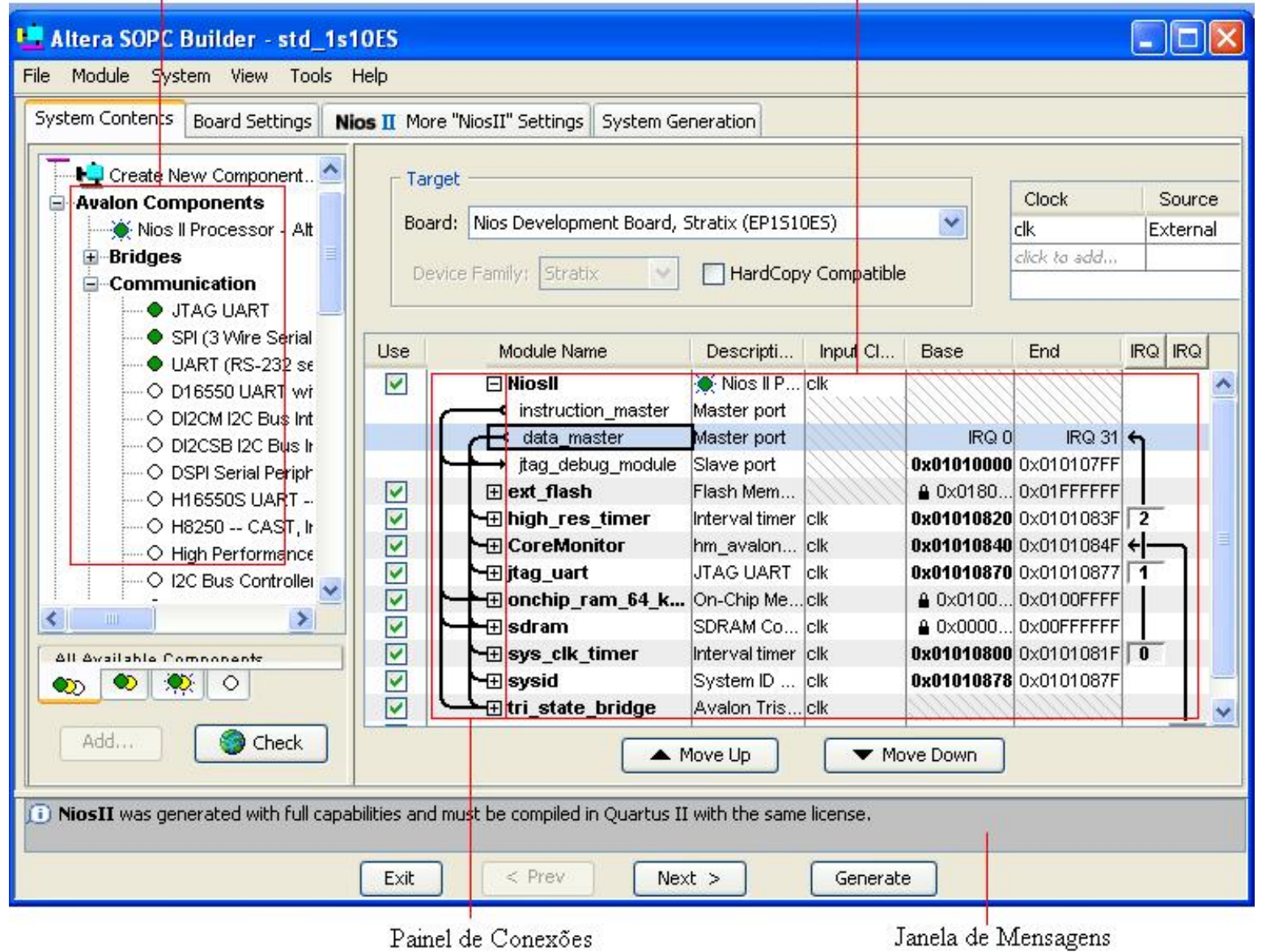

Figura 5.3: Interface da ferramenta SOPC builder 


\subsubsection{Arquitetura do Sistema SOPC Builder}

O SOPC Builder possui uma grande quantidade de componentes em sua biblioteca, mas também permite que outros módulos sejam identificados e integrados automaticamente ao sistema. Esta ferramenta conecta todos os componentes do projeto de forma única através da criação de um arquivo HDL principal (top-level) chamado de módulo de sistema. Este arquivo representa toda lógica que gerencia a conectividade dos componentes no sistema, esta lógica de conexão de componentes no barramento Avalon é denominada de Avalon switch fabric. A Figura 5.4 mostra um exemplo de um módulo de sistema com vários componentes mestre/escravo conectados através do Avalon switch fabric.

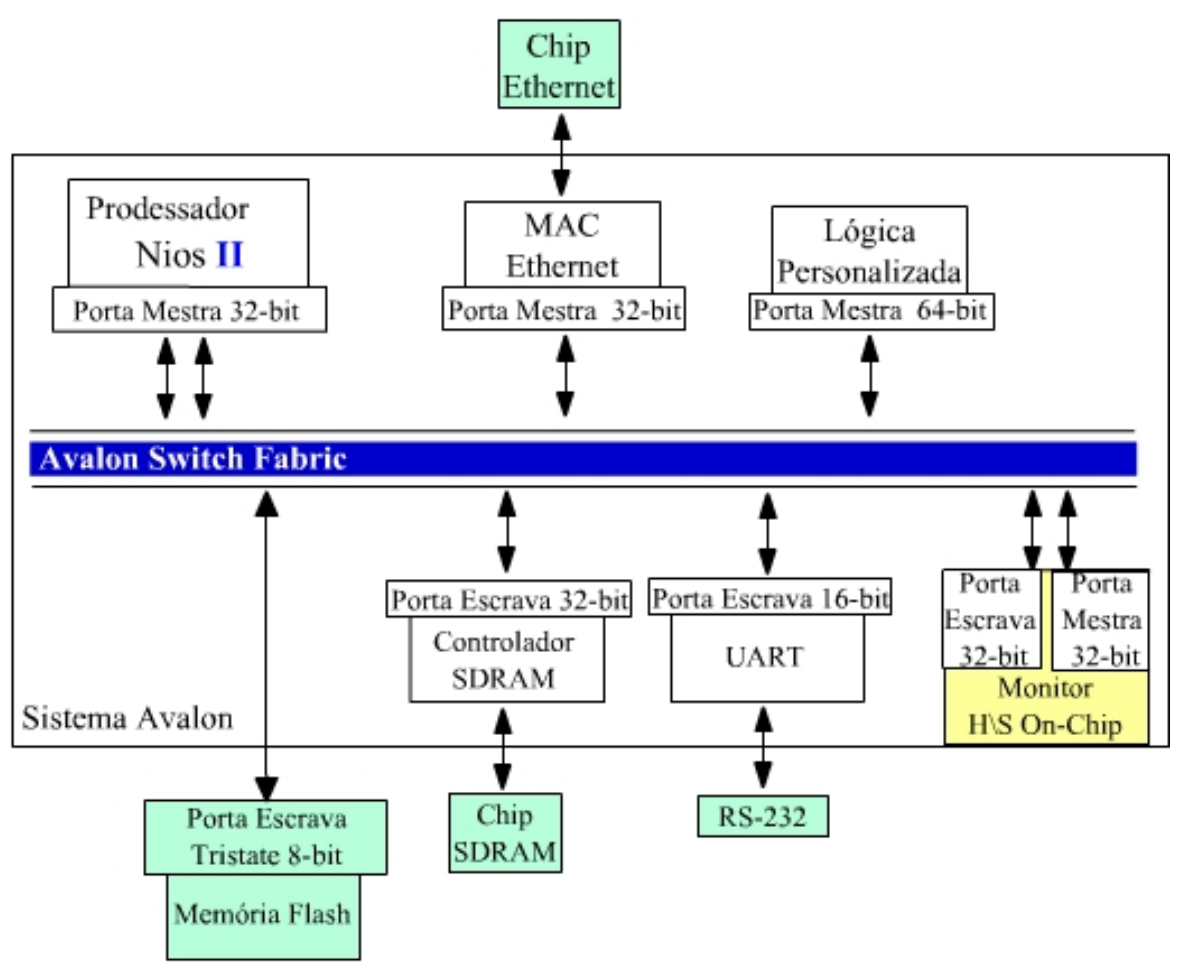

Figura 5.4: Exemplo de um sistema gerado pelo SOPC Builder

O Avalon switch fabric é uma lógica que uni ao mesmo tempo os componentes gerados no SOPC Builder. Ele é uma coleção de sinais e lógicas de componentes mestre e escravo, incluindo decodificador de endereço, multiplexador comprimento de dados, gerador de sinais de estado de espera (wait-state), controlador de interrupção, entre outras funcionalidades. E isto é feito automaticamente pelo SOPC Builder, não necessitando de 
nenhuma intervenção do projetista.

Desta forma o SOPC Builder retira a complexidade da lógica de conexão, permitindo ao projetista focar-se nos detalhes de personalização dos componentes e na arquitetura do sistema, em um nível mais alto de abstração.

Normalmente os projetos criados nesta ferramenta são baseados no processador Nios II. No entanto, o SOPC Builder é uma ferramenta de propósito geral, permitindo a criação de projetos SOPC que podem ou não conter um processador.

\subsubsection{Componentes do SOPC Builder}

Os componentes do SOPC Builder são blocos lógicos que utilizam a interface do barramento Avalon para a conexão física dos componentes com qualquer outro dispositivo lógico (seja on-chip ou off-chip) que também tenha interface Avalon. A interface Avalon utiliza um protocolo de leitura/escrita com endereços mapeados, que permite aos componentes mestres ler e/ou escrever em qualquer componente escravo. Para mais detalhes sobre o barramento Avalon, veja a seção 5.4 .

Um componente pode ser representado no módulo de sistema de três formas: (i) através de um componente que está integralmente localizado dentro do módulo, como o processador Nios II ou o módulo de monitoramento (Figura 5.4), (ii) através de um componente que tem uma interface para um dispositivo fora do chip (off-chip), como a interface UART ou SDRAM) e além disso, (iii) um componente pode ter outro sinais que conectam com uma lógica fora do módulo de sistema. Sinais não pertencentes ao barramento Avalon podem fornecer uma interface especial ao módulo de sistema, como por exemplo, MAC Ethernet.

A Altera e desenvolvedores externos fornecem uma série de componentes para o SOPC pronto para o uso (ready-to-use), alguns destes componentes são citados a seguir:

- Microprocessadores, como o processador Nios II;

- Periféricos microcontroladores;

- Marcadores de tempo (Timers); 
- Comunicação com a interface serial, como a UART;

- Interfaces para dispositivos fora do chip;

- Controladores de memória;

- Barramentos ou pontes (bridges) externas;

Além destes componentes o SOPC Builder prove um método o usuário desenvolver e conectar seu próprio componente. Através da interface Avalon, a lógica definida pelo usuário adere-se a uma simples interface baseada em endereços, dados e sinais que habilitam a leitura e a escrita no barramento.

\subsubsection{Fluxo de Desenvolvimento de Componentes}

Esta seção prove uma visão geral do processo de desenvolvimento de componentes para o SOPC Builder, cobrindo tanto os aspectos de desenvolvimento de hardware quanto de software. O SOPC builder possui um editor de componentes que auxilia o projetista a criar e editar os próprios componentes. As características do editor de componentes também serão descritas nesta seção.

\subsubsection{Projeto de Hardware do Componente}

Como em qualquer processo desenvolvimento de projetos lógicos, a implementação do componente de hardware começa depois da fase de especificação. A criação dos arquivos HDLs é um processo iterativo, no qual o projetista escreve e verifica a lógica HDL seguindo as especificações iniciais.

A arquitetura de um projeto de hardware para um componente do SOPC Builder consiste dos seguintes blocos funcionais (Figura 5.5):

- Lógica Funcional: Este bloco implementa a função essencial do componente, sendo totalmente dependente do projeto proposto.

- Arquivo de Registro: Este bloco lógico fornece um caminho para a comunicação dos sinais entre a lógica funcional e o mundo exterior, e vice versa. Este bloco mapeia as 


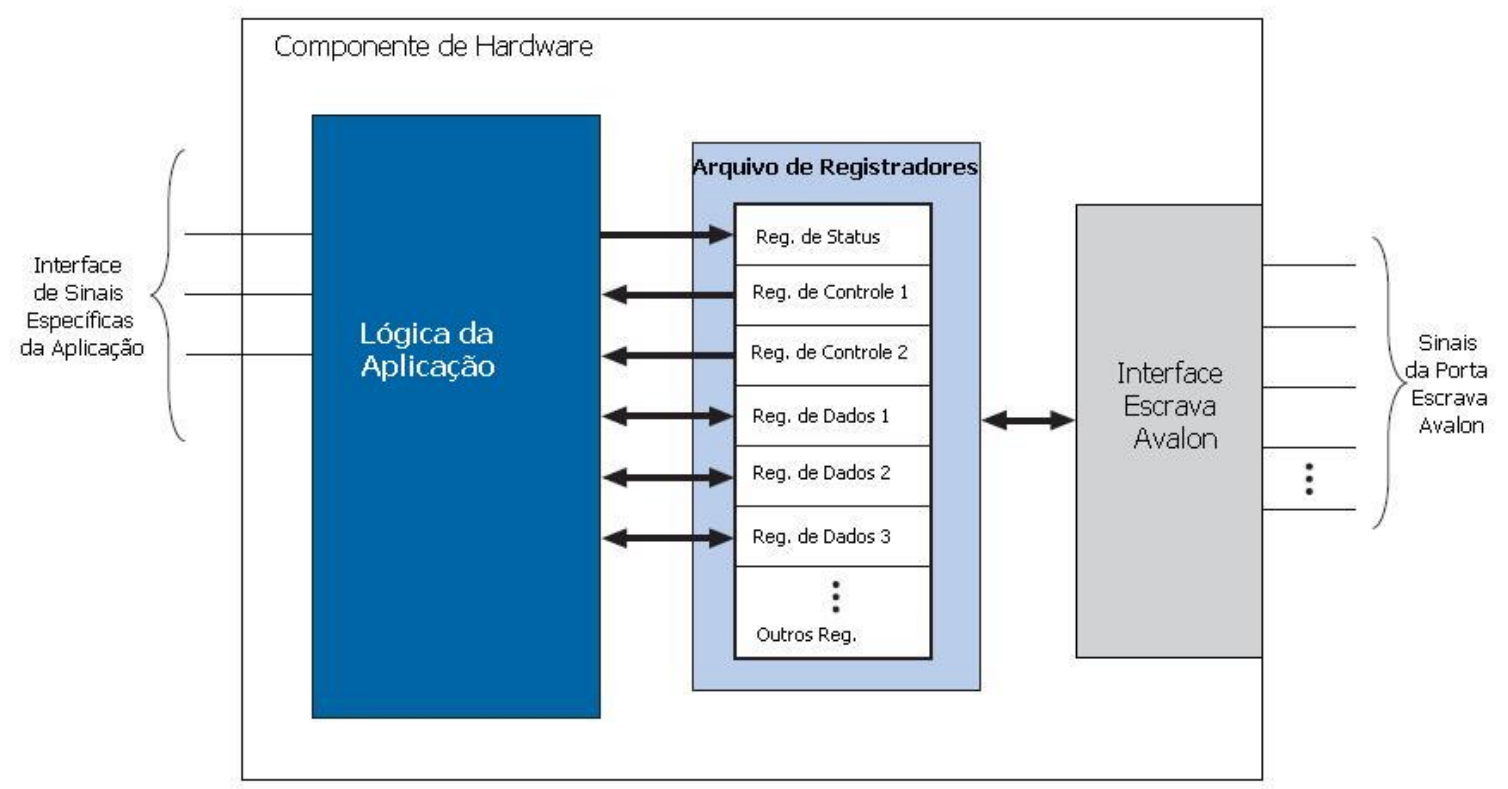

Figura 5.5: Diagrama de blocos de um típico componente com uma interface escrava

estruturas internas endereçáveis, tornando possível a leitura e escrita pela interface Avalon.

- Interface Avalon: Este bloco fornece uma interface (em inglês, front-end) com o padrão Avalon e o arquivo de registro. Esta interface utiliza os sinais Avalon para acessar o arquivo de registro e fornecer suporte as transferências requeridas pela lógica funcional. A seguir são citados alguns fatores que influenciam a interface Avalon:

- Quão largo é o dado a ser transferido?

- Qual é o ritmo de transferência (em inglês, throughput) requerida para esta transferência de dados?

- É uma interface para controle ou para dados? As transferências são constantes ou esporádicas?

- É um hardware relativamente rápido ou lento se comparado com o outro componente no qual esta se comunicando? 


\subsubsection{Projeto de Software do Componente}

Se a intenção do projetista é que seu componente personalizado seja controlado por um microprocessador, então é necessário fornecer arquivos de software (conhecidos como drivers) para que representem a arquitetura do componente para a aplicação. Neste caso, o projetista deverá criar no mínimo um mapa dos registradores do componente, sendo que, para cada porta escrava que for acessível pelo processador deverá ter um registrador relacionado.

Através do editor de componentes do SOPC Builder é possível adicionar um arquivo de cabeçalho (em inglês, header file) na linguagem C para definir estas características do componente. Normalmente, neste tipo de arquivo são declaradas macros para a leitura e escrita dos registradores pertencente ao componente. Nestas macros também deve-se determinar o valor relativo ao endereço base de cada registrador, para que o microprocessador possa executar as operações de leitura e escrita de forma exata.

Na Figura 5.6 pode-se ver uma parte do mapa de registradores do componente UART, no qual são definidas macros de leitura e escrita para os registradores de dados rx e tx.

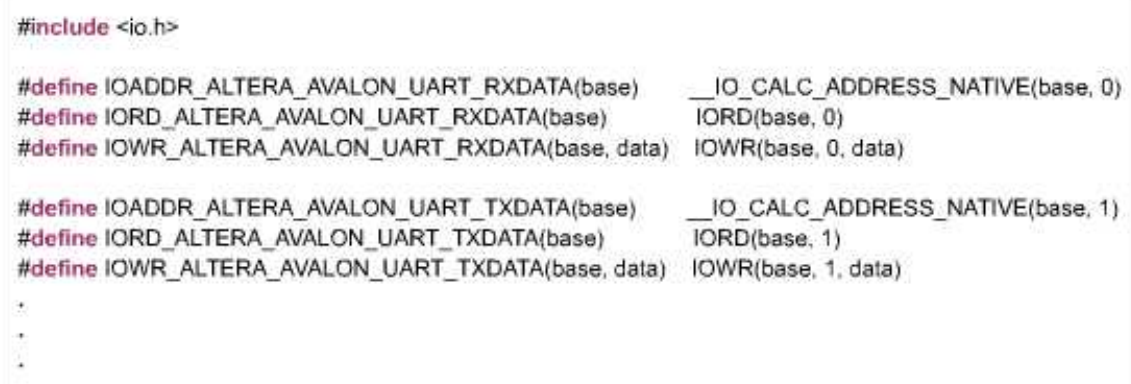

Figura 5.6: Uma parte do mapa de registradores do componente UART

Os drivers abstraem detalhes do hardware pertencente ao componente, para que a aplicação possa ter acesso aos componentes através de funções em alto nível. Os requisitos do driver variam de acordo com a necessidade do componente, na maioria das vezes ele é composto por rotinas de inicialização do hardware, leitura e escrita de dados.

Estes drivers são inerentemente dependentes do processador alvo, porque todo o seu desenvolvimento é baseado nas características do processador. Como a maioria dos componentes adicionados ao SOPC Builder são implementados visando o processador Nios 
II, o editor de componentes do SOPC Builder possui uma ferramenta que adapta automaticamente estes drivers, fornecidos pelo projetista, a camada de abstração de hardware (HAL) do processador Nios II.

\subsubsection{Editor de Componentes}

O SOPC Builder disponibiliza uma interface gráfica que possibilita ao projetista criar e editar seus próprios componentes. Esta GUI é composta por interfaces internas (abas) que compõem o editor de componentes e por meio desta interface gráfica é possível realizar as seguintes funções:

- Importar os arquivos em linguagem de descrição de hardware (HDL) que descrevem o hardware do componente;

- Especificar a(s) interface(s) de hardware que o componente possui;

- Adicionar os softwares (drivers) dentro do diretório do componente;

- Declarar qualquer parâmetro que possa alterar a estrutura ou funcionalidade do componente e definir a interface que o projetista utiliza para instanciar parâmetros do componente.

Durante a adição de cada arquivo HDL (aba de arquivos HDL), o editor de componente executa em segundo plano o Analisador Lógico do Quartus II que os verifica. Caso seja analisado com sucesso, o editor de componente identifica o módulo descrito no arquivo e o inseri na lista de módulos do componente. Desta forma, se houver mais de um módulo, o projetista deverá selecionar qual destes módulos contidos na lista será o módulo principal (top-level) do projeto.

Após a inserção dos arquivos HDL, os sinais que estão definidos no módulo principal aparecem na aba de sinais do editor de componentes (Figura 5.7). Os sinais que não são automaticamente identificados como sinais pertencentes à interface Avalon, devem ser manualmente definidos pelos projetistas, sejam eles pertencentes à interface Avalon o a alguma lógica externa (sinais do tipo export). 


\begin{tabular}{|c|c|c|c|c|c|}
\hline \multicolumn{5}{|c|}{ I Component Editor - hm_avalon_interface } & $=\square \times$ \\
\hline \multicolumn{6}{|l|}{ File Templates } \\
\hline Introduction & \multirow[t]{2}{*}{ Interfaces } & \multirow[t]{2}{*}{ SW Files } & \multicolumn{2}{|l|}{ Component Wizard } & \\
\hline \multicolumn{4}{|l|}{$D$ About Signals } & & \\
\hline Name & Interface & \multicolumn{2}{|r|}{ Signal Type } & Width & Direction \\
\hline V/, clk & Global siana|s & \multicolumn{2}{|r|}{$\checkmark$ 回k $\vee$} & 1 & input \\
\hline resetn & global_signals & & reset_n & 1 & input \\
\hline S_chip_select & avalon_slave_0 & & chipselect & 1 & input \\
\hline S_write_data & avalon_slave_0 & & writedata & 32 & inpust \\
\hline s_read_data & avalon_slave_0 & & readdata & 32 & output \\
\hline S_address & avalon_slave_0 & & address & 2 & input \\
\hline \begin{tabular}{l|l} 
s_write \\
\end{tabular} & avalon_slave_0 & & write & 1 & input \\
\hline \begin{tabular}{|l|l} 
s_read \\
\end{tabular} & avalon_slave_0 & & read & 1 & input \\
\hline DS_readyfordata & avalon_slave_0 & & readyfordata & 1 & output \\
\hline Wr_ead_data & avalon_master_0 & & readdata & 16 & input \\
\hline M m_irq & avalon_master_0 & & irq & 32 & input \\
\hline WI_endorpacket & avalon_master_0 & & endofpacket & 1 & input \\
\hline DIm_wait_request & avalon_master_0 & & waitrequest & 1 & input \\
\hline$<$ & & & IIii) & & \\
\hline 6k) Component "hm_avalo & n_interface" is ok. & & & & \\
\hline & $<$ Prev & Next & Finish... & & \\
\hline
\end{tabular}

Figura 5.7: Aba de configuração de sinais do editor de componentes

A aba de interface permite ao projetista configurar as propriedades referentes a todas as interfaces contidas no componente como, nome da interface, propriedades de tempo (latência de leitura (transferências pipelines), ciclos de espera para leituras e/ou escrita etc), entre outras propriedades.

Por fim, existem as abas de software e de configuração do componente que são responsáveis por adicionar os arquivos de software e especificar as configurações presentes na interface do componente, respectivamente.

O editor de componentes cria uma certa estrutura de diretórios alguns arquivos de configuração, que são utilizados pelo SOPC Builder durante a geração do sistema. Estes arquivos e diretórios são descritos a seguir:

- Arquivo class.ptf: Este arquivo identifica o componente e define as conexões do hardware com o sistema. Além disso, contém a declaração dos parâmetros que são configuráveis em tempo de projeto, como por exemplo, a velocidade de transmissão $(115200,57600, \ldots)$ do módulo UART. 
- Arquivo cb_generator.pl: Este arquivo é um script utilizado pelo SOPC Builder durante a geração do sistema, no qual gera as instancias do componentes de hardware.

- Arquivos de Software: Caso o componente seja um periférico controlado por um processador, o projetista poderá associar estes arquivos para atuarem como drives do componente.

- Diretório $H D L$ : Este diretório contém os arquivos HDLs que englobam a lógica do sistema.

\subsection{Considerações Finais}

Neste capítulo foram apresentados os recursos de hardware utilizados como plataforma de desenvolvimento deste trabalho e os recursos de software, enfatizando a ferramenta SOPC Builder que se mostrou essencial para a portabilidade do módulo de monitoramento. Para uma melhor compreensão deste trabalho, este capítulo também detalhou a estrutura do processador Nios II e do barramento Avalon.

No próximo capítulo serão apresentados os detalhes da implementação de todo o sistema de monitoramento proposto neste trabalho. 


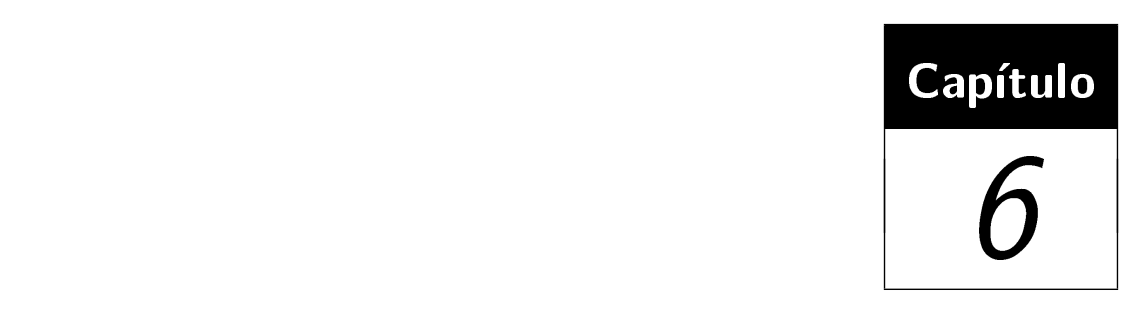

Implementação e Resultados

\subsection{Considerações Iniciais}

Este capítulo apresenta todas as etapas da implementação do módulo (em inglês, core) de monitoramento baseado em hardware reconfigurável proposto neste trabalho, como também o aplicativo para configuração do monitor e análise dos dados oriundos do monitoramento. Para o desenvolvimento das funcionalidades apresentadas neste capítulo foram utilizadas avançadas ferramentas EDA, essências para a implementação, simulação e depuração de projetos de hardware e o dispositivo reconfigurável (FPGA) apresentados na seção 5 (Plataforma de Desenvolvimento). A linguagem utilizada na implementação do módulo de monitoramento foi o Verilog [23], que contou também com a adição de alguns componentes lógicos fornecidos pela ferramenta Quartus II [5].

Primeiramente será apresentado uma exemplo de fluxo de projeto $S o C$, contextualizando a arquitetura do ambiente a ser monitorado. Seguindo com a organização do Sistema de monitoramento, detalhando seus componentes, funções e estrutura interna. Por fim, são expostos as análises e os resultados gerados pelo monitor. 


\subsection{Fluxo de um Projeto Hardware/Software em Am-}

\section{biente Altera}

O objetivo desta seção é discutir como são construídos os sistemas embarcados compostos de hardware/software utilizando blocos ou módulos de propriedade intelectual (em inglês, intellectual property - IP cores) no ambiente de design da Altera. O fluxo de desenvolvimento deste tipo de sistema está ilustrado na Figura 6.1 e será descrito a seguir.

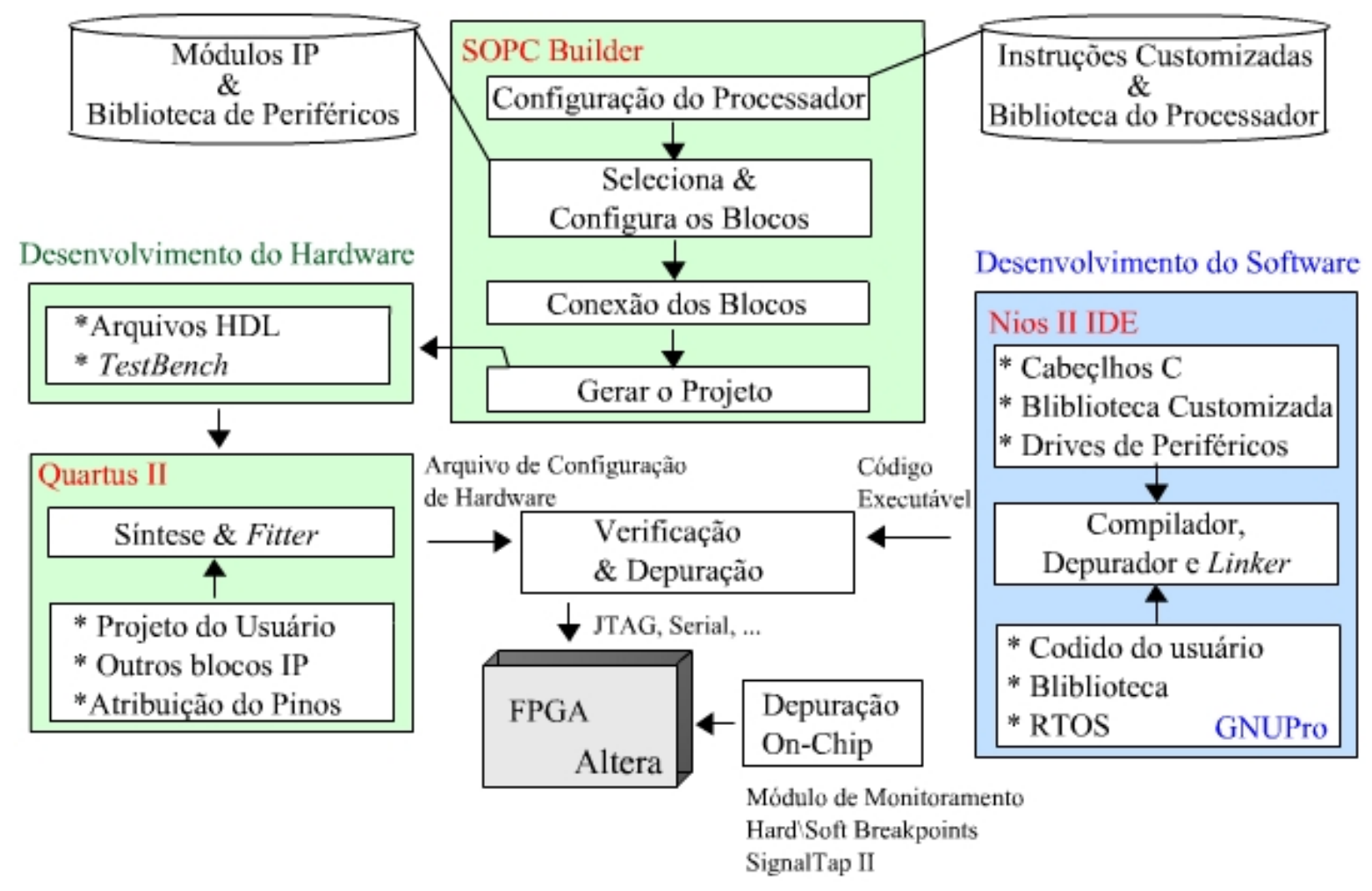

Figura 6.1: Fluxo de Projeto HW/SW com ferramentas Altera, figura baseada em [33]

\subsubsection{Desenvolvimento do Hardware}

Normalmente o projeto de um sistema embarcado em ambiente Altera inicia-se com o software Quartus II, através da criação de um projeto. Depois de criado o projeto, o Quartus II possibilita o acesso à ferramenta SOPC Builder, no qual grande parte do sistema é construída.

Na ferramenta SOPC Builder (ver seção SOPC Builder) o primeiro passo é adicionar o 
processador soft core que será utilizado no sistema, este processador pode ser configurado de acordo com as necessidades do projetista (ver seção 5.3). Além do processador Nios II, o SOPC Builder também disponibiliza vários componentes desenvolvidos pela Altera ou lógicas customizadas por usuários como, controladores de memória, dispositivos de comunicação, módulo de monitoramento, entre outros, que também podem ser configurados e adicionados ao sistema.

Após adicionar os componentes, o projetista precisará interligá-los para que o SOPC Builder possa ter as informações necessárias para gerar o barramento Avalon junto com toda lógica de conexão entre os componentes e o barramento (sinais de controle, arbitragem etc).

O SOPC Builder gera automaticamente os arquivos $H D L s$, arquivos de simulação e um símbolo do projeto principal, quando a geração do sistema é completada com sucesso. Este símbolo é adicionado ao diagrama de blocos do sistema no software Quartus II, para que o projetista possa incorporar, caso necessário, outros blocos lógicos ao sistema. É importante destacar que estes novos blocos lógicos não serão incorporados ao barramento Avalon, podendo somente interagir com os sinais de E/S do bloco gerado pelo SOPC Builder.

Outra função que o projetista não só pode, mas deve fazer nesta etapa, é definir os sinais que serão atribuídos aos pinos pertencentes à placa de desenvolvimento como, sinais de clock, pinos para acessar memórias externas (Flash, SRAM, DDR) ou periféricos (UART, Ethernet) etc. Estes pinos são específicos para cada placa de desenvolvimento (família Stratix, Stratix II etc).

Terminada estas configurações, o projetista pode agora realizar a compilação completa do sistema, através do Quartus II. Esta compilação é composta pelas seguintes etapas:

- Análise e síntese: Realiza a síntese lógica do projeto para minimizar o uso dos recursos disponíveis no dispositivo como, elementos lógicos e memória.

- Fitter: Traça as rotas e posiciona a lógica do projeto dentro do dispositivo.

- Assembly: Converte a lógica, os pinos e o fitter do projeto em arquivos de pro- 
gramação para o dispositivo.

- Analisador de tempo: É a ultima parte da compilação, ele relata as informações de tempo de toda lógica do projeto.

Este processo verifica todo o sistema projetado e ao final gera o arquivo que contém a configuração do hardware em baixo nível para ser carregado no dispositivo (arquivo de bitstream), através da ferramenta Programmer, também pertencente ao Quartus II. Neste estágio a estrutura de hardware do sistema esta completa.

\subsubsection{Desenvolvimento do Software}

A criação do software é necessária para a utilização e verificação do correto funcionamento do hardware projetado. A Altera disponibiliza a ferramenta Nios II IDE (Integrated Development Environment), no qual o projeto de software é construído. Esta ferramenta fornece quatro funções essências para o desenvolvimento do software.

- Gerenciamento de Projeto: Provê serviços que aumentam a velocidade de criação e de aplicações para sistemas embarcados como, (i) o Project wizard: que automatiza a criação dos projetos $\mathrm{C} / \mathrm{C}++$, (ii) Modelo de projetos de software: que fornece exemplos de códigos na forma de modelos de aplicações, contendo uma coleção de arquivos de software e configurações de projeto, (iii) Componentes de software: permite ao projetista personalizar seu sistema através da inclusão de componentes como, a biblioteca do Nios II (conhecida como Camada de Abstração de Hardware (HAL)), pilha TCP/IP, sistema operacional em tempo real (MicroC/OS-II) e um sistema de arquivo (Altera Zip).

- Editor e Compilador: Provê um completo editor de código fonte com destacador de sintaxe, auxílio para completar comandos, auto-correção, características de depuração, tópicos de ajuda e tutorias etc. O compilador $\mathrm{C} / \mathrm{C}++$ é baseado no padrão industrial da ferramenta GNU. Ele fornece uma interface gráfica para o compilador GCC e constrói ambientes automaticamente produzindo um makefile (arquivo que descreve 
como o sistema é arquitetado) baseado nas configurações do sistema especificado pelo usuário no SOPC Builder.

- Depurador: Contém um software de depuração baseado na ferramenta GDB (GNU Debugger) que prove algumas características básicas de depuração como, controle de execução, visualização da pilha de execução, software breackpoints, informações de depuração etc. Além de características avançadas de depuração como, hardware breackpoints, triggers de dados e trace de instruções.

- Programador da Memória Flash: Muitos projetos que utilizam o processador Nios II também incorporam a memória flash como meio de armazenar no FPGA dados do programa ou configurações do processador. Desta forma a ferramenta Nios II IDE inclui um método de programar esta memória. Qualquer interface padrão para memória flash (Common Flash Interface (CFI)), que seja compatível com o dispositivo flash conectado ao FPGA, pode ser programado utilizando esta ferramenta.

Os desenvolvedores de software são responsáveis por criar as rotinas do sistema, entre elas a rotina principal (main()). Estas aplicações interagem com os recursos do sistema através da biblioteca padrão C, ou através da biblioteca $H A L$ (Camada de Abstração de Hardware) do sistema.

A biblioteca HAL define um conjunto de instruções que são empregadas para inicializar e utilizar cada classe de dispositivos. Esta API (Application Program Interface) é consistente, e não leva em consideração a implementação em baixo nível dos dispositivos. Por exemplo, para acessar dispositivos em modo de comando e subsistemas de arquivos, o programador pode usar as funções da biblioteca padrão $\mathrm{C}$ como, printf() e fopen(). Desta maneira os projetistas de aplicações em software não precisam escrever rotinas em baixo nível, necessitando apenas de estabelecer uma comunicação básica com o hardware destas classes de periféricos. A Figura 6.2 ilustra um sistema baseado na biblioteca $H A L$ partindo do nível mais baixo (hardware) até o programa do usuário (software).

A biblioteca de sistema $H A L$ interage com a biblioteca padrão C (ANSI C) em tempo de execução. Ela utiliza também a newlib [38, que é uma implementação de código 


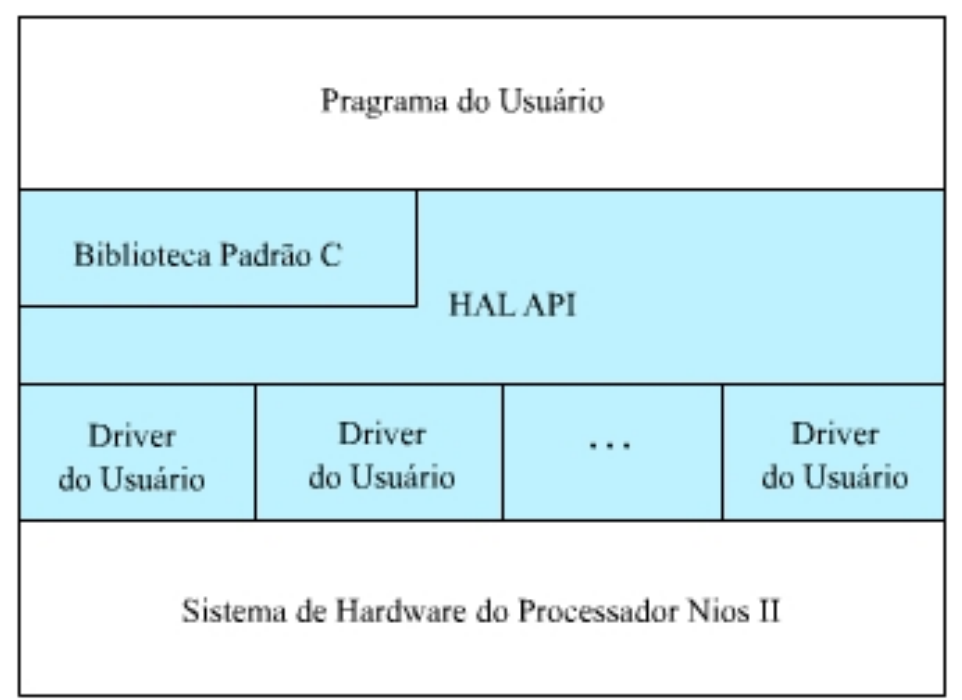

Figura 6.2: Camadas de um sistema baseado na biblioteca $H A L$, baseado em [3]

aberto da biblioteca padrão C, utilizada em sistemas embarcados, que traz uma perfeita adaptação entre a $H A L$ e o processador Nios II.

Uma aplicação desenvolvida na ferramenta Nios II IDE consiste de dois projetos separados (ver Figura 6.3): um projeto que contém a aplicação feita pelo usuário, e um projeto que é composto pela biblioteca $H A L$. O projeto da aplicação contém todos os códigos desenvolvidos pelo usuário e à imagem executável gerada é resultado da compilação deste projeto.

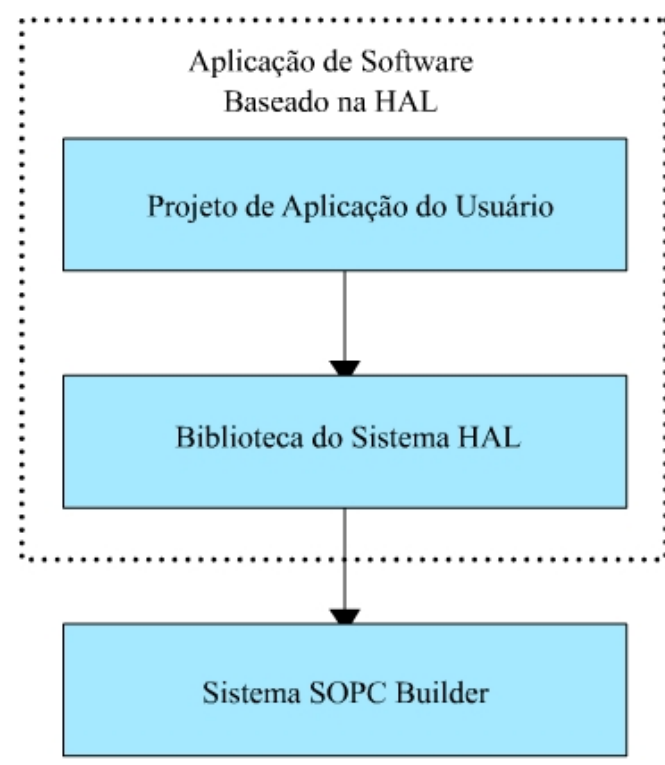

Conhecido como: Projeto do usuário

Descrito por: Arquivos .c, .h e .s

Criado por: Usuário

Conhecido como: HAL ou biblioteca do sistema

Descrito por: Configurações de projeto no Nios II IDE

Criado por: Nios II IDE

Conhecido como: Sistema do processador Nios II ou o hardware Descrito por: Arquivo .ptf

Criado por: SOPC Builder

Figura 6.3: Estrutura de uma aplicação criada na ferramenta Nios II IDE, baseado em [3] 
A ferramenta Nios II IDE gera automaticamente o projeto $H A L$ quando o projetista cria o projeto de aplicação. Este projeto contém todas as informações necessárias para conectar o programa do usuário com o hardware projetado. Em tempo de compilação, todo os drivers relevantes ao sistema gerado no SOPC Builder são adicionados à biblioteca do projeto, como também todas as configurações da camada de abstração de hardware $(H A L)$.

\subsection{Sistema de Monitoramento Hardware/Software On-Chip}

Esta seção descreve todo o sistema de monitoramento, que é composto pelo Módulo de Monitoramento Hardware/Software On-Chip e pela ferramenta ACAD (Análise, Configuração e Aquisição de Dados). A Figura 6.4 ilustra um projeto de hardware intregrado com o Sistema de Monitoramento proposto neste trabalho.

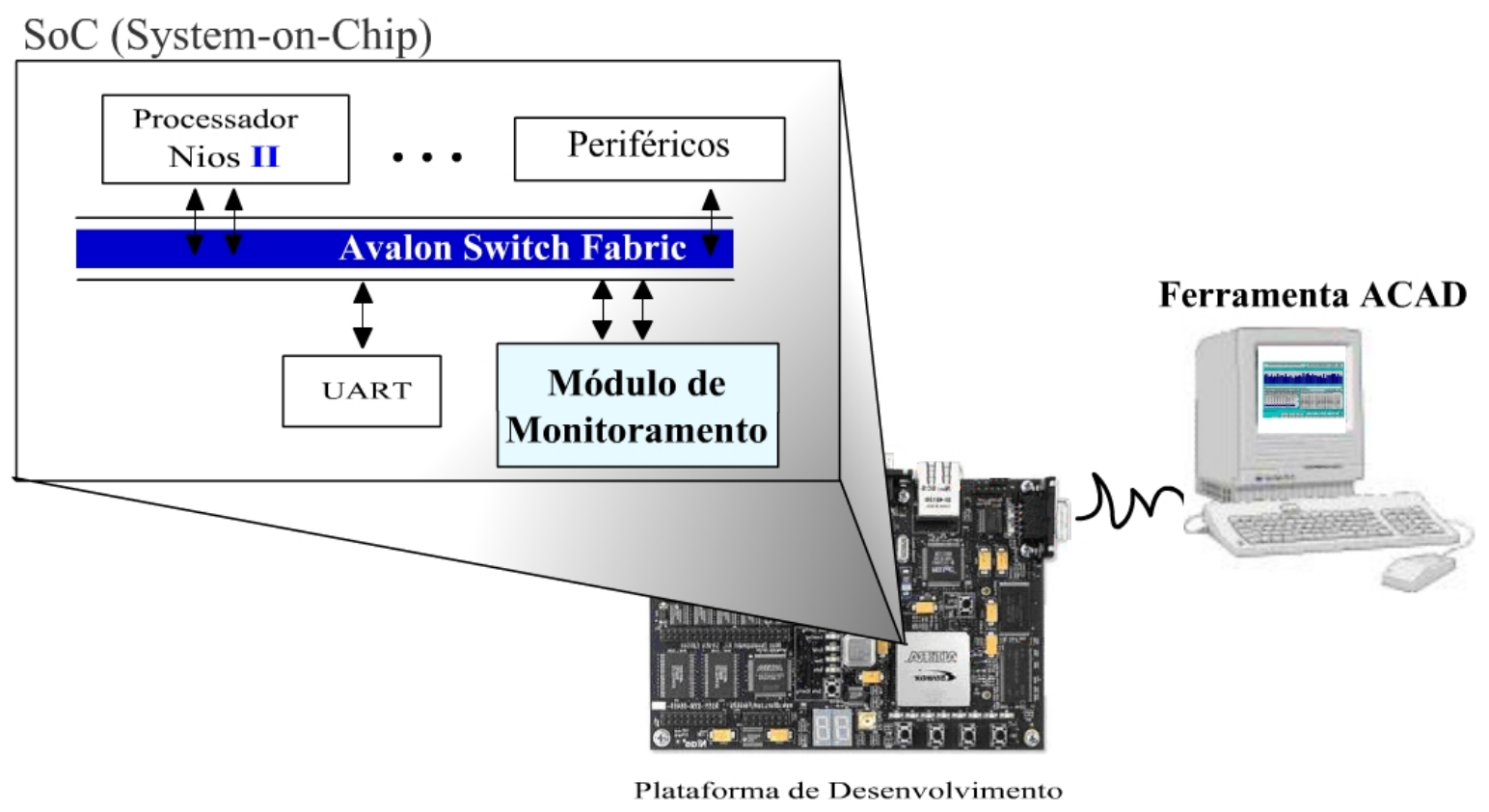

Figura 6.4: Visão Superficial do Sistema de Monitoramento Hardware/Software On-Chip 


\subsubsection{Modulo de Monitoramento Hardware/Software On-Chip}

Esta subseção descreve a arquitetura do módulo de monitoramento, identificando os componentes internos e suas respectivas funções. A Figura 6.5 mostra o diagrama de blocos do sistema de monitoramento e suas conexões no barramento Avalon [2]. O papel desempenhado por cada bloco do sistema será descrito seguindo a ordem de captura dos sinais no barramento (módulo de aquisição de sinais), passando pela lógica de análise e composição do sinal detectado (módulo de monitoramento (core)), até a saída do pacote em direção a interface UART.

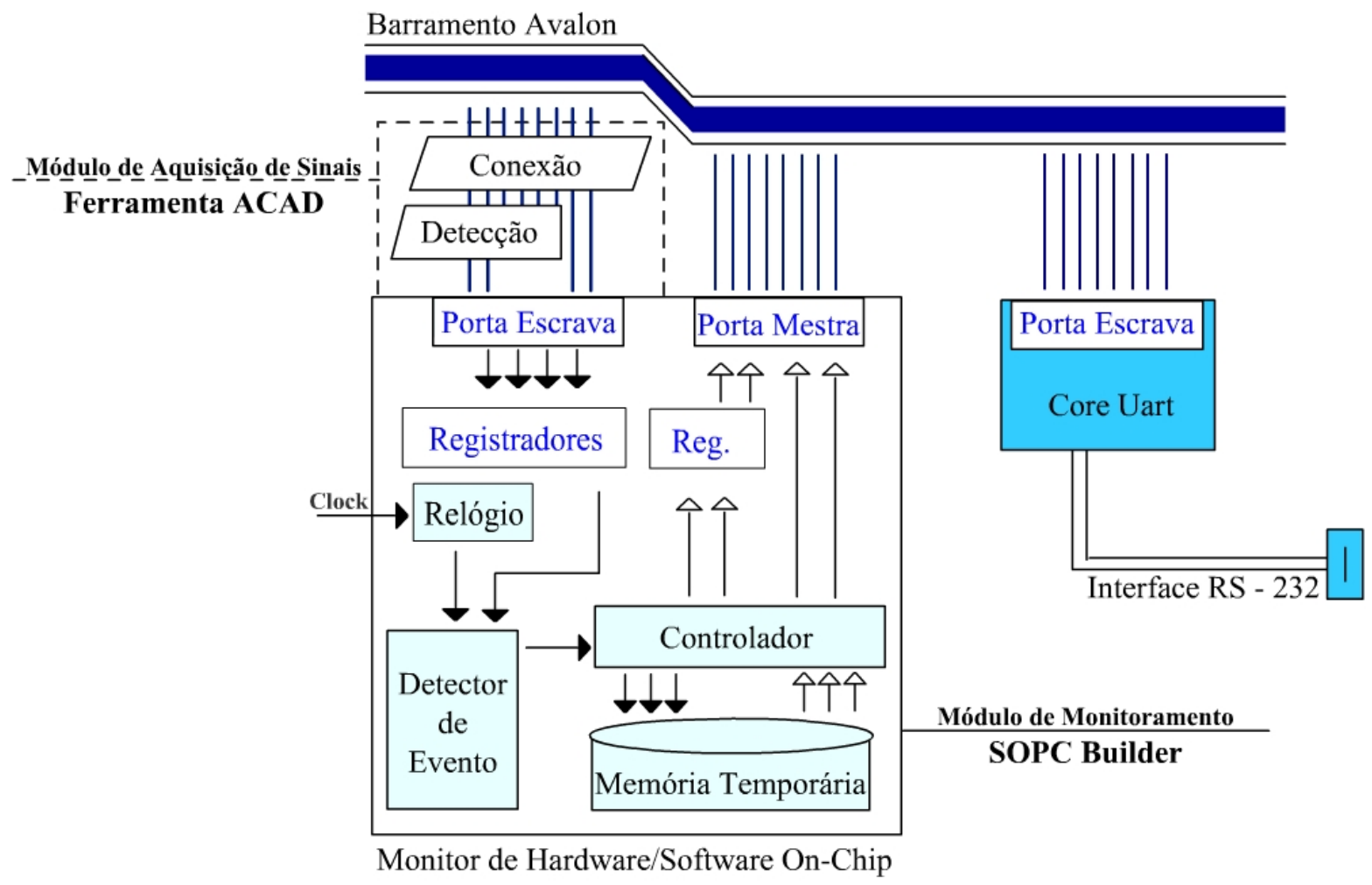

Figura 6.5: Diagrama de Blocos do Módulo de Monitoramento

\subsubsection{Módulo de Aquisição de Sinais}

- Bloco de Conexão

Quando o processador Nios II ou qualquer outro periférico inicia uma transferência no barramento Avalon, são atribuídos valores aos sinais do barramento como, sinais de dados, endereço e controle, além do sinal de chip-select que é ger- 
ado pelo módulo Avalon. Estes sinais que estão trafegando no barramento, e não são destinados ao sistema de monitoramento, são capturados pelo bloco de conexão (ilustrado no topo do monitor, Figura 6.5).

O bloco de conexão possui uma interface que se conecta ao barramento Avalon, permitindo o acesso a todos os sinais do barramento, sem provocar nenhum tipo de interferência ou atraso nos sinais ou qualquer interrupção na comunicação dos periféricos com o sistema de monitoramento.

Todos os sinais capturados pelo bloco de conexão são analisados e encaminhados para o bloco de detecção ou para o bloco principal, dependendo do destino dos sinais capturados. Os sinais originados no Nios II e destinados para qualquer outro periférico que não seja o sistema de monitoramento são encaminhados para o bloco de detecção. Já os sinais que são realmente endereçados ao sistema de monitoramento (instruções de Escrita/Leitura nos registradores locais) não passam pelo bloco de detecção e são encaminhados diretamente ao bloco principal.

\section{- Bloco de Detecção}

Como o monitor captura eventos no nível de transferência de registradores $(R T L)$, a quantidade de sinais gerados pelo sistema é enorme fazendo com que o monitor fique sobrecarregado caso não tenha nenhum bloco que filtre os sinais que trafegam no barramento. Com isso, antes de encaminhar os sinais ao monitor é necessário realizar uma filtragem, para que passem pelo bloco somente os sinais de relevância ao monitoramento.

O componente responsável por realizar esta função é o bloco de detecção. Este bloco tem por objetivo receber os sinais endereçados pelo processador aos demais módulos do sistema (periféricos/memórias) e verificar o tipo de evento/transferência que esta ocorrendo no barramento. Depois de verificar o tipo de evento/transferência atuante no barramento o bloco de detecção descarta os sinais de transferências identificados como não pertencente ao conjunto de sinais que fazem parte do escopo do monitoramento como, sinais destinados a memórias ou periféricos não assinalados 
pelo projetista para serem monitorados. Fazendo com que somente os eventos de interesse sejam informados ao módulo principal do monitor, minimizando desta forma as chances de perda de dados através da diminuição do overhead de informações.

Desta forma o papel do bloco é receber um conjunto de sinais e identificá-los da seguinte forma:

- Leitura/Escrita de dados em periféricos/memória;

- Leitura de instrução na memória;

- Identificar qual o periférico/memória que se destina à transação;

- Identificar qual o tipo de instrução lida (caso ocorra uma leitura de instrução), as instruções estão distribuídas em 7 (sete) categorias: instrução de load, store, call, branch incondicional, branch condicional, instruções customizadas, outras (demais) instruções.

O bloco de detecção possui vários contadores de 40 e 32 bits que, a medida em que os sinais são identificados, estes contadores são incrementados e ao final do monitoramento estes dados são repassados ao módulo principal para que sejam encaminhados à ferramenta de análise. Através destes contadores é possível saber o número de leitura e escrita realizada pelo processador a cada dispositivo (periférico/memória), o número de instruções lidas das memórias e dentre estas o número de cada conjunto de instruções (load, store etc.) executadas pelo processador.

O conjunto de eventos detectados pelo bloco depende exclusivamente das aspirações do projetista, expressadas através da configuração do arquivo de projeto gerado pelo SOPC Builder. Na ferramenta de análise o projetista indica quais os periféricos ou memórias que deseja monitorar e esta configuração é feita de forma automática, sem a necessidade de qualquer instrumentação no código do projeto pelo desenvolvedor (a ferramenta de análise é detalhada na seção 6.3.2. 


\subsubsection{Módulo de Monitoramento (Core)}

- Relógio

Este bloco é responsável por marcar o tempo absoluto do monitoramento e também por identificar o momento em que ocorreu algum evento de software. Esta informação é requisitada pelo Detector de Eventos, que a utilizará para compor a mensagem de identificação do evento. Este bloco contém um contador 40-bit atualizado na freqüência do clock do sistema, obtendo com isso um tempo com precisão em nanosegundos.

\section{- Detector de Eventos}

Os eventos que chegam ao módulo principal do monitor sejam eles de software ou hardware, passam primeiramente pela porta escrava, que é a interface de comunicação entre o meio externo (sinais do barramento) e o meio interno (registradores) do monitor. Após passar pela interface de comunicação os evento são armazenados nos registradores, que são específicos para cada tipo de evento. Existe um registrador dedicado aos eventos oriundos do software e um registrador para os eventos oriundos do hardware.

O Detector de Eventos é então ativado a cada informação que é gravada nos registradores do monitor. Quando acionado, ele detecta qual registrador teve sua informação atualizada e partindo desta informação gera a mensagem que posteriormente será enviada a ferramenta de análise.

O Detector de Eventos gera dois tipos de mensagens que são descritas a seguir:

- Mensagem originada pelo Software (Figura 6.6), que é composta por três campos: (i) Parâmetros: possui informações adicionais sobre o evento como, por exemplo, o tipo de evento detectado (hardware/software), (ii) Seção ID: identifica qual seção do software foi iniciada ou encerrada e (iii) Tempo de Ocorrência: determina o momento em que o evento de foi detectado pelo monitor. 


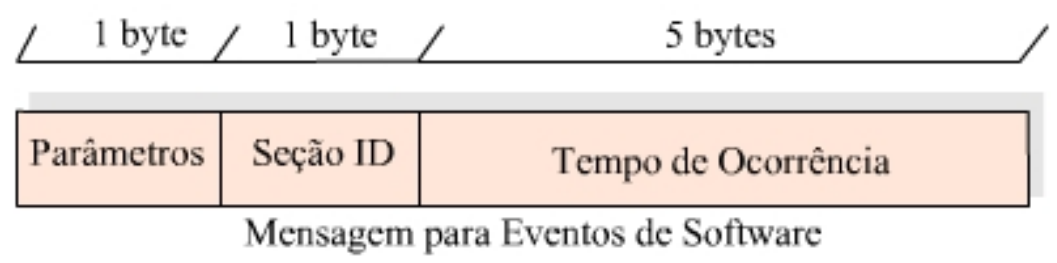

Figura 6.6: Formato da mensagem originada pelo software

- Mensagem originada pelo Hardware (Figura 6.7), que também é composta por três campos: (i) Parâmetros: possui informações adicionais sobre o evento como, por exemplo, o tipo de evento detectado (hardware/software), (ii) Evento ID: identifica qual evento foi detectado, dentro dos possíveis eventos de hardware, e (iii) Número de Ocorrência: determina a quantidade de eventos gerados pelo processador direcionado a um determinado dispositivo (número de leitura na memória RAM, por exemplo).

\begin{tabular}{|l|c|c|}
\hline 1 byte $/ 1$ byte $/$ & 5 bytes \\
\hline Parâmetros & Evento ID & Número de Ocorrência \\
\hline
\end{tabular}

Figura 6.7: Formato da mensagem originada pelo hardware

\section{- Controlador}

Visto que a quantidade de eventos captados pode ser maior que a capacidade de vazão destes eventos para a ferramenta de análise, a necessidade de uma memória temporária é essencial para que não comprometa a integridade do monitoramento com perda de dados. Neste sentido, o Controlador se responsabiliza por mover as mensagens geradas pelo Detector de Eventos para a memória temporária, verificando sua capacidade para que a transação possa ser realizada com segurança. A memória temporária possui alguns indicadores de estado que é a todo o momento checado pelo Controlador, caso o nível de ocupação se torne crítico (quase cheio) ele gerará uma mensagem para a ferramenta de análise informando este fato, de posse desta informação o projetista poderá ajustar melhor a capacidade da memória temporária em futuros monitoramentos. 
Por outro lado, o Controlador também é responsável pelo envio destas mensagens para a ferramenta de análise, que é realizado através do módulo UART (interface serial, RS-232) adicionado ao sistema. Ele gerencia a disponibilidade da interface serial em receber os dados e ao mesmo tempo verifica a necessidade do monitor em enviá-las para a ferramenta de análise.

A interface serial possui um buffer capaz de armazenar no máximo um byte por transação, como a mensagem com as informações do sinal detectado possui um tamanho de 7 bytes, isto faz com que o Controlador seja responsável também por dividir e enviar byte a byte da mensagem de forma sincronizada, para que ela possa ser novamente agrupada pela ferramenta de análise.

\section{- Memória Temporária}

A memória temporária é uma RAM FIFO de 2 vias embutida no chip, com 56-bit de largura e capacidade de armazenamento (número de palavras) variável. Isto é, depende da configuração do projetista e da disponibilidade do dispositivo reconfigurável. Além disso, ela possui sinais que indicam se está vazia, cheia ou quando começa a ficar cheia.

A taxa em que o Detector de Eventos gera e armazena a mensagem na memória temporária é sujeita a freqüência do clock do sistema. O Detector de eventos necessita de 1 ciclo de clock para detectar o evento e gerar a mensagem e mais 2 ciclos de clock para armazenar a mensagem na memória temporária. Isto faz com que no pior caso os eventos sejam gerados num intervalo de 2 ciclos de clock para que não ocorra perda de dados.

A taxa de esvaziamento dos dados da memória temporária é estritamente ligada ao desempenho da interface de comunicação com a ferramenta de análise, a interface serial (RS-232) no caso. A interface serial [19] permite uma taxa de transmissão de até 115,2 Kbps (kilobits por segundo), sendo que são acrescidos bits de sincronismo e de verificação de erros, dependendo da configuração. Por exemplo, para enviar 8 bits pela serial é necessário acrescer no mínimo 2 bits de sincronismo, um bit de 
inicio e um de fim no conjunto de dados $(1+8+1)$, então para se obter a taxa de transmissão em mensagens por segundo é indispensável acrescentar 7x2 bits ao tamanho da mensagem (7 bytes). Com isso, a taxa de esvaziamento dos dados na memória temporária é de 115200 bits dividido por 70 bits (tamanho total da mensagem após a inclusão dos bits de sincronismo) que resulta em aproximadamente $1,65 \mathrm{~K}$ mensagens por segundo.

\section{- Módulo UART}

O módulo UART (universal asynchronous receiver/transmitter) [8] desenvolvido pela Altera, possui interface para o barramento Avalon (Figura 6.5) e pode ser facilmente adicionado a qualquer sistema gerado no SOPC Builder. Este módulo proporciona uma comunicação serial entre o sistema embarcado em uma FPGA Altera e o dispositivo externo.

Este componente contém uma interface escrava para o barramento Avalon, provendo acesso aos seus registradores internos por qualquer periférico mestre, possibilitando o controle e a transferência de dados pela conexão serial. Como os dispositivos escravos não possuem acesso ao barramento, a menos que algum dispositivo mestre lhe faça alguma requisição, este módulo necessita de um sinal de interrupção $(I R Q)$ para requisitar a atenção do periférico mestre, isto ocorre quando novos dados são recebidos ou quando o módulo está pronto para transmitir outro caractere.

Cabe ao projetista configurar o módulo para que se encaixe de forma ótima no projeto, sabendo que todas as suas características seguem o padrão RS-232 [19]. Isto deve ser feito em tempo de projeto através da ferramenta SOPC Builder, dentre os parâmetros possíveis de configuração podem-se citar, a velocidade de transmissão, a inclusão de bits de paridade, o número de bits de sincronismo, a utilização de sinais de fluxo de controle etc. 


\subsubsection{Características do Módulo de Monitoramento}

Esta seção tem o objetivo de detalhar as características do Módulo de Monitoramento, tais como, quais as informações que são capturadas, a quantidade de elementos lógicos que o módulo ocupa na FPGA, dentre outras coisas.

As informações capturadas pelo módulo podem ser dividas em 2 (duas) partes:

1. Informações provenientes do software: Estas informações são capturadas conforme o usuário define as seções (parte do código) que deseja monitorar. O Módulo de Monitoramento tem a capacidade de monitorar até 128 (cento e vinte e oito) seções simultaneamente. As informações oriundas do software são detalhadas da seguinte forma:

- Instante em que iniciou a seção (segundos e/ou número de clocks);

- Instante em que encerrou a seção (segundos e/ou número de clocks);

- Tempo gasto para executar a seção (segundos e/ou número de clocks);

2. Informações provenientes do hardware: Estas informações são capturadas do processador durante a execução do software. O Módulo de Monitoramento captura informações sobre o acesso do processador aos periféricos e memórias e também obtém informações sobre as instruções que são executadas pelo processador. Estas informações estão detalhadas a seguir:

- Acesso a periféricos e memórias:

- Número de leitura de dados;

- Número de escrita de dados;

- Número de leitura de instruções (memórias);

- Instruções executadas: Como o processador Nios II [28] possui um número elevado de instruções, optou-se por criar conjuntos de instruções, nos quais, representassem instruções com funções parecidas e que tivessem de certa forma o mesmo custo computacional. Portanto o Módulo de Monitoramento fornece 
ao usuário o número de instruções que foram executas pelo processador aglutinadas nos seguintes conjunto:

(a) Intrusões do tipo Load: Carrega dados da memória ou de periféricos $(\mathrm{E} / \mathrm{S})$;

(b) Intrusões do tipo Store: Armazena dados na memória ou em periféricos $(\mathrm{E} / \mathrm{S})$

(c) Instruções do tipo Call: Chamadas de sub-rotinas;

(d) Instruções do tipo Branch condicional: Altera o fluxo do programa de forma condicional;

(e) Instruções do tipo Branch incondicional: Altera o fluxo do programa de forma incondicional;

(f) Instruções do tipo Flush: Esvazia memórias temporárias de dados ou de instruções;

(g) Instruções do tipo Aritméticas: Realiza cálculos (adição, subtração, etc);

(h) Instruções do tipo Lógicas: Realiza operações lógicas (And, Or, Xor, etc);

(i) Instruções do tipo Comparativas: Realiza comparações (igual, maior, menor, etc);

(j) Instruções do tipo Customizadas: Instruções que são projetadas pelo usuário;

(k) Instruções do tipo Outras: O restante de instruções;

O Módulo de Monitoramento ocupa cerca de 1.300 ELs (Elementos Lógicos), este número pode variar dependo da quantidade de periféricos que o usuário optar por monitorar. Para cada periférico ou memória adicionada na configuração do monitoramento tem se um acréscimo de 70 ELs. Outro fator é a adição do módulo UART (180 ELs), que é essencial e deve contar como parte do total de elementos lógicos utilizado pelo módulo.

A quantidade de memória utilizada pelo módulo também é dependente da configuração do usuário. É aconselhável o uso de no mínimo 1024 palavras (1024X56bits), para que não ocorra perda de dados e por conseqüência o comprometimento do monitoramento. A quantidade de memória temporária que o módulo irá possuir deve ser proporcional ao 
número de eventos gerados pelo sistema, cabendo ao usuário determinar qual a melhor quantidade.

A Figura6.8 ilustra o Módulo de Monitoramento portado na ferramenta SOPC Builder e pronto para ser inserido no projeto do usuário.

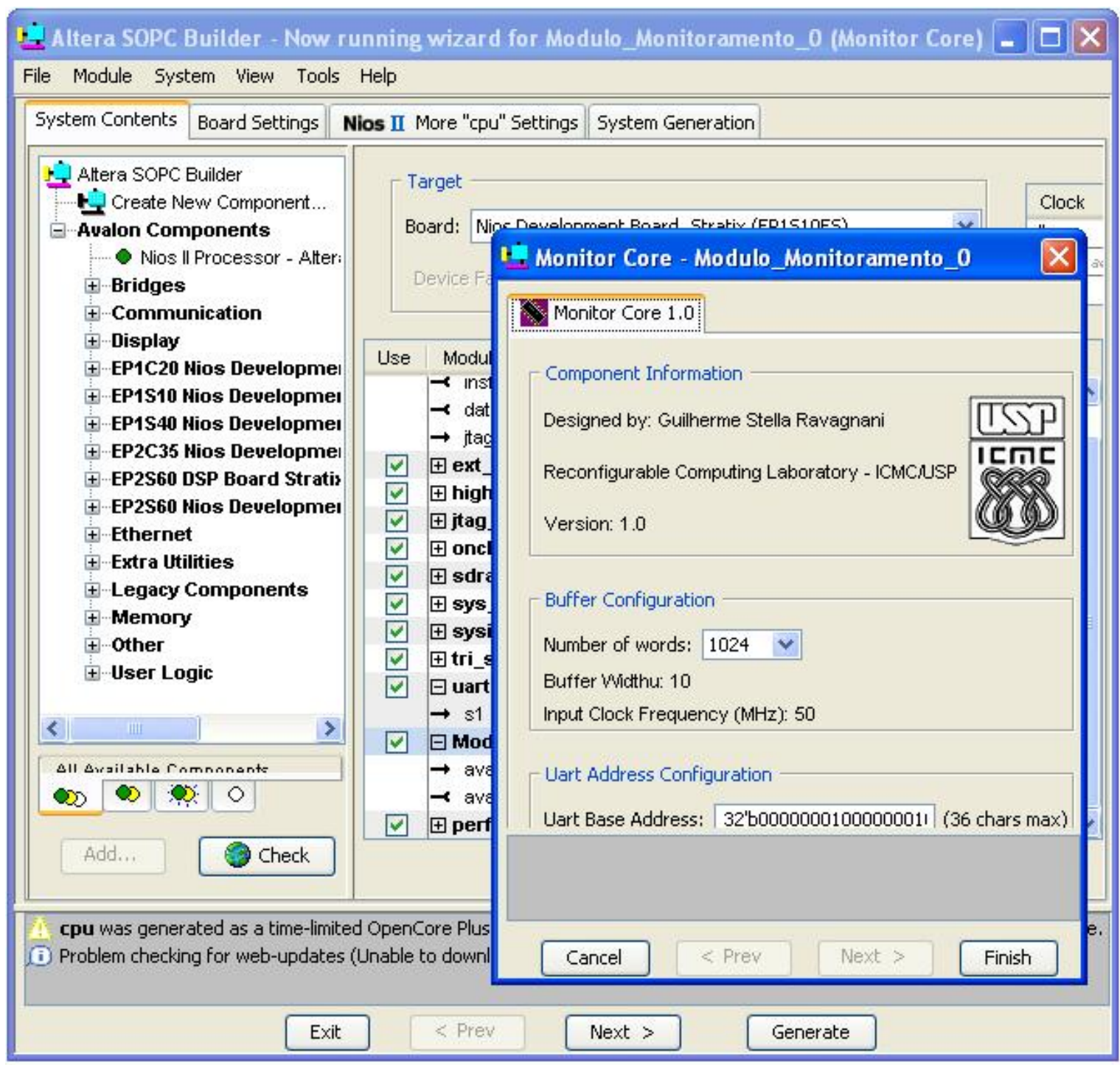

Figura 6.8: Módulo de Monitoramento portado para o SOPC Builder

\subsubsection{Ferramenta ACAD (Aquisição, Configuração e Análise dos}

\section{Dados)}

O propósito da ferramenta ACAD ( Figura 6.9) é prover ao usuário um ambiente que seja capaz de capturar e analisar os dados produzidos pelo monitoramento, através da geração de relatórios e histogramas, configurar a conexão da ferramenta com o monitor e 
realizar configurações no módulo de monitoramento para concluir a formatação do projeto de hardware do usuário.

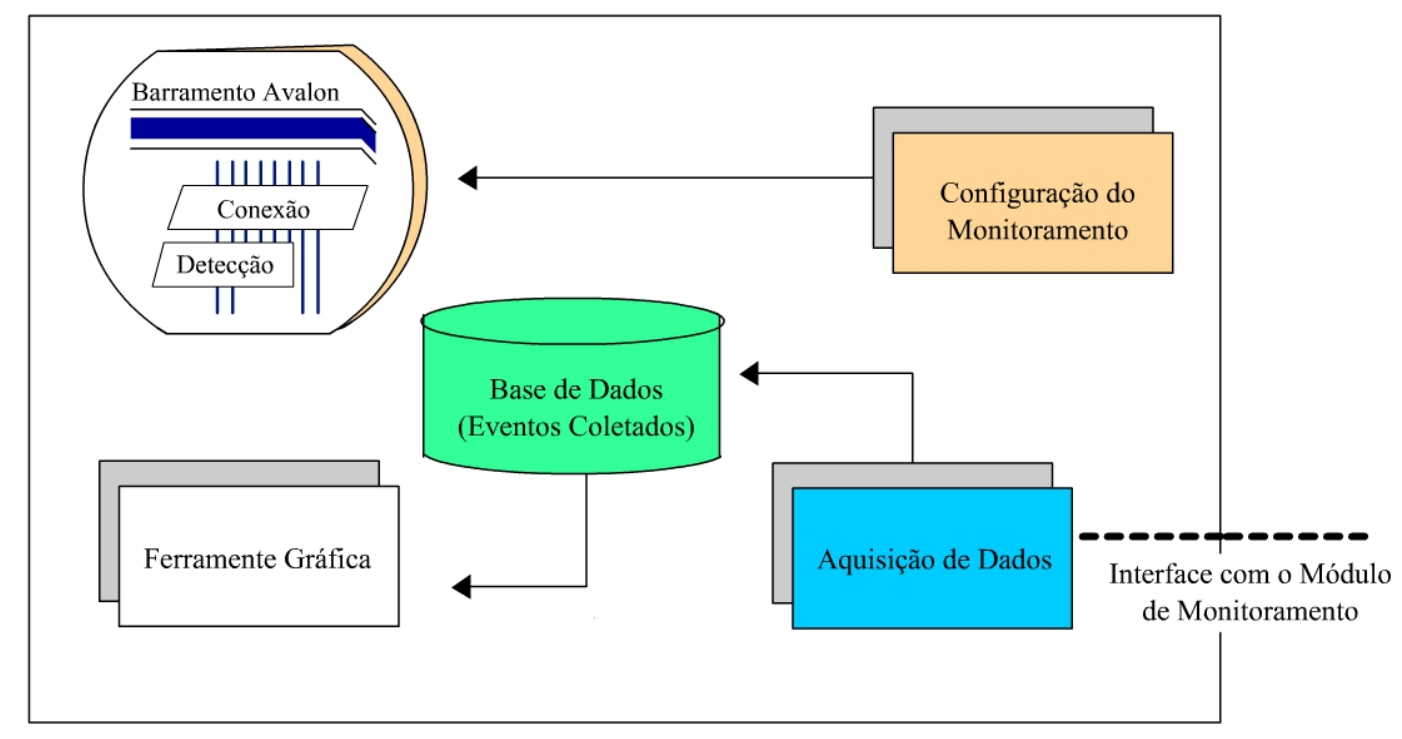

Figura 6.9: Estrutura de funcionalidades da aplicação

\subsubsection{Aquisição dos dados}

O processo de monitoramento deve ser iniciado e terminado através de inserções de rotinas no software que o usuário for monitorar. Estas rotinas estão definidas nas bibliotecas de acesso ao módulo de monitoramento. Uma vez ativado o processo de detecção e geração de eventos, o monitor iniciará o envio dos dados coletados para ferramenta ACAD em tempo de execução.

Os eventos coletados pelo módulo de monitoramento são transferidos para a ferramenta via uma conexão UART (a configuração necessária para ativar esta conexão será detalhada na seção 6.3.2.2 (Configuração do Monitoramento). Esta conexão, além de receber os dados provenientes do monitoramento, também permite que a ferramenta mantenha o módulo de monitoramento informado sobre sua capacidade de receber os eventos. A ferramenta envia um sinal de aviso, que é identificado pelo módulo de monitoramento, fazendo com que o módulo interrompa momentaneamente o envio de dados.

A ferramenta ACAD possui uma barra de progresso, responsável por informar ao usuário que o monitoramento esta em andamento. Este tipo de feedback é importante pois tranqüiliza o usuário e facilita o acompanhamento do envio de dados a ferramenta. 
Os eventos coletados são identificados pela ferramenta, na qual determina se o evento gerado é proveniente do monitoramento do software ou do hardware. Depois de identificados, a ferramenta os armazena em arquivos devidamente estruturados, para que os eventos ali registrados possam ser utilizados de forma otimizada na geração de relatórios e histogramas.

\subsubsection{Configuração do Monitoramento}

A configuração do monitoramento pode ser dividida em duas partes: (i) Configuração da conexão; (ii) Configuração do módulo de monitoramento. Estas configurações são necessárias, porque o usuário precisa definir alguns parâmetros de conexão como, velocidade de transmissão e também determinar quais os periféricos e/ ou memórias que serão monitorados.

- Configuração da Conexão

A conexão entre a ferramenta ACAD e o módulo de monitoramento só é estabelecida de forma correta, se ambas estiverem com os parâmetros devidamente configurados.

O módulo de monitoramento possui uma interface UART responsável por enviar os dados para a ferramenta ACAD, a configuração desta interface é feita durante o design do projeto na ferramenta SOPC Builder. Por outro lado, a ferramenta ACAD possui uma interface UART responsável por receber os dados provenientes do monitoramento. Para que estes dados cheguem de forma sincronizada e capaz de serem compreendidos pela ferramenta, é necessário que os valores dos parâmetros da interface UART sejam correspondentes aos valores instanciados na interface UART do módulo de monitoramento.

A Figura 6.10 ilustra a janela de configuração da porta UART com seus principais parâmetros.

- Configuração do Módulo de Monitoramento 


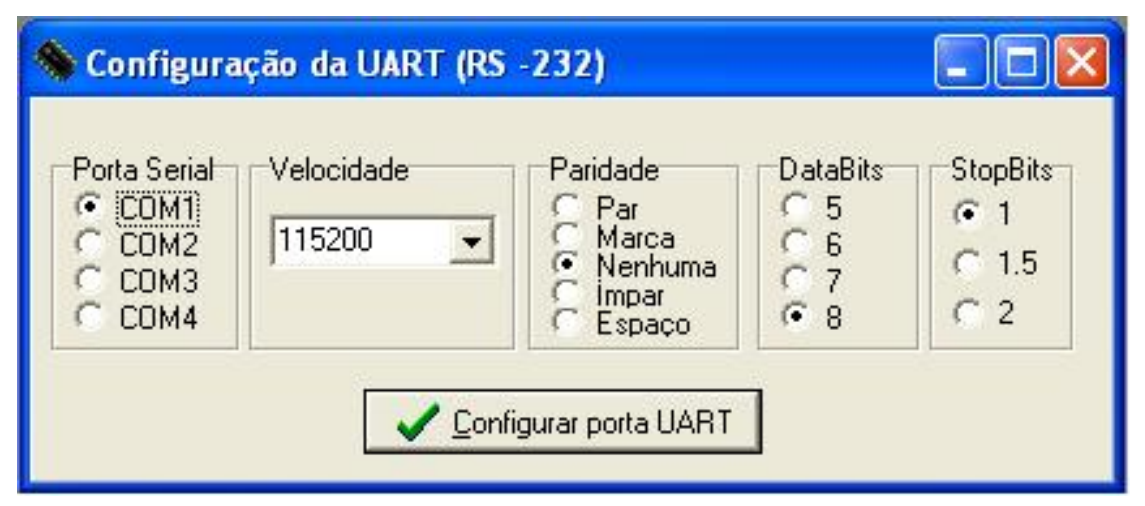

Figura 6.10: Configuração da interface UART

Para que o módulo de monitoramento possua a funcionalidade de detectar os eventos gerados pelo processador Nios II (tais como, acesso a algum dispositivo de armazenamento ou a execução de alguma instrução de load ou store, etc), sem que o monitoramento interfira no desempenho do processador é preciso construir uma ligação direta entre o módulo de monitoramento e o respectivo processador.

A construção desta ligação não é possível através da ferramenta SOPC Builder. Isto porque durante o design do projeto, o usuário define todas as interconexões entre os periféricos e o processador, para que o SOPC Builder possa gerar um barramento (barramento Avalon) capaz de conectar todos estes componentes. O problema é que esta ligação direta entre o módulo de monitoramento e o processador Nios II não pode ser feita através do barramento, porque o barramento Avalon só permite acesso aos sinais que são destinados ao módulo de monitoramento, não permitindo com isso acesso a todos os sinais que trafegam no barramento. Por estes motivos vê-se a necessidade de criar o Bloco de Conexão, que é construído pela ferramenta ACAD de modo automático, sendo apenas necessário a configuração de alguns parâmetros inerentes ao projeto do usuário (como pode-se ver na Figura 6.11).

Uma outra função da ferramenta ACAD é projetar o Bloco de Detecção. O usuário define quais os periféricos e dispositivos de armazenamento que ele pretende monitorar, de posse desta informação a ferramenta ACAD inicia o processo de concepção do bloco. Criando desta forma um Bloco de Detecção personalizado para cada monitoramento, fazendo com que a quantidade de lógica utilizada para realizar o 


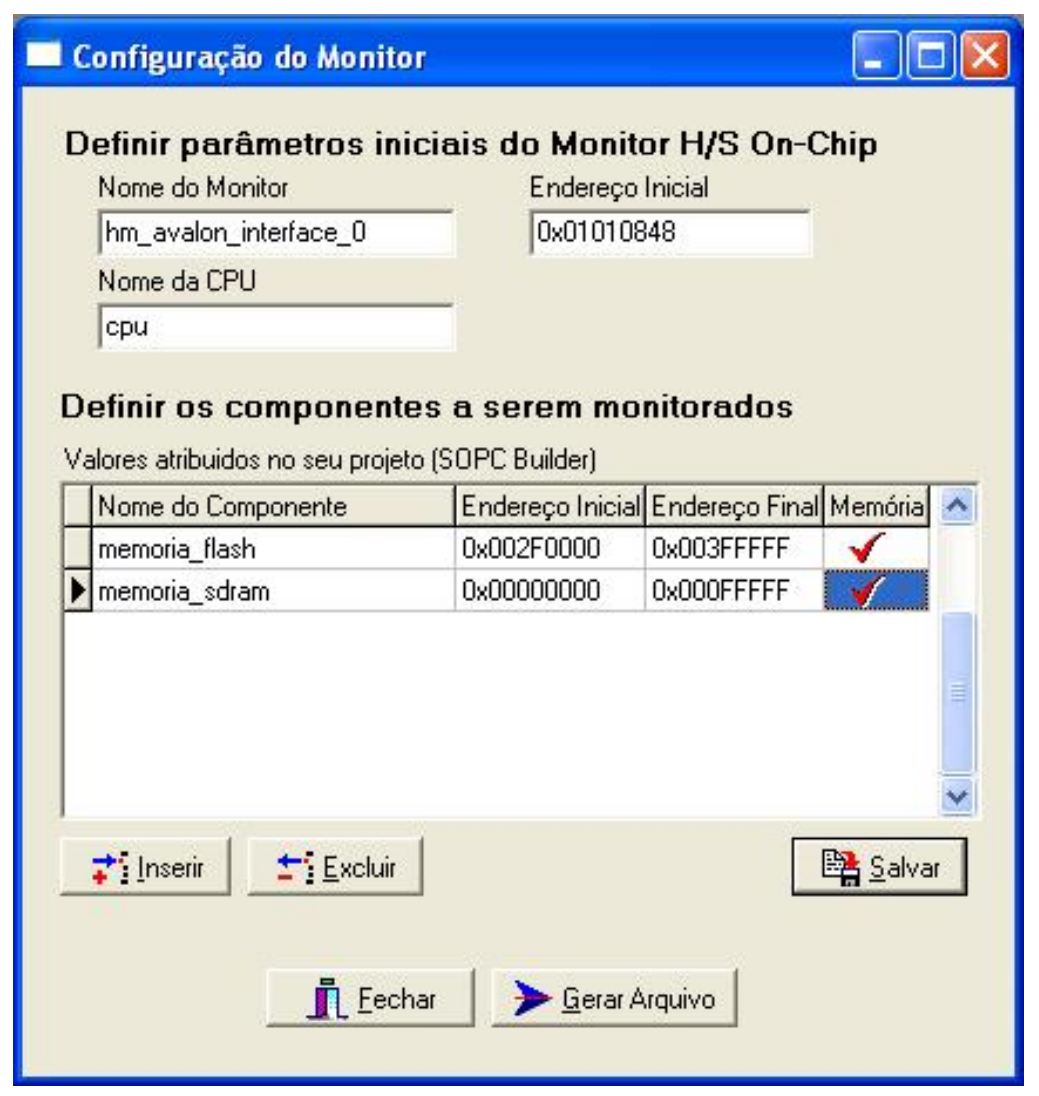

Figura 6.11: Configuração do Módulo de Monitoramento através da ferramenta ACAD

monitoramento seja a mais otimizada possível, minimizando e simplificando o projeto do módulo de monitoramento.Portanto, depois deste processo de configuração e geração dos blocos, a ferramenta ACAD terá finalizado as ligações do módulo de monitoramento, unindo o processador Nios II com os Blocos de Conexão e Detecção e unindo estes blocos ao módulo de monitoramento.

As funcionalidades do Bloco de Conexão e do Bloco de Detecção estão detalhadas na seção que aborda o módulo de monitoramento (seção 6.3.1.2).

\subsubsection{Análise dos dados}

A ferramenta ACAD proporciona algumas funcionalidades de análise de dados, que permitem ao usuário observar melhor o fluxo do monitoramento e interpretar de forma clara os dados coletados durante o monitoramento.

Um exemplo destas funcionalidades é o Histograma de Eventos, ilustrado na Figura 6.12. que mostra, seguindo uma linha do tempo de execução, os eventos gerados pelo 
software monitorado. Desta maneira, o usuário pode verificar em que momento cada bloco de programa foi iniciado e terminado, podendo compreender o fluxo do projeto e possivelmente encontrar algum erro de execução.

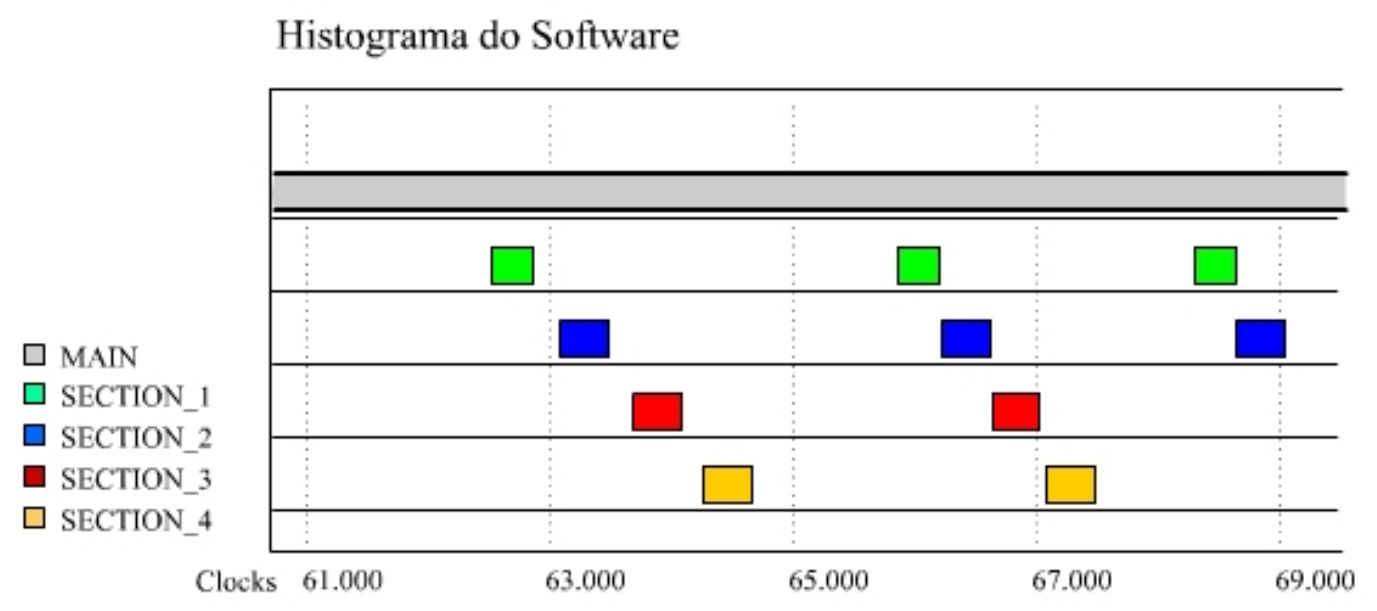

Figura 6.12: Parte de um histograma gerado pela ferramenta ACAD

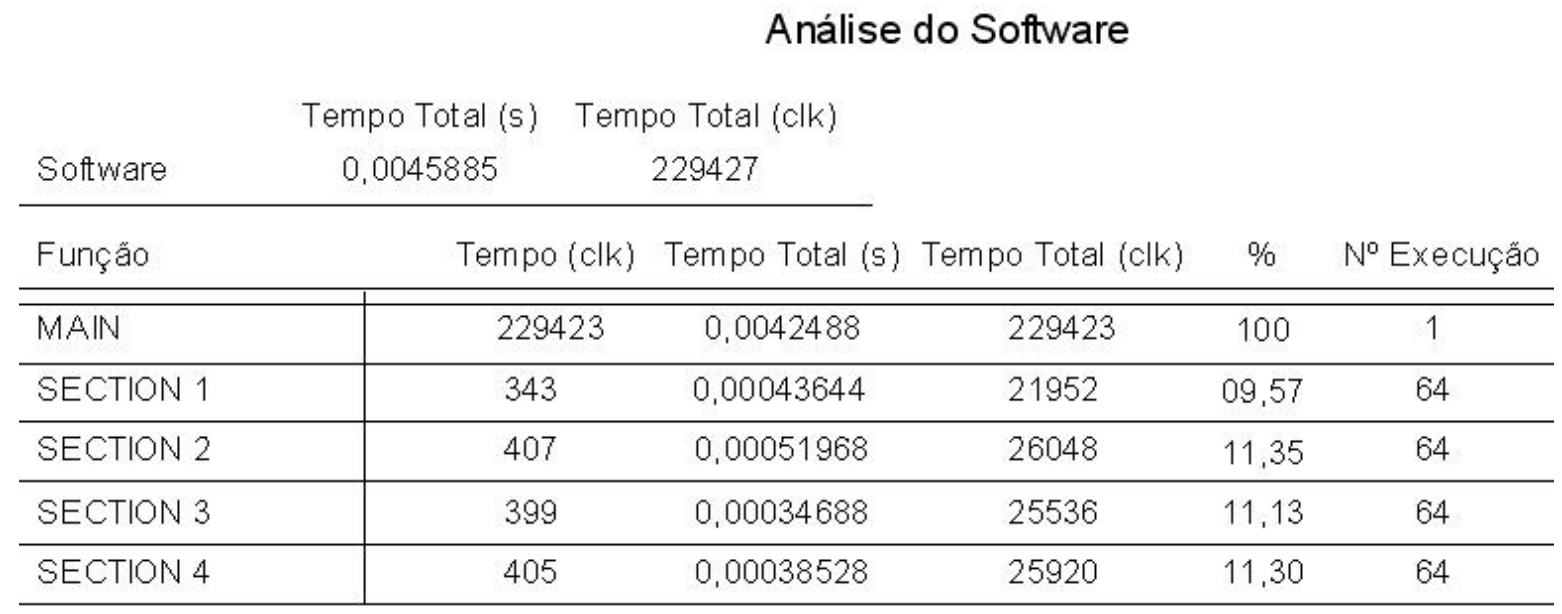

Figura 6.13: Exemplo de relatório sobre o monitoramento do software (ferramenta ACAD)

Um outro exemplo de funcionalidade são os relatórios gerados pela ferramenta. Relatório de Eventos de Software, ilustrado na Figura 6.13, que possui uma tabela com os dados coletados sobre o software contendo: o instante em que os blocos do programa foram iniciados, qual o tempo de execução em clocks ou em segundos, o número de vezes que cada bloco foi executado, etc. Relatório de Eventos de Hardware, ilustrado na Figura 6.14, que possui uma tabela com os dados coletados do processador Nios II contendo: O número de escrita e leitura de dados e leitura de instruções feita pelo processador em cada 
periférico ou memória e também quais foram as instruções executadas pelo processador e a quantidade de execução de cada uma.

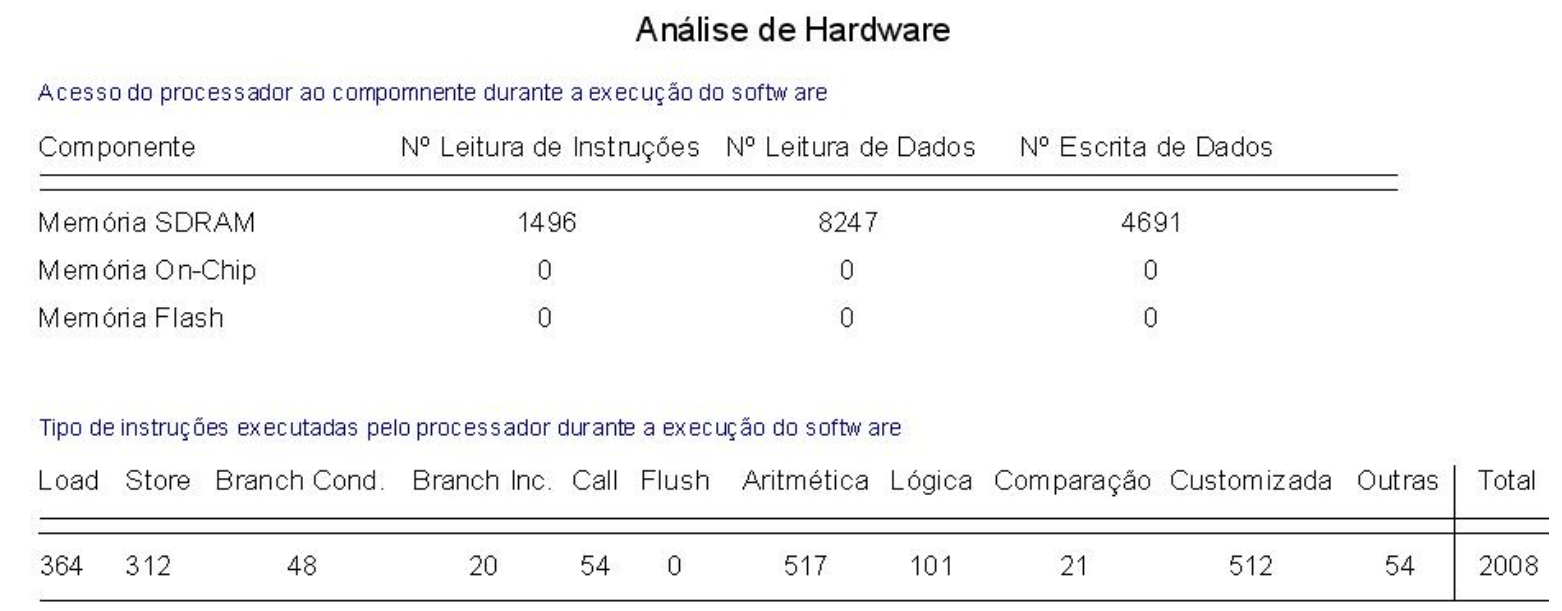

Figura 6.14: Exemplo de relatório sobre o monitoramento do hardware (ferramenta ACAD)

\subsubsection{Estrutura de Arquivos do Módulo de Monitoramento}

A estrutura de arquivos do módulo de monitoramento pode ser dividida em duas partes: (i) Componente de Hardware, que define uma estrutura de lógica aritmética, controle de fluxo e armazenamento de dados, além de pinos de conexão, pelos quais são coletadas e processadas as informações geradas pelo Nios II durante a execução do código do usuário; (ii) Componente de Software, que possibilita o acesso ao módulo de monitoramento pelo processador Nios II através da inserção de rotinas pré-definidas no software do usuário.

Como o módulo de monitoramento foi projetado para ser incorporado a ferramenta SOPC Builder, toda sua estrutura de arquivos foi implementada seguindo as recomendações da Altera [5], para que se adeque perfeitamente a ferramenta. Possibilitando desta forma, sua completa utilização sem a perda de performance ou interferência negativa no projeto do usuário.

É desejável que o componente de hardware tenha sua estrutura de arquivos divida em três partes: (i) Interface de conexão; (ii) Interface para os registradores; (iii) Interface para a lógica do módulo, proporcionando ao usuário uma estrutura de fácil entendimento 
das funcionalidades do mesmo, além de possibilitar a ampliação e manutenção do código por outros projetistas.

Pensando neste tipo de estrutura que o módulo de monitoramento foi projetado, como pode-se ver na Figura 6.15 .

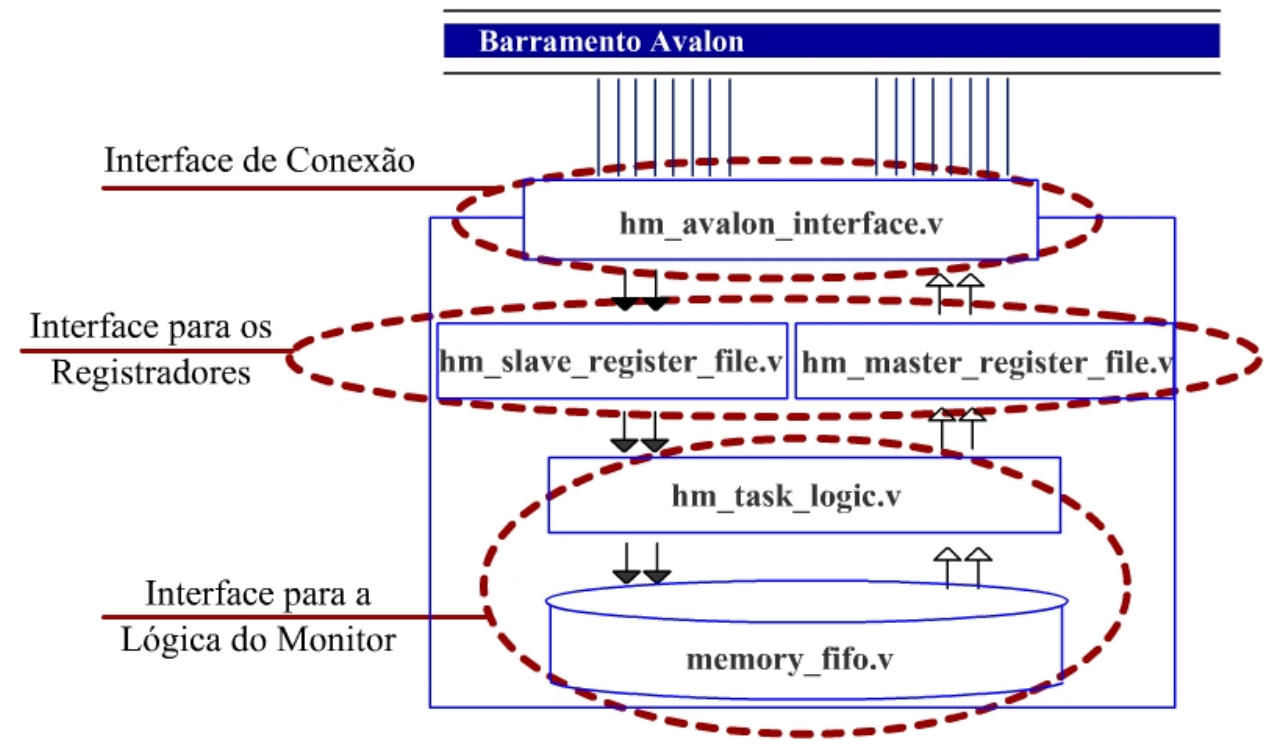

Figura 6.15: Estrutura de arquivos do Módulo de Monitoramento

A funcionalidade de cada arquivo que compõem o módulo de monitoramento é descrita a seguir na Tabela 6.1. Esta tabela descreve a estrutura do componente de hardware, iniciada pelo diretório / $h m_{-} h w$ e a estrutura do componente de software, que é iniciada pelo diretório /hm_sw.

\subsubsection{Utilizando o Sistema de Monitoramento}

Para que o processador Nios II possa ter acesso ao módulo de monitoramento, é necessário à definição de algumas funções, que ao serem adicionadas ao código do usuário são interpretadas pelo processador, possibilitando o acesso correto ao módulo de monitoramento.

A Tabela 6.2 ilustra as macros utilizadas para acessar a estrutura do módulo de monitoramento. Estas macros estão detalhadas no Apêncide A.

O endereço base do módulo de monitoramento é uma constante de hardware definida durante o design do projeto. Esta constante é definida no arquivo system.h pela ferra- 


\begin{tabular}{|c|c|}
\hline Nome do Arquivo & Descrição \\
\hline$/ h m_{-} h w$ & $\begin{array}{l}\text { Este diretório contém os arquivos HDLs que descrevem } \\
\text { o componente de hardware. }\end{array}$ \\
\hline hm_task_logic.v & $\begin{array}{l}\text { Este arquivo contém toda a lógica aritmética, detecção de } \\
\text { evento e controle de fluxo do módulo. }\end{array}$ \\
\hline memory_fifo.v & $\begin{array}{l}\text { Este arquivo contém a lógica para o armazenamento } \\
\text { temporário dos dados coletados. }\end{array}$ \\
\hline hm_slave_register_file.v & $\begin{array}{l}\text { Este arquivo contém a lógica para a leitura e escrita } \\
\text { dos registradores que são acessados pelo processador } \\
\text { Nios II. }\end{array}$ \\
\hline hm_master_register_file.v & $\begin{array}{l}\text { Este arquivo contém a lógica para a leitura e escrita dos } \\
\text { registradores que são utilizados para enviar dados ao } \\
\text { módulo UART. }\end{array}$ \\
\hline hm_avalon_interface.v & $\begin{array}{l}\text { Este arquivo instancia os arquivos de lógica do módulo, } \\
\text { os arquivos de registradores e prove uma interface ao } \\
\text { barramento Avalon. Este arquivo contém o módulo } \\
\text { principal (top-level) do projeto. }\end{array}$ \\
\hline$/ h m_{-} s w$ & $\begin{array}{l}\text { Este diretório contém os arquivos em linguagem } \mathrm{C} \text { que } \\
\text { descrevem a interface de software para o componente. }\end{array}$ \\
\hline /inc & $\begin{array}{l}\text { Este diretório contem os arquivos que definem uma } \\
\text { interface de baixo nível do hardware. }\end{array}$ \\
\hline altera_avalon_hm_routines.h & $\begin{array}{l}\text { Este arquivo contém os protótipos das macros que são } \\
\text { utilizadas para acessar o módulo de monitoramento. }\end{array}$ \\
\hline$/ H A L$ & $\begin{array}{l}\text { Este diretório contém os drivers } H A L \text { para o processador } \\
\text { Nios II. }\end{array}$ \\
\hline /inc & $\begin{array}{l}\text { Este diretório contém os arquivos que são incluídos no } \\
\text { desenvolvimento dos drivers. }\end{array}$ \\
\hline altera_avalon_hm_regs.h & $\begin{array}{l}\text { Este arquivo define as macros para acessar os } \\
\text { registradores do módulo de monitoramento. }\end{array}$ \\
\hline
\end{tabular}

Tabela 6.1: Estrutura de Arquivos do Módulo de Monitoramento

\begin{tabular}{|l|l|}
\hline Nome da Macro & \multicolumn{1}{c|}{ Descrição } \\
\hline \hline$M C_{-} S T A R T \_M E A S U R I N G()$ & $\begin{array}{l}\text { Inicia monitoramento, ativando os contadores e os } \\
\text { detectores de eventos de hardware. }\end{array}$ \\
\hline$M C_{-} S T O P \_M E A S U R I N G()$ & $\begin{array}{l}\text { Para o monitoramento, desativando os detectores } \\
\text { de eventos de software. }\end{array}$ \\
\hline$M C_{-}$BEGIN_SECTION() & Inicia o monitoramento da seção de código. \\
\hline$M C_{-} E N D \_S E C T I O N()$ & Finaliza o monitoramento da seção de código. \\
\hline$M C_{-} F I N A L I Z E()$ & Finaliza o monitoramento do sistema. \\
\hline
\end{tabular}

Tabela 6.2: Macros de acesso contitas no drive do Módulo de Monitoramento

menta SOPC Builder e é instanciada de acordo com o nome dado pelo usuário durante a configuração do módulo de monitoramento. Por exemplo, se o usuário nomear o módulo de monitoramento de monitor_core, a constante que representa o endereço base do com- 
ponente será definida como MONITOR_CORE_BASE. Esta constante deverá ser usada como parâmetro de entrada nas macros de acesso ao módulo de monitoramento.

Para realizar o monitoramento é necessário inserir as macros que ativam e desativam os contadores e o bloco de detecção, estas macros devem ser inseridas respectivamente no inicio e no fim do software monitorado.

Caso o usuário optar por monitorar somente o comportamento do hardware, apenas estas macros são utilizadas. Caso contrário, para cada bloco de código que for monitorado é preciso inserir as macros de ativação das seções, para cada seção que o usuário desejar monitorar.

Estas macros realizam um escrita simples no módulo de monitoramento, portanto não interferem de forma significativa no tempo de processamento.

A Figura 6.16 ilustra um exemplo de utilização das macros para monitorar o hardware e algumas seções do software do usuário.

Antes de carregar o software no hardware projetado e iniciar o monitoramento, é preciso configurar e ativar a ferramenta ACAD para que ela esteja pronta para receber os dados enviados pelo módulo de monitoramento.

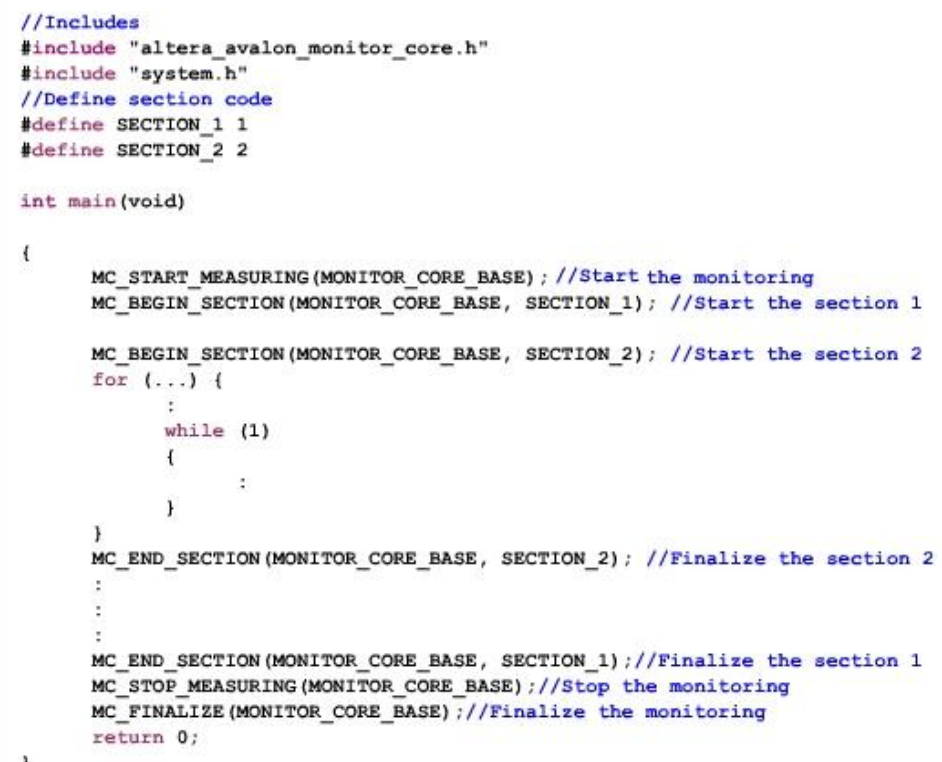

Figura 6.16: Exemplo de um Software com Macros de Monitoramento 


\subsection{Validação e Resultados}

\subsubsection{Processo de Validação}

Para a validação do sistema de monitoramento proposto neste trabalho, optou-se por avaliar um algoritmo (ver Apêndice B) que faz uma série de cálculos de transformadas discretas de cosseno rápidas (FDCT - Fast Discrete Cosine Transform). Algoritmos deste tipo são amplamente utilizados na compressão de imagens e vídeo, a fim de desassociar imagem ou dados residuais antes de algumas etapas da codificação.

A escolha deste algoritmo foi motivada pela sua relevância e por já ter sido matéria de estudo no Laboratório de Computação Reconfigurável (ver referencia [22]). Neste estudo realizado no LCR, foi feita uma análise de desempenho deste algoritmo através da inserção ou não de instruções customizadas a fim de verificar melhorias no tempo de execução. Para esta análise foi utilizado o módulo Performance Counter da Altera para a coleta destas informações.

Basicamente, é este tipo de análise que será feita neste algoritmo para que o sistema proposto seja validado. Para que se tenha algum parâmetro de análise dos dados coletados, foi feito um teste comparativo com a ferramenta Performance Counter da Altera. Desta forma, é possível verificar de maneira mais objetiva a qualidade dos dados coletados. Foi necessário uma nova coleta de dados deste algoritmo com o Performance Counter, devido a diferença de plataforma de desenvolvimento utilizada neste presente trabalho se comparado com o estudo anterior realizado no LCR. Tanto o algoritmo quanto a instrução customizada utilizada na validação do presente trabalho foram tiradas deste estudo (ver referencia [22]).

O hardware utilizado para a validação do sistema é composto de um processador (Nios II - configuração econômica) e um conjunto de memórias (SDRAM e memória On-Chip). Tanto o software quanto o hardware utilizado para a validação são testados na placa de desenvolvimento Nios - Edição Stratix.

É importante destacar que não é objetivo desta validação realizar uma análise de desempenho do algoritmo monitorado e sim enfatizar a qualidade dos dados coletados 
pelo Módulo de Monitoramento.

\subsubsection{Realização dos Experimentos}

Para que os experimentos fossem feitos, o algoritmo teve de ser modificado de forma que as principais operações da transformada fossem mapeadas para funções (Apêndice B), nomeadas como Section_1, Section_2, Section_3 e Section_4. Isso possibilita que o Módulo de Monitoramento ou o Performance Counter calcule o tempo gasto por cada uma dessas funções. O bloco de execução principal também foi mapeado, este bloco engloba todo o programa e foi nomeado como MAIN.

Foram realizados 4 (quatro) experimentos que são descritos a seguir. Todos os experimentos foram repetidos diversas vezes e os resultados se mantiveram praticamente iguais.

Os experimentos 1 (um) e 2 (dois) correspondem respectivamente ao Módulo de Monitoramento (MM) e ao Performance Counter (PC), analisando o algoritmo FDTC sem a adição de instruções customizadas. Os experimentos 3 (três) e 4 (quatro) correspondem respectivamente ao Módulo de Monitoramento (MM) e ao Performance Counter (PC), analisando o algoritmo FDTC com a adição de instruções customizadas.

Os dados coletados nestes monitoramentos são apresentados a seguir. Todas as informações geradas pelo PC e as informações referentes ao monitoramento do software geradas pelo MM foram aglutinadas em duas tabelas comparativas (Tabelas 6.3 e 6.5 relativas aos experimentos 1 (um) e 2 (dois) e os experimentos 3 (três) e 4 (quatro). Além destas tabelas, são apresentados dois histogramas (Figuras 6.17 e 6.18 ilustrando o comportamento do software em relação ao tempo de execução e duas tabelas (Tabelas 6.4 e 6.6) referentes aos dados oriundos do hardware monitorado. Estes histogramas e estas informações do hardware monitorado são gerados somente pelo MM, por isto, não tem dados comparativos com o PC. 


\begin{tabular}{|l|c|c|c|c|c|c|c|c|}
\hline \multicolumn{2}{|l|}{ Módulo de Monitoramento } & \multicolumn{2}{c|}{ Tempo T: 0.0045885 segs } & \multicolumn{2}{c|}{ Tempo T: 229427 clks } \\
\hline \multicolumn{3}{|c|}{ Performance Counter } & \multicolumn{2}{c|}{ Tempo T: 0.0047225 segs } & \multicolumn{2}{c|}{ Tempo T: 236125 clks } \\
\hline \hline Seção & \multicolumn{3}{|c|}{$\%$} & \multicolumn{2}{c|}{ Tempo (seg) } & \multicolumn{2}{c|}{ Tempo (clk) } & Ocorrência \\
\hline \hline & MM & PC & MM & PC & MM & PC & MM & PC \\
\hline MAIN & 100 & 100 & 0.0045882 & 0.00472 & 229413 & 236117 & 1 & 1 \\
\hline SECTION_1 & 09.57 & 09.37 & 0.0004390 & 0.00044 & 21952 & 22121 & 64 & 64 \\
\hline SECTION_2 & 11.35 & 12 & 0.0005210 & 0.00057 & 26048 & 28370 & 64 & 64 \\
\hline SECTION_3 & 11.13 & 11.8 & 0.0005107 & 0.00056 & 25536 & 27959 & 64 & 64 \\
\hline SECTION_4 & 11.30 & 13.5 & 0.0005184 & 0.00064 & 25920 & 31965 & 64 & 64 \\
\hline
\end{tabular}

Tabela 6.3: Dados comparativos entre o MM e o PC (sem instrução customizada)

Histograma do Software

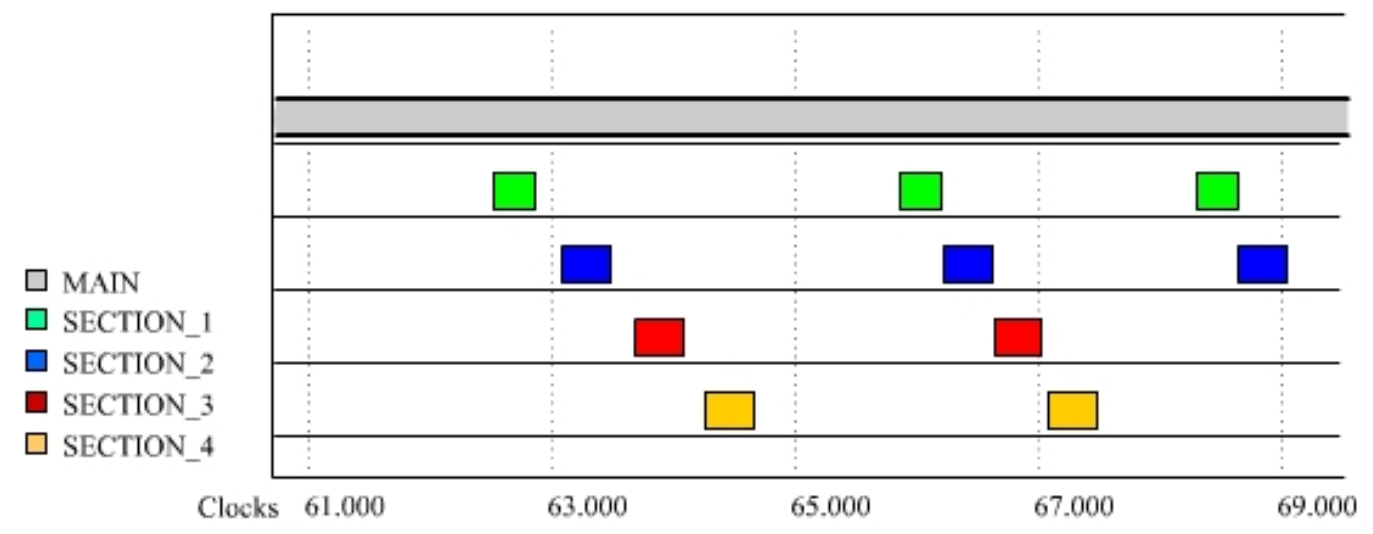

Figura 6.17: Parte do histograma sobre o comportamento do software (sem instrução customizada)

\begin{tabular}{|l|c|c|c|}
\hline \multicolumn{4}{|c|}{ Análise de Hardware } \\
\hline Acessos do processador ao componente durante a execução do software \\
\hline Componente & Leitura Instruções & Leitura Dados & Escrita Dados \\
\hline \hline Memória SDRAM & 1784 & 9328 & 4861 \\
\hline Memória On-Chip & 0 & 0 & 0 \\
\hline \multicolumn{4}{|c|}{} \\
\hline Conjunto de intruções executadas pelo processador durante a execução do software \\
\hline Conj. Intruções & Execuções & Conj. Intruções & Execuções \\
\hline \hline Load & 488 & Store & 385 \\
\hline Branch Cond. & 77 & Branch Inc. & 23 \\
\hline Call & 55 & Flush & 0 \\
\hline Aritmética & 562 & Lógica & 99 \\
\hline Comparação & 44 & Customizada & 0 \\
\hline Outras & 51 & Total & 1784 \\
\hline
\end{tabular}

Tabela 6.4: Dados do comportamento do hardware (sem instrução customizada) 


\begin{tabular}{|l|c|c|c|c|c|c|c|c|}
\hline \multicolumn{2}{|c|}{ Módulo de Monitoramento } & \multicolumn{2}{c|}{ Tempo T: 0.0042488 segs } & \multicolumn{2}{c|}{ Tempo T: 212448 clks } \\
\hline \multicolumn{2}{|c|}{ Performance Counter } & \multicolumn{2}{c|}{ Tempo T: 0.00435842 segs } & \multicolumn{2}{c|}{ Tempo T: 217921 clks } \\
\hline \hline Seção & \multicolumn{2}{|c|}{$\%$} & \multicolumn{2}{c|}{ Tempo (seg) } & \multicolumn{2}{c|}{ Tempo (clk) } & Ocorrência \\
\hline \hline & MM & PC & MM & PC & MM & PC & MM & PC \\
\hline MAIN & 100 & 100 & 0.0042487 & 0.00436 & 212437 & 217883 & 1 & 1 \\
\hline SECTION_1 & 10.27 & 10.2 & 0.0004364 & 0.00044 & 21824 & 22191 & 64 & 64 \\
\hline SECTION_2 & 12.23 & 12.2 & 0.0005197 & 0.00053 & 25984 & 26521 & 64 & 64 \\
\hline SECTION_3 & 08.16 & 10.2 & 0.0003469 & 0.00045 & 17344 & 22298 & 64 & 64 \\
\hline SECTION_4 & 09.06 & 10.1 & 0.0003853 & 0.00044 & 19264 & 22087 & 64 & 64 \\
\hline
\end{tabular}

Tabela 6.5: Dados comparativos entre o MM e o PC (com instrução customizada)

Histograma do Software

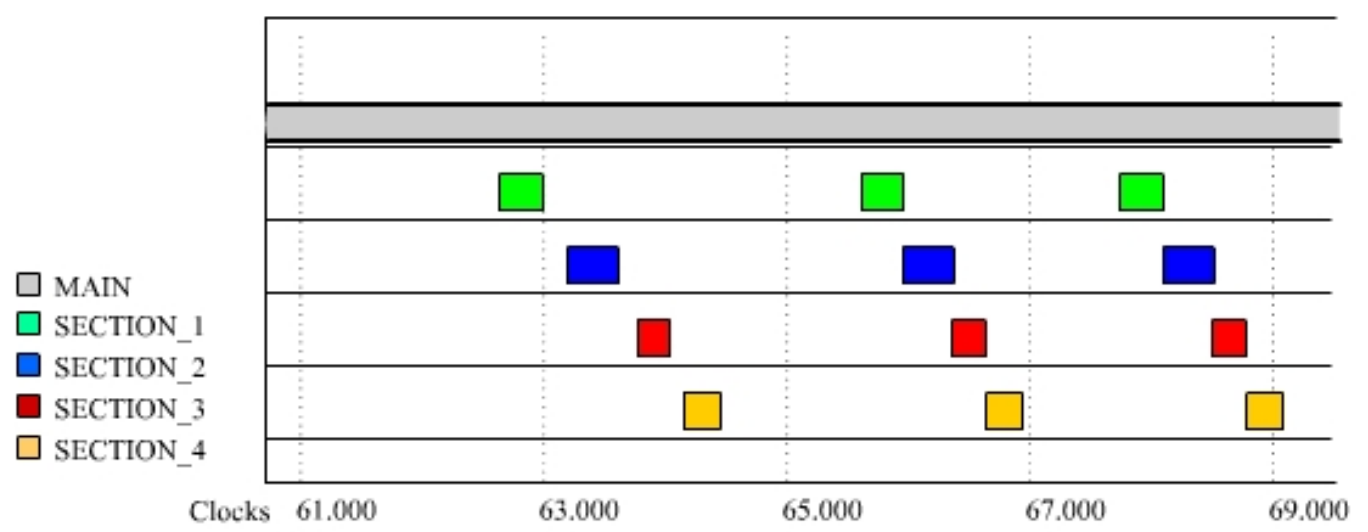

Figura 6.18: Parte do histograma sobre o comportamento do software (com instrução customizada)

\begin{tabular}{|l|c|c|c|}
\hline \multicolumn{4}{|c|}{ Análise de Hardware } \\
\hline Acessos do processador ao componente durante a execução do software \\
\hline Componente & Leitura Instruções & Leitura Dados & Escrita Dados \\
\hline \hline Memória SDRAM & 1496 & 8247 & 4691 \\
\hline Memória On-Chip & 0 & 0 & 0 \\
\hline \multicolumn{4}{|l|}{} \\
\hline Conjunto de intruções executadas pelo processador durante a execução do software \\
\hline Conj. Intruções & Execuções & Conj. Intruções & Execuções \\
\hline \hline Load & 364 & Store & 312 \\
\hline Branch Cond. & 48 & Branch Inc. & 20 \\
\hline Call & 54 & Flush & 0 \\
\hline Aritmética & 517 & Lógica & 101 \\
\hline Comparação & 21 & Customizada & 512 \\
\hline Outras & 54 & Total & 2008 \\
\hline
\end{tabular}

Tabela 6.6: Dados do comportamento do hardware (com instrução customizada)

\subsubsection{Análise dos Resultados}

Através da análise comparativa entre os dados gerados pelo MM e pelo PC pode-se ver uma enorme semelhança nos resultados duas ferramentas. Sendo importante ressaltar que 
mesmo tendo o HB (Hardware Base - composto pelo processador e por periféricos) igual, por meio da adição do Performance Counter o hardware final (HB + PC) se transforma em um hardware diferente se comparado ao HB adicionado com o Módulo de Monitoramento (Figura 6.19). Esta pequena alteração no hardware final explica a ligeira diferença nos dados coletados das duas ferramentas, além dos detalhes de implementação de cada uma.
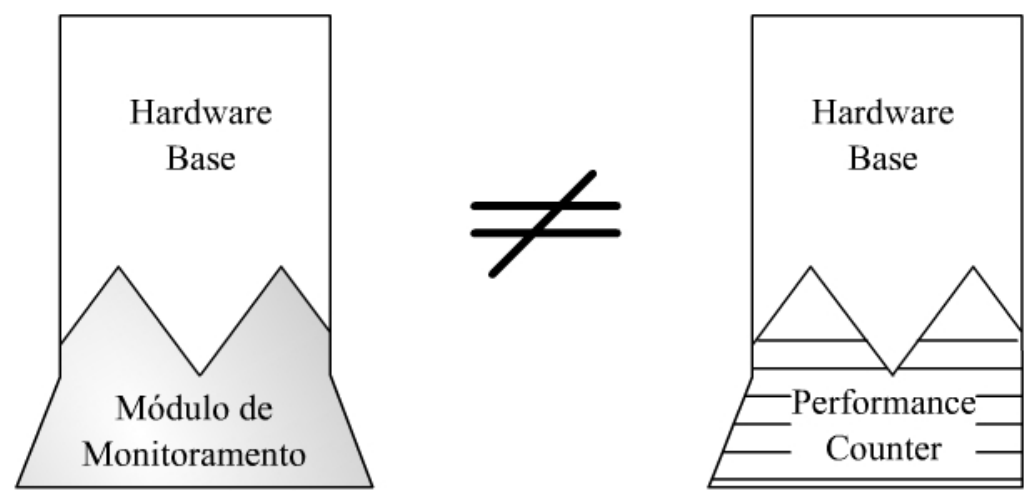

Figura 6.19: Diferença entre o hadware composto pelo MM e o composto pelo PC

Analisando a Tabela 6.3 nota-se que vários valores ficaram muito próximos como, por exemplo, o tempo total de execução, a porcentagem que cada seção teve em relação ao tempo total de execução do algoritmo, etc. A mesma análise pode ser feita na Tabela 6.5. Se compararmos as Tabelas 6.3 e 6.5 nota-se novamente a semelhança entre os dados coletados pelas duas ferramentas. O tempo total de monitoramento caiu praticamente nas mesmas proporções, comparando-se o algoritmo sem instrução customizada e com instrução customizada. Da mesma forma ocorreu com as seções Section_2, Section_3, Section_4 (cada uma influenciada pelo tipo e pelo número de instruções customizadas empregadas). Por último, pode-se verificar que a seção Section_1 praticamente não alterou seu tempo de execução devido à ausência de instruções customizadas permanecendo, portanto, igual em todos os experimentos.

O Módulo de Monitoramento, como já dito, também coleta dados sobre o comportamento do hardware durante a execução do software monitorado. Como estas informações não podem sem comparadas com o Performance Counter, optou-se por citar algumas análises que podem ser feitas por meio destes dados. Comparando as Tabelas 6.4 e 6.6 é possível ver que: 
- O algoritmo com instrução customizada faz com que o processador acesse menos a memória SDRAM na busca por instruções ou para armazenar dados temporários. Isso porque a instrução customizada faz várias operações por conta própria, retornando o resultado após concluir a operação. Além disso, o processador Nios II possui uma ligação direta com o módulo que executa a instrução customizada, permitindo que o Nios II execute a instrução sem ter que passar pela ULA (Unidade Lógica Aritmética) ou ocupar recursos do barramento.

- O algoritmo sem instrução customizada por outro lado, obrigou o processador Nios II a executar mais instruções nativas, podendo destacar as instruções aritméticas que teve um ganho de aproximadamente $10 \%$ em relação ao algoritmo com instrução customizada.

- Os dados utilizados pelo processador para a execução do programa ficam armazenados na memória SDRAM e este algoritmo não faz nenhum acesso a outro dispositivo de armazenamento, por este motivo é que a memória SDRAM foi à única acessada.

Como se pode ver, existem várias formas de analisar os dados coletados pelo Módulo de Monitoramento, cabendo ao usuário decidir quais os dados que mais lhe interessam. Além dos dados numéricos fornecidos pelos relatórios a ferramenta ACAD também proporciona ao usuário histogramas, permitindo um melhor entendimento do fluxo de execução do software analisado. Como, por exemplo, as duas partes de histogramas destacados nas Figuras 6.17 e 6.18, que em uma análise comparativa rápida, o usuário teria percebido perfeitamente que o algoritmo com instrução customizada é executado mais rapidamente, além de poder quantificar de forma visual a participação que cada seção tem no tempo de execução.

O relatório fornecido pelo Performance Counter detalha somente os dados sobre o comportamento do software de um modo geral e o Sistema de Monitoramento proposto neste trabalho além de obter estas informações coletadas pelo PC, constrói um histograma ilustrando o comportamento do software em relação ao tempo de execução e principalmente, fornece um conjunto de informações do comportamento do hardware durante a 
execução do software analisado. Entretanto, o uso do PC para a validação deste projeto foi de grande valia, pois esta ferramenta é muito utilizada na análise de desempenho de softwares executados sobre plataformas reconfiguráveis, além de ser uma ferramenta projetada pela Altera, uma das maiores fabricantes de FPGAs.

\subsection{Considerações Finais}

Neste capítulo foram apresentados todos os detalhes da implementação do sistema de monitoramento proposto neste trabalho. Para melhor compreensão, este capítulo também detalhou o desenvolvimento de um projeto composto de hardware e software, além de dedicar uma seção para exemplificar o uso do sistema de monitoramento em um software fictício.

No próximo capítulo serão apresentadas as conclusões, ressaltando os pontos mais relevantes oriundos deste trabalho e citando alguns trabalhos que possam ser feitos futuramente para expandir este sistema de monitoramento. 


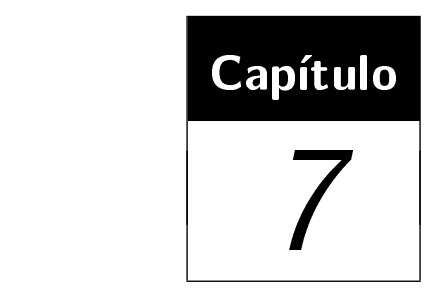

\section{Conclusões}

A construção do módulo de monitoramento foi de crucial importância para as pesquisas do Laboratório de Computação Reconfigurável (LCR). Este módulo possibilita uma melhor análise e compreensão dos projetos embarcados que serão num futuro próximo desenvolvidos.

A implementação de todo o módulo utilizando-se a linguagem de descrição de hardware Verilog demonstrou-se robusta e bastante eficiente, além de tornar a implementação independe do hardware em que se deseja aplicar.

A utilização de ferramentas EDA foi determinante para a conclusão deste projeto, pois auxiliou bastante no processo de simulação e depuração do mesmo, uma vez que que estas ferramentas permitem criar testes mais completos, que respondam aos sinais do módulo projetado. O uso da placa Stratix da Altera, que é composta basicamente por uma FPGA da família Stratix e alguns circuitos auxiliares, possibilitou o pleno desenvolvimento do sistema apresentado neste trabalho.

Todos os objetivos iniciais deste trabalho foram atingidos através da criação de um módulo de monitoramento capaz de extrair informações importantes sobre a execução do hardware e do software, sem interferência no sistema monitorado. Assim, este projeto atende as necessidades de monitoramento e análise dos sistemas desenvolvidos no laboratório (indispensável em sistemas embarcados), principalmente nos tempos atuais, 
quando se deseja otimizar ao máximo o uso de recursos lógicos dos projetos de hardware e uma depuração mais completa.

A integração com o SoPC Builder da Altera é outro ponto positivo deste projeto, de modo a disponibilizar o monitor como um componente da biblioteca (core). Isto é fundamental para que outros usuários possam inserir o módulo de monitoramento da maneira mais fácil possível em seu projeto, agilizando o tempo de desenvolvimento do mesmo.

Por envolver diversas áreas de conhecimento tais como: arquitetura de processadores, sistemas de monitoramento, projeto de hardware com HDL, manipulação de cores, conhecimento de sinalização de barramento, e compreensão da tecnologia de hardware reconfigurável (FPGA), este trabalho foi de suma importância para o crescimento intelectual do mestrando.

\subsection{Trabalhos Futuros}

Alguns dos trabalhos futuros que podem ser realizados para a continuidade desta pesquisa são:

- Implementar uma interface de comunicação mais veloz entre o módulo de monitoramento e a ferramenta de ACAD: uma interface paralela ou uma interface USB. Como o número de eventos gerados através de um monitoramento de hardware é muito elevado. Torna-se importante o aumento da taxa de transmissão destes dados armazenados na memória temporária do módulo para a ferramenta de análise, para que não haja perda de dados e o comprometimento do monitoramento.

- Incorporar mais funcionalidades a ferramenta ACAD como, a possibilidade de se realizar uma análise mais profunda dos dados coletados e fornecer ao usuário um relatório contendo os possíveis lugares de gargalo do projeto e indicar alternativas de melhorias. Atualmente, cabe ao usuário a interpretação destes dados.

- Incorporar algumas funcionalidades de depuração ao projeto como, a possibilidade de interromper a qualquer momento o processador, para que o usuário analise to- 
das as varáveis do projeto o instante que desejar. Aproveitando que o módulo de monitoramento já possui uma comunicação direta com o processador. 


\section{Referências Bibliográficas}

[1] ACM/UIUC; Reconfigurable Computing: Using FPGAs to build dynamically reconfigurable computers. , Disponível em: http://www.acm.uiuc.edu/sigarch/projects/reconf, 1995. (Acessado 01/2007).

[2] Altera; Avalon Bus Specification Reference Manual. Altera Corp. Disponível em http://www.altera.com, julho de 2003. (Acessado em 10/2006).

[3] Altera; Nios II Software Developer's Handbook. Altera Corp. Disponível em http://www.altera.com, maio de 2006. (Acessado em 10/2006).

[4] Altera; Performance Counter Core with Avalon Interface. Altera Corp. Disponível em http://www.altera.com, dezembro de 2005. (Acessado em 01/2007).

[5] Altera; Quartus II Version 6.0 Handbook and Volume 4: SOPC Builder. Altera Corp. Disponível em http://www.altera.com, abril de 2006. (Acessado em 09/2006).

[6] Altera; Design Debugging Using the SignalTap II Logic Analyzer. Altera Corp. Disponível em http://www.altera.com, dezembro de 2005. (Acessado em 01/2007).

[7] Altera; Stratix II Device Handbook. Altera Corp. Vol. 1, v. 1.2, Oct 2004. Disponível em http://www.altera.com. (Acessado em 07/2006).

[8] Altera; UART Core with Avalon Interface. Altera Corp. Disponível em http://www.altera.com, dezembro de 2005. (Acessado em 03/2006).

[9] ARM; Embedded Trace Macrocell. ARM White Papers. Disponível em: http://www.arm.com/products/solutions/ETM.html. (Acessado 10/2006).

[10] ARM; Embedded Trace Macrocell (ETM) Performance Characteristics Clive Watts, ETM Product Manager, ARM White Papers. Disponível em http://www.arm.com, julho de 2001. (Acessado em 09/2006). 
[11] Bergamaschi, R. A.; Bhattacharya, S.; Wagner, R.; Fellenz, C.; Muhlada, M.; White, F.; Daveau, J. M.; Lee, W. R.; Automating the design of SOCs using cores. In IEEE Design $\&$ Test of Computers, vol. 18, n. 5, Sept. 2001, pp. 32 -45.

[12] Calvez J.P.; Pasquier O.; Performance Monitoring and Assessment of Embedded HW/SW Systems. In Design Automation for Embedded Systems journal, vol. 2, Kluwer Academic Publishers, 1997.

[13] Case, J.; Gupta, N.; Mittal, J.; Ridgeway, D.; Design Methodologies for Core-Based FPGA Designs. XILINX Publications, http://www.xilinx.com, April 1997.

[14] Chan, P. K.; Mourad, S.; Digital Design Using Field-Programmable Gate Arrays. Prentice Hall, 1994.

[15] Charles E. McDowell; David P. Helmbold.; Debugging Concurrent Programs In ACM Computing Surveys, vol. 21, n. 4, pp. 593-621, Dec. 1989.

[16] Chassin de Kergommeaux, J.; Maillet, E.; Vincent, J. M.; Monitoring Parallel Programs for Performance Tuning in Cluster Environments. In J. Cunha, et al. (Eds.), Parallel Program Development for Cluster Computing: Methodology, Tools and Integrated Environments, vol. 5, Nova Science, 2001, Chapter 6, pp. 131-150.

[17] Chodrow, S.; Jahanian, F.; Donner, M.; Run-Time Monitoring of Real-Time Systems In Proc. IEEE Real-Time Systems Symposium, IEEE Computer Society Press, 1991, pp. 74-83.

[18] Compton K.; Hauck S.; An introduction to reconfigurable computing. IEEE Computer, 2000.

[19] ANSI/TIA/EIA; 9-Position Non-Synchronous Interface between Data Terminal Equipment and Data Circuit-Terminating Equipment Employing Serial Binary Data Interchange. Reaffirmation and redesignation of ANSI/TIA/EIA 574-1990 (R1998), pag. 574-1990 (R2003), maio de 2003.

[20] Habibi, A.; Tahar, S.; A Survey: System-on-a-Chip Design and Verification. Technical Report, Concordia University, Department of Electrical and Computer Engineering, Jan. 2003.

[21] Hadley, J. D.; Hutchings, B. L.; Design methodologies for partially reconfigured systems. In IEEE Workshop on FPGAs For Custom Computing Machines, pp.78-84, 1995.

[22] Holanda, J.A.M.; Projeto de blocos do codificador de vídeo H.264/AVC em hardware reconfigurável. Monografia de conclusão de curso do Instituto de Ciências Matemática e Computacional, Universidade de São Paulo, São Carlos, novembro de 2005. 
[23] IEEE Standard Description Language Based on the Verilog Hardware Description Language. Std 1364, 2001.

[24] IEEE Standard VHDL Language Reference Manual. Std 1076, 2002.

[25] John, L.; Performance Evaluation: Techniques, Tools and Benchmarks. In The Computer Engineering Handbook, CRC Press, 2001.

[26] Kirschbaum, A.; Becker, J.; Glesner, M.; Run-Time Monitoring of Communication Activities in a Rapid Prototyping Environment In Darmstadt University of Technology, Institute of Microelectronic Systems, D-64283 Darmstadt, Germany, 1998.

[27] Lennart Lindh, Tommy Klevin, and Johan Furunäs; Scalable architectures for realtime applications - SARA. In CAD \& CG'99, December 1999.

[28] MacDougall, M. H.; Nios II Processor Reference Handbook. Altera Corp. Disponível em http://www.altera.com/literature/lit-nio2.jsp, 2005. (Acessado em 02/2005).

[29] Malony A. D.; Reed D. A.; Wijshoff H. A. G.; Performance measurement intrusion and perturbation analysis. In IEEE Trans. on Parallel and Distributed Systems, pp. 433-450, Jul 1992.

[30] Marinissen, E. J.; Zorian, Y.; Kapur, R.; Taylor, T.; Whetsel, L.; Towards a Standard for Embedded Core Test: An Example In IEEE International Test Conference, 1999, pp. 616-626.

[31] Mellin, J.; Resource-Predictable and Efficient Monitoring of Events. In PhD thesis, Department of Computer Science, University of Skovde, June 2004.

[32] Morris, K.; In FPGA and Programmable Logic Journal, Feb. 2004. Disponível em http://www.fpgajournal.com/articles/stratix2.htm. (Acessado em 03/2005).

[33] Nagy, Z; HW/SW Co-design of embedded systems within Alteras design environment. Mälardalen Real-Time Research Centre, Mälardalen University, Fevereiro de 2006.

[34] Rincon, A. M.; Cherichetti, C.; James, A. M.; Stauffer, D. R.; Trick, M. T.; Core Design and System-on-a-chip Integration. In IEEE Design 8 Test of Computers, vol. 14, n. 4, Out-Dez. 1997, pp. 26-35.

[35] Shobaki, M. E.; On-Chip Monitoring for Non-Intrusive Hardware/ Software Observability. In Dissertation for the degree of Licentiate of Technology in Computer System at Uppsala University, 2004.

[36] SIA - Semiconductor Industry Association; The National Technology Roadmap for Semiconductors. Disponível em: http://public.itrs.net/files/1999_SIA_Roadmap/, 1999. (Acessado 03/2005). 
[37] Snodgrass R.; A relational approach to monitoring complex systems. In ACM Transactions on Computer Systems, vol. 6, n. 2, pp. 157-196, 1988.

[38] Steve Chamberlain, Roland Pesch, Jeff Johnston, and Red Hat Support. The red hat newlib c library Red Hat, Inc. Janeiro 2004.

[39] Wolf, W. H.; Hardware-software Co-Design of embedded systems. In Proceedings of the IEEE, vol. 82, n. 7, jul. 1994, pp 967-989.

[40] Xilinx; ChipScope Pro at a Glance. Xilinx, Inc. Disponível em http://www.xilinx.com, 2005. (Acessado 10/2006).

[41] Zorian,Y.; Gupta, R. K.; Introduction to Core-Based Design. In 1EEE Design and Test of Computers, Oct. 1997 


\section{Apêndice A}

Descrição das macros que são utilizadas para acessar a estrutura do módulo de monitoramento.

\begin{tabular}{|l|l|}
\hline Nome da Macro & \multicolumn{1}{c|}{$M C_{-} S T A R T \_M E A S U R I N G()$} \\
\hline \hline Protótipo: & MC_START_MEASURING(p1) \\
\hline Parâmetro: & o p1: Endereço base do módulo de monitoramento. \\
\hline Retorno: & Não tem retorno. \\
\hline Arquivo: & altera_avalon_monitor_core.h \\
\hline Descrição & $\begin{array}{l}\text { Inicia monitoramento, ativando os contadores e os } \\
\text { detectores de eventos de hardware. }\end{array}$ \\
\hline
\end{tabular}

Tabela 8.1: Macro que Ativa o Módulo de Monitoramento.

\begin{tabular}{|l|l|}
\hline Nome da Macro & \multicolumn{1}{|c|}{$M C_{-} S T O P \_M E A S U R I N G()$} \\
\hline \hline Protótipo: & MC_STOP_MEASURING()(p1) \\
\hline Parâmetro: & o p1: Endereço base do módulo de monitoramento. \\
\hline Retorno: & Não tem retorno. \\
\hline Arquivo: & altera_avalon_monitor_core.h \\
\hline Descrição & $\begin{array}{l}\text { Para o monitoramento, desativando os detectores } \\
\text { de eventos de software. }\end{array}$ \\
\hline
\end{tabular}

Tabela 8.2: Macro que Desativa o Módulo de Monitoramento.

\begin{tabular}{|l|l|}
\hline Nome da Macro & \multicolumn{1}{c|}{$M C_{-}$BEGIN_SECTION() } \\
\hline \hline Protótipo: & MC_BEGIN_SECTION()(p1,p2) \\
\hline Parâmetro: & $\begin{array}{l}\text { o p1: Endereço base do módulo de monitoramento. } \\
\text { o p2: Número da seção. A seção sempre inicia no } \\
\text { número 1(um). }\end{array}$ \\
\hline Retorno: & Não tem retorno. \\
\hline Arquivo: & altera_avalon_monitor_core.h \\
\hline Descrição & Inicia o monitoramento da seção de código. \\
\hline
\end{tabular}

Tabela 8.3: Macro que Inicia o Monitoramento de uma Seção. 


\begin{tabular}{|l|l|}
\hline Nome da Macro & \multicolumn{1}{c|}{$M C_{-} E N D \_S E C T I O N()$} \\
\hline \hline Protótipo: & MC_END_SECTION()(p1,p2) \\
\hline Parâmetro: & $\begin{array}{l}\text { o p1: Endereço base do módulo de monitoramento. } \\
\text { o p2: Número da seção. A seção sempre inicia no } \\
\text { número 1(um). }\end{array}$ \\
\hline Retorno: & Não tem retorno. \\
\hline Arquivo: & altera_avalon_monitor_core.h \\
\hline Descrição & Finaliza o monitoramento da seção de código. \\
\hline
\end{tabular}

Tabela 8.4: Macro que Finaliza o Monitoramento de uma Seção.

\begin{tabular}{|l|l|}
\hline Nome da Macro & \multicolumn{1}{|c|}{ MC_FINALIZE() } \\
\hline \hline Protótipo: & MC_FINALIZE()(p1) \\
\hline Parâmetro: & o p1: Endereço base do módulo de monitoramento. \\
\hline Retorno: & Não tem retorno. \\
\hline Arquivo: & altera_avalon_monitor_core.h \\
\hline Descrição & Finaliza o monitoramento do sistema. \\
\hline
\end{tabular}

Tabela 8.5: Macro que Finaliza o Monitoramento. 


\section{Apêndice B}

Código-fonte da Transformada Rápida Discreta de Cosseno [22] modificada para utilizar o Sistema de Monitoramento proposto neste trabalho.

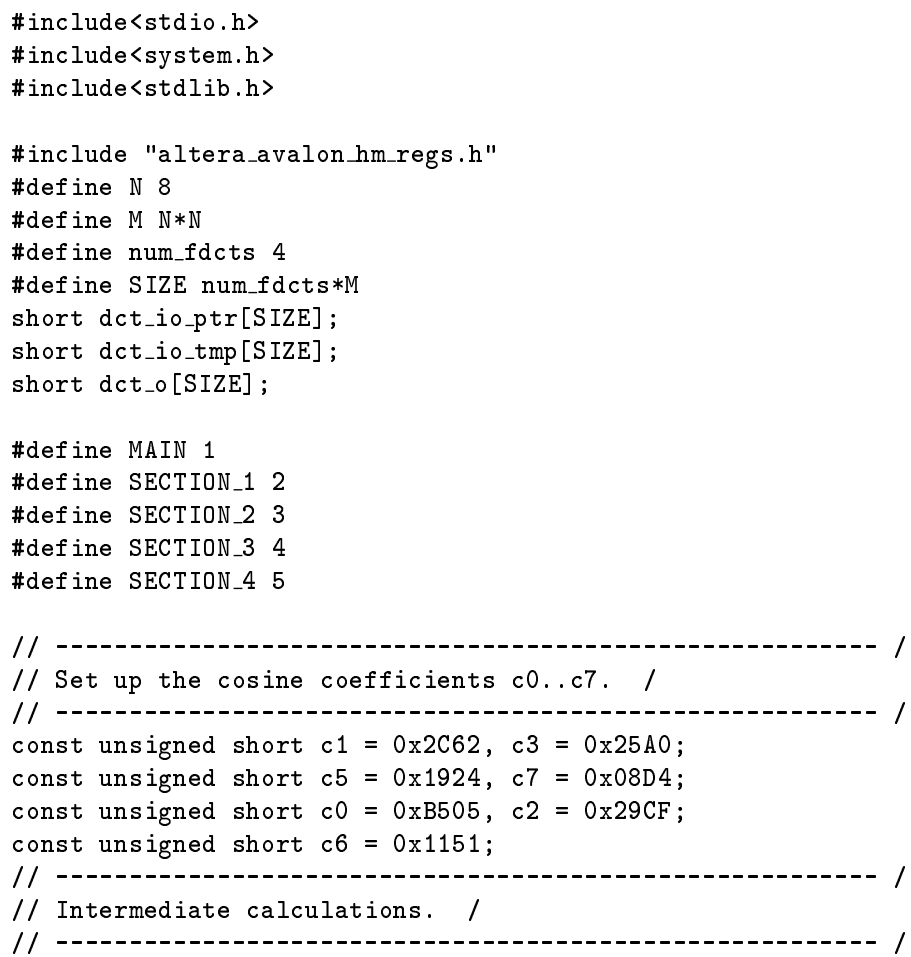

short $f 0, f 1, f 2, f 3, f 4, f 5, f 6, f 7 ; / /$ Spatial domain samples. int g0, g1, h0, h1,p0, p1; // Even-half intermediate.

short r0, r1; // Even-half intermediate.

int PO, P1, R0, R1; // Even-half intermediate.

short g2, g3, h2, h3; // Odd-half intermediate.

short q0a,s0a,q0, q1,s0, s1;// Odd-half intermediate.

short Q0, Q1, S0, S1; // Odd-half intermediate.

int F0, F1, F2, F3, F4, F5, F6, F7; // Freq. domain results.

int $\mathrm{F} 0 \mathrm{r}, \mathrm{F} 1 \mathrm{r}, \mathrm{F} 2 \mathrm{r}, \mathrm{F} 3 \mathrm{r}, \mathrm{F} 4 \mathrm{r}, \mathrm{F} 5 \mathrm{r}, \mathrm{F} 6 \mathrm{r}, \mathrm{F} 7 \mathrm{r}$; // Rounded, truncated results.

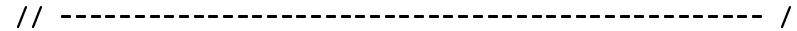

// Stage 1: Separate into even and odd halves. /

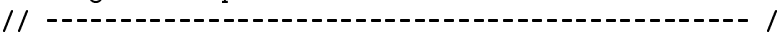

int Stage1() \{

$\mathrm{g} 0=\mathrm{f} 0+\mathrm{f} 7 ; \mathrm{h} 2=\mathrm{f} 0-\mathrm{f} 7$;

$\mathrm{g} 1=\mathrm{f} 1+\mathrm{f} 6 ; \mathrm{h} 3=\mathrm{f} 1-\mathrm{f} 6$;

$\mathrm{h} 1=\mathrm{f} 2+\mathrm{f} 5 ; \mathrm{g} 3=\mathrm{f} 2-\mathrm{f} 5 ;$

$\mathrm{h} 0=\mathrm{f} 3+\mathrm{f} 4 ; \mathrm{g} 2=\mathrm{f} 3-\mathrm{f} 4$;

return(1):

\}

int Stage2() $\{\mathrm{p} 0=\mathrm{g} 0+\mathrm{h} 0 ; \mathrm{r} 0=\mathrm{g} 0-\mathrm{h} 0$;

$\mathrm{p} 1=\mathrm{g} 1+\mathrm{h} 1 ; \mathrm{r} 1=\mathrm{g} 1-\mathrm{h} 1$.

$\mathrm{q} 1=\mathrm{g} 2 ; \mathrm{s} 1=\mathrm{h} 2$;

$\mathrm{s} 0 \mathrm{a}=\mathrm{h} 3+\mathrm{g} 3 ; \mathrm{qOa}=\mathrm{h} 3-\mathrm{g} 3$;

$/ / \mathrm{s} 0=$ ALT_CI_AUX_DCT $(0, \mathrm{~s} 0 \mathrm{a}, \mathrm{qOa}) ; / /$ instrucao customizada

$/ / \mathrm{qO}=\mathrm{ALT} \_\mathrm{CI} \_\mathrm{AUX} \_\mathrm{DCT}(0, \mathrm{qOa}, \mathrm{s} 0 \mathrm{a}) ; / /$ instrucao customizada

$\mathrm{s} 0=(\mathrm{s} 0 \mathrm{a} * \mathrm{c} 0+0 \mathrm{x} 7 \mathrm{FFF}) \gg 16$;

$\mathrm{qO}=(\mathrm{qOa} * \mathrm{cO}+\mathrm{Ox} 7 \mathrm{FFF}) \gg 16$; 


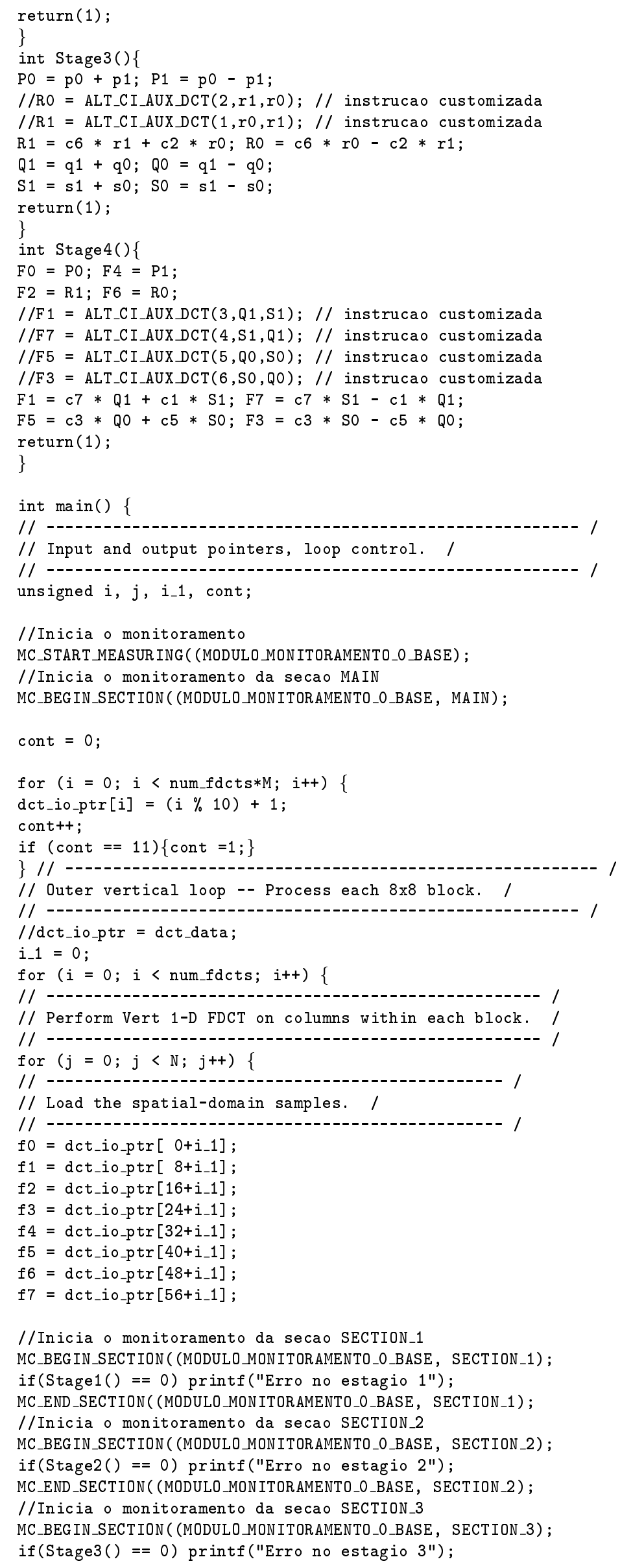

//Inicia o monitoramento da secao SECTION_1 MC_BEGIN_SECTION ( (MODULO_MONITORAMENTO_O_BASE, SECTION_1) ; if (Stage1() $==0$ ) printf ("Erro no estagio 1");

MC_END_SECT ION ( (MODULO_MONITORAMENTO_0_BASE, SECTION_1); //Inicia o monitoramento da secao SECTION_2

MC_BEGIN_SECTION ( (MODULO_MONITORAMENTO_0_BASE, SECTION_2); if (Stage2() == 0) printf ("Erro no estagio 2"); MC_END_SECTION ( (MODULO_MONITORAMENTO_O_BASE, SECTION_2); //Inicia o monitoramento da secao SECTION_3 MC_BEGIN_SECTION ( (MODULO_MONITORAMENTO_O_BASE, SECTION_3); if (Stage3() == 0) printf ("Erro no estagio 3"); 
MC_END_SECTION ( (MODULO_MONITORAMENTO_O_BASE, SECTION_3); //Inicia o monitoramento da secao SECTION_4 MC_BEGIN_SECTION ( (MODULO_MONITORAMENTO_O_BASE, SECTION_4); if $($ Stage 4()$==0)$ printf ("Erro no estagio 4"); MC_END_SECTION ( (MODULO_MONITORAMENTO_O_BASE, SECTION_4);

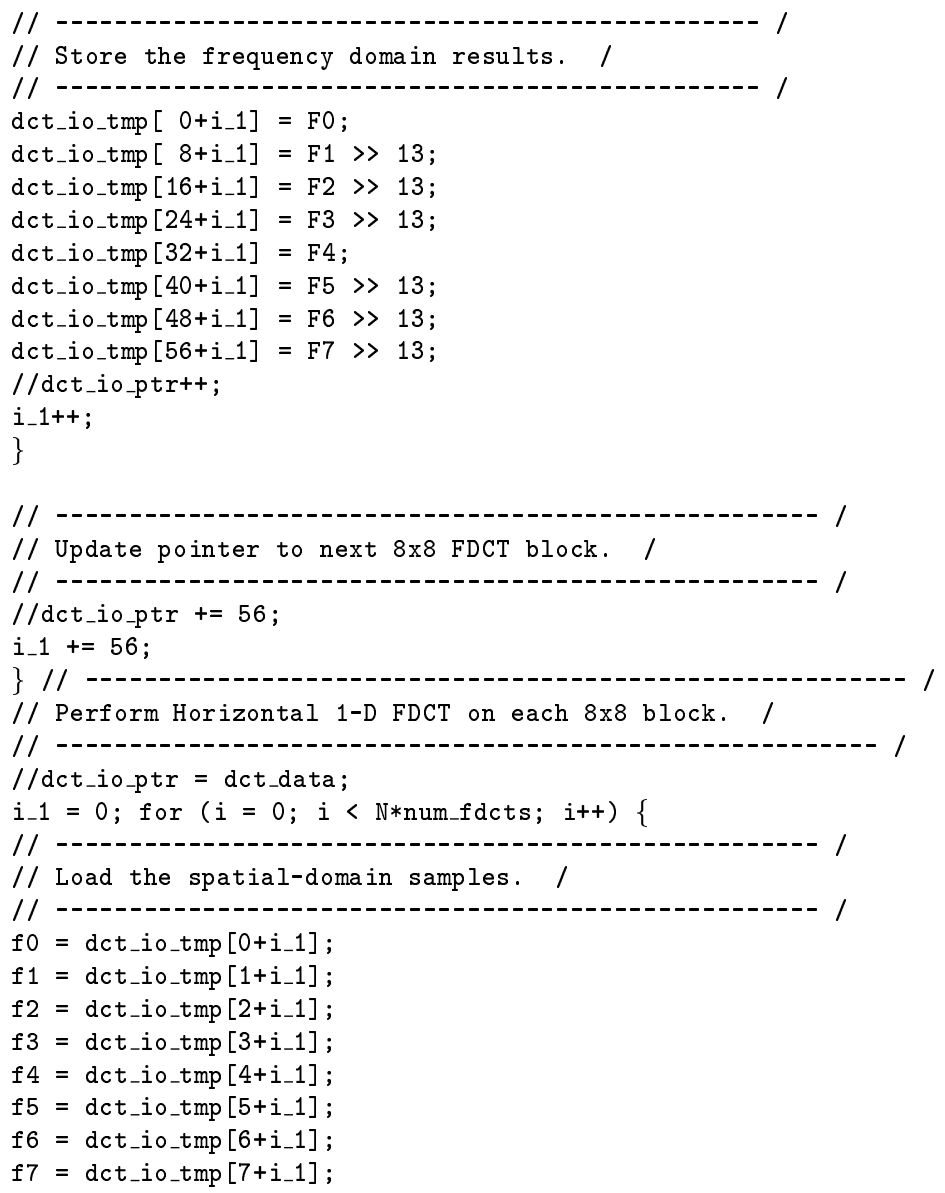

//Inicia o monitoramento da secao SECTION_1 MC_BEGIN_SECT ION ( (MODULO_MONITORAMENTO_O_BASE, SECTION_1); if $($ Stage 1()$==0)$ printf ("Erro no estagio 1"); MC_END_SECTION ( (MODULO_MONITORAMENTO_O_BASE, SECTION_1); //Inicia o monitoramento da secao SECTION_2 MC_BEGIN_SECTION ( (MODULO_MONITORAMENTO_O_BASE, SECTION_2); if (Stage2() $==0)$ printf ("Erro no estagio 2"); MC_END_SECTION ( (MODULO_MONITORAMENTO_O_BASE, SECTION_2); //Inicia o monitoramento da secao SECTION_3 MC_BEGIN_SECTION ( (MODULO_MONITORAMENTO_O_BASE, SECTION_3); if (Stage3() $==0)$ printf ("Erro no estagio 3"); MC_END_SECTION ( (MODULO_MONITORAMENTO_O_BASE, SECTION_3); //Inicia o monitoramento da secao SECTION_4

MC_BEGIN_SECTION ( (MODULO_MONITORAMENTO_O_BASE, SECTION_4); if (Stage4() $==0)$ printf ("Erro no estagio 4"); MC_END_SECTION ( (MODULO_MONITORAMENTO_O_BASE, SECTION_4);

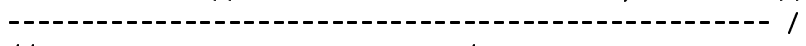
$/ /$ Round and truncate values.

// /

// Note: F0 and F4 have different rounding since no / // MPYs have been applied to either term. Also, FO's / $/ /$ rounding is slightly different to offset the /

// truncation effects from the horizontal pass (which / // does not round). /

// ----------------------------------------- /

$\mathrm{F} 0 \mathrm{r}=(\mathrm{F} 0+0 \mathrm{x} 0006) \gg 3$

$\mathrm{F} 1 \mathrm{r}=(\mathrm{F} 1+0 \times 7 \mathrm{FFF}) \gg 16$

$\mathrm{F} 3 \mathrm{r}=(\mathrm{F} 3+0 \times 7 \mathrm{FFF}) \gg 16$; 
$\mathrm{F} 4 \mathrm{r}=(\mathrm{F} 4+0 \mathrm{x} 0004)>>3$

$\mathrm{F} 5 \mathrm{r}=(\mathrm{F} 5+0 \mathrm{x} 7 \mathrm{FFF}) \gg 16$;

$\mathrm{F} 6 \mathrm{r}=(\mathrm{F} 6+0 \mathrm{x} 7 \mathrm{FFF})>16 ;$

$\mathrm{F} 7 \mathrm{r}=(\mathrm{F} 7+0 \mathrm{x} 7 \mathrm{FFF}) \gg 16$;

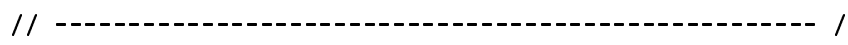

// Store the results /

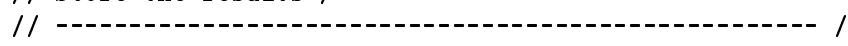

dct_o $\left[0+i_{-} 1\right]=$ F0r;

dct $_{-}\left[{ }_{1+i_{-}} 1\right]=\mathrm{F} 1 \mathrm{r}$;

$\mathrm{dct}_{-} \mathrm{o}\left[2+i_{-} 1\right]=\mathrm{F} 2 \mathrm{r}$

dct $_{-}\left[3+i_{-} 1\right]=\mathrm{F} 3 \mathrm{r}$

$\mathrm{dct}_{-} \mathrm{o}\left[4+i_{-} 1\right]=\mathrm{F} 4 \mathrm{r}$;

dct_o[5+i_1] = F5r;

dct_o[6+i_1] = F6r;

dct_o[7+i_1] $=\mathrm{F} 7 \mathrm{r}$

// -------------------------------------------- /

// Update pointer to next FDCT row. /

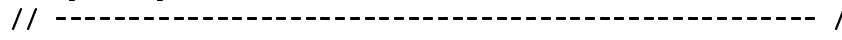

//dct_io_ptr $+=8$;

i_1 $+=8$;

\}

//Finaliza a secao MAIN

MC_END_SECTION ( (MODULO_MONITORAMENTO_O_BASE, MA IN) ;

//Para os detectores e Finaliza o moniotramento

MC_STOP_MEASURING ( (MODULO_MONITORAMENTO_O_BASE) ;

MC_FINALIZE( (MODULO_MONITORAMENTO_O_BASE) ;

\} 